\title{
Picornaviruses: A View from 3A
}

\author{
Terry Jackson ${ }^{1}$ and Graham J. Belsham ${ }^{2, *}$ (i) \\ 1 The Pirbright Institute, Pirbright, Woking, Surrey GU24 0NF, UK; terry.jackson@pirbright.ac.uk \\ 2 Department of Veterinary and Animal Sciences, University of Copenhagen, 1870 Frederiksberg, Denmark \\ * Correspondence: grbe@sund.ku.dk
}

check for

updates

Citation: Jackson, T.; Belsham, G.J.

Picornaviruses: A View from 3A.

Viruses 2021, 13, 456. https://doi.org/ $10.3390 / \mathrm{v} 13030456$

Academic Editor: Caroline Tapparel

Received: 15 February 2021

Accepted: 9 March 2021

Published: 11 March 2021

Publisher's Note: MDPI stays neutral with regard to jurisdictional claims in published maps and institutional affiliations.

\begin{abstract}
Picornaviruses are comprised of a positive-sense RNA genome surrounded by a protein shell (or capsid). They are ubiquitous in vertebrates and cause a wide range of important human and animal diseases. The genome encodes a single large polyprotein that is processed to structural (capsid) and non-structural proteins. The non-structural proteins have key functions within the viral replication complex. Some, such as 3 $\mathrm{D}^{\mathrm{pol}}$ (the RNA dependent RNA polymerase) have conserved functions and participate directly in replicating the viral genome, whereas others, such as 3A, have accessory roles. The $3 \mathrm{~A}$ proteins are highly divergent across the Picornaviridae and have specific roles both within and outside of the replication complex, which differ between the different genera. These roles include subverting host proteins to generate replication organelles and inhibition of cellular functions (such as protein secretion) to influence virus replication efficiency and the host response to infection. In addition, 3A proteins are associated with the determination of host range. However, recent observations have challenged some of the roles assigned to $3 \mathrm{~A}$ and suggest that other viral proteins may carry them out. In this review, we revisit the roles of $3 \mathrm{~A}$ in the picornavirus life cycle. The $3 \mathrm{AB}$ precursor and mature $3 \mathrm{~A}$ have distinct functions during viral replication and, therefore, we have also included discussion of some of the roles assigned to $3 \mathrm{AB}$.
\end{abstract}

Keywords: virus replication; replication organelles; protein interactions; membrane interactions; protein trafficking; lipid droplets; virus host-range; phosphatidylinositol 4-kinase; RNA replication

\section{Picornaviruses}

Picornaviruses are ubiquitous in nature and have been identified in all vertebrate classes [1]. They are responsible for many diseases of medical importance, such as poliomyelitis (caused by poliovirus; PV), hand-foot-and mouth disease (caused by coxsackievirus (CV) A16; CVA9, and enterovirus A71; EV-A71) and the common cold (caused by human rhinoviruses; RV) [2]. They are also responsible for some important veterinary diseases, notably foot-and-mouth disease (caused by foot-and-mouth disease virus; FMDV) [3,4].

Picornaviruses are small and non-enveloped; they have positive-sense RNA genomes. Over the last two decades, many new picornaviruses have been identified and currently the picornavirus family (the Picornaviridae) is composed of 47 genera with over 100 different species [5]. As new picornaviruses are characterized, it has become clear that they show considerable diversity in their genome organization and proteins (Table 1) [6-9]. The 3A proteins of picornaviruses are some of the most divergent across the different genera. They have important roles in forming both the viral replication complex (RC) and replication organelles ( $\mathrm{RO}$ ), and are also involved in pathogenesis and determining host range. However, most of the current knowledge of picornavirus biology comes from studies on mammalian picornaviruses from the Enterovirus, Cardiovirus, Aphthovirus and Kobuvirus genera, and therefore the $3 \mathrm{~A}$ proteins of these viruses are the main focus of this review. The 3A proteins are present within infected cells, not only in their mature form but also as part of larger $3 \mathrm{~A}$-containing precursor proteins, notably $3 \mathrm{AB}$. It has been known for many years that $3 \mathrm{~A}$ and $3 \mathrm{AB}$ have distinct roles in the picornavirus replication cycle and, therefore, a discussion of the main roles of $3 \mathrm{AB}$ in picornavirus replication is also included. 
Table 1. Genome organization and genus specific differences of selected picornaviruses.

\begin{tabular}{|c|c|c|c|c|}
\hline \multicolumn{5}{|c|}{$\begin{array}{l}\text { Picornavirus General Genome Organization: } \\
\qquad 1 \times \text { ORF } \\
\text { S -( } \pm \text { L)-1A-1B-1C-1D-2A-2B-2C-3A-3B-3C-3D -3'-UTR-poly(A) }\end{array}$} \\
\hline Genus & IRES & & Genus Specific Differences & \\
\hline Aphthovirus & II & $\mathrm{L}^{\text {pro }}$ & $2 A^{\text {npgp }}$ & $3 \mathrm{~B}_{1} 3 \mathrm{~B}_{2} 3 \mathrm{~B}_{3}$ \\
\hline Aalivirus & IV & $1 \mathrm{AB}$ & $2 \mathrm{~A}_{1}{ }^{\mathrm{npgp}} 2 \mathrm{~A}_{2}{ }^{\mathrm{npgp}} 2 \mathrm{~A}_{3}{ }^{\mathrm{npgp}} 2 \mathrm{~A}_{4}{ }^{\mathrm{npgp}} 2 \mathrm{~A}_{5} 2 \mathrm{~A}_{6}$ & \\
\hline Aquamavirus & IV & $1 \mathrm{AB}$ & $2 \mathrm{~A}_{1}^{\mathrm{npgp}} 2 \mathrm{~A}_{2}$ & $3 \mathrm{~B}_{1} 3 \mathrm{~B}_{2}$ \\
\hline Avihepatovirus & IV & $1 \mathrm{AB}$ & $2 \mathrm{~A}_{1}{ }^{\text {npgp }} 2 \mathrm{~A}_{2}{ }_{\text {NTPase }} 2 \mathrm{~A}_{3} \mathrm{H}$-box $/ \mathrm{NC}$ & \\
\hline Cardiovirus & II & $\mathrm{L}$ & $2 \mathrm{~A}^{\mathrm{npgp}}$ & \\
\hline Enterovirus & I & & $2 \mathrm{~A}$ pro & \\
\hline Kobuvirus & $\mathrm{V}$ & $1 \mathrm{AB}$ & $2 \mathrm{~A}^{\mathrm{H}-\mathrm{box} / \mathrm{NC}}$ & \\
\hline Limnipivirus & IV & $1 \mathrm{AB}$ & $2 \mathrm{~A}_{1}{ }^{\mathrm{npgp}} 2 \mathrm{~A}_{2} \mathrm{npgp}$ & \\
\hline Mosavirus & II & $\mathrm{L}$ & $2 A^{\text {npgp }}$ & $3 \mathrm{~B}_{1} 3 \mathrm{~B}_{2}$ \\
\hline Parechovirus & II & $1 \mathrm{AB}$ & $2 \mathrm{~A}_{1}{ }^{\text {npgp }} 2 \mathrm{~A}_{2}{ }^{\mathrm{H}-\mathrm{box} / \mathrm{NC}}$ & \\
\hline & $5^{\prime}$-UTR & $\begin{array}{r}2 \times C \\
-1 B-1 C-1 D-I G R-I R E S\end{array}$ & B-2C-3A-3B-3C-3D -3'-UTR-poly(A) & \\
\hline Dicipivirus & $\mathrm{II}^{1} / \mathrm{I}^{2}$ & $\begin{array}{c}\text { ORF1 } \\
\text { 1A-1B-1C-1D }\end{array}$ & $\begin{array}{c}\text { ORF2 } \\
\text { 2A-2B-2C }\end{array}$ & $\begin{array}{c}\text { ORF2 } \\
\text { 3A-3B-3C-3D }\end{array}$ \\
\hline
\end{tabular}

The genomes of most picornaviruses conform to the general layout of VPg-5'-UTR-Open Reading Frame (ORF)-3'-UTR-poly(A). Internal ribosome entry site (IRES) elements are one of at least five types ( $\mathrm{I}$ to $\mathrm{V}) .1 \mathrm{~A}, 1 \mathrm{~B}, 1 \mathrm{C}$ and $1 \mathrm{D}$ encode the mature capsid proteins. 2A, 2B, 2C, 3A, $3 \mathrm{~B}, 3 \mathrm{C}$ and $3 \mathrm{D}$ encode the nsps. Genus specific differences are shown. Some picornaviruses encode a Leader protein before $1 \mathrm{~A}$ ( $\mathrm{L}=\mathrm{Leader}$ protein; $\mathrm{L}^{\mathrm{pro}}=$ Leader protein has protease activity). $1 \mathrm{AB}$ indicates that VP0 (i.e. VP4-VP2) remains un-processed. Some picornaviruses encode more than one $2 \mathrm{~A}$ protein. The different types of $2 \mathrm{~A}$ proteins are indicated; $2 \mathrm{~A}^{\mathrm{npgp}}=2 \mathrm{~A}$ has an NPG $/ \mathrm{P}$ motif; $2 \mathrm{~A}^{\mathrm{NTPase}}=2 \mathrm{~A}$ with an NTP-binding motif; $2 \mathrm{~A}^{\mathrm{H}-\mathrm{box} / \mathrm{NC}}=2 \mathrm{~A}$ with a $\mathrm{H}$-box $/ \mathrm{NC}$ motif; $2 \mathrm{~A}^{\text {pro }}=2 \mathrm{~A}$ has proteinase activity; $2 \mathrm{~A}=2 \mathrm{~A}$ lacking a signature motif. When the first copy of $2 \mathrm{~A}$ has an NPG/P motif it can be expected that the 2A protein forms part of the capsid precursor P1-2A (as shown for FMDV). Some picornaviruses encode more than one 3B (VPg) protein. Dicipiviruses are unusual and have two ORFs that are separated by an intergenic region (IGR) and therefore have two IRES elements.

\section{Key Features of Picornavirus Genomes}

A typical picornavirus genome (ca. 7.5-8.5kb) includes a single large open reading frame (ORF) flanked by $5^{\prime}$ - and $3^{\prime}$-untranslated regions (UTRs) (Table 1). As a consequence of the RNA replication mechanism, the $5^{\prime}$-terminus of the genomic RNA is covalently linked to a small virus-encoded peptide, VPg (viral protein genome-linked), which is encoded by the 3B region of the genome [10-14]. The $5^{\prime}$-UTR varies in length (typically between about 650 and 1300 nucleotides (nt)) across different picornaviruses and includes several structural elements that are critical for virus replication. These include the IRES (internal ribosome entry site), which directs cap-independent initiation of protein synthesis, and also genus-specific elements such as the cloverleaf (CL: enteroviruses) and the $S$ fragment (aphthoviruses), which are required for viral RNA (vRNA) replication [6,15-19]. The $3^{\prime}$-UTR is usually relatively short $(<100 \mathrm{nt})$ and followed by a poly(A) tail. The poly(A) tail, and the unique sequences and structures in the $3^{\prime}$-UTR are required for negative-strand vRNA synthesis [20-25]. In addition, picornavirus genomes also contain other RNA elements that are required for vRNA replication such as the position-independent, internal cis-acting replication element (cre), which serves as the template for uridylylation of VPg (see below) [26-30]. For many picornaviruses (e.g., enteroviruses) the region of the genome that includes the ORF is divided into three main regions encoding the precursor proteins P1, P2 and P3; the P1 precursor is cleaved to the capsid proteins, while the P2 and P3 precursors are processed to the non-structural proteins (nsps). However, for some other picornaviruses (e.g., aphthoviruses and cardioviruses) the capsid precursor is P1-2A; thus, to cover both forms, the terms P1 and P1-(2A) are used here. For some picornaviruses, such as the aphthoviruses, cardioviruses and kobuviruses, the genome also encodes a Leader (L) protein at the $\mathrm{N}$-terminus of the polyprotein sequence (Table 1). 


\section{Key Features of the Picornavirus Replication-Cycle}

Picornavirus entry into cells culminates in the delivery of the infectious viral genome into the cytosol, where vRNA replication occurs [31-33]). During replication, RNA structures within the UTRs and coding regions of the genome cooperate to regulate initiation of viral protein synthesis and the sequential synthesis of negative- and positive-strand vRNA $[20,21,25]$. Initially, the genomic vRNA functions as a mRNA and translation initiation is directed by the IRES using a cap-independent mechanism [6]. For PV and FMDV, the CL and structures within the $3^{\prime}$-UTR, respectively, modulate IRES function [34-37]. The full-length viral polyprotein is never observed as it is rapidly processed, both coand post-translationally (in cis and in trans), by virus-encoded proteases. These are: $2 \mathrm{~A}^{\text {pro }}, 3 \mathrm{C}^{\text {pro }}$ and $3 \mathrm{CD}^{\text {pro }}$ (enteroviruses); $\mathrm{L}^{\text {pro }}$ and $3 \mathrm{C}^{\text {pro }}$ (aphthoviruses); $3 \mathrm{C}^{\text {pro }}$ and $3 \mathrm{CD}^{\text {pro }}$ (cardioviruses and kobuviruses). Processing generates the L protein (for aphthoviruses, cardioviruses and kobuviruses) and the primary precursor polyproteins, P1 or P1-(2A) (dependent on the location of the primary cleavage at either the N-terminus or C-terminus of 2A), P2 and P3 [38-41]. The L protein ( $\mathrm{L}^{\text {pro }}$ ) of FMDV is a papain-like protease and cleaves at the junction between its own C-terminus and the N-terminal Gly residue of P1-2A [42], whereas the L proteins of cardioviruses and kobuviruses are not proteases and are cleaved from P1-2A (cardioviruses) or P1 (kobuviruses) by $3 C^{\text {pro }} / 3 \mathrm{CD}^{\text {pro }}[43,44]$. Further processing of the $\mathrm{P} 1 / \mathrm{P} 1-(2 \mathrm{~A}), \mathrm{P} 2$ and $\mathrm{P} 3$ precursors generates the mature viral proteins. The P1/P1-(2A) precursor is cleaved to make the capsid proteins (VP0, VP3 and VP1) plus, where applicable, 2A, while $\mathrm{P} 2$ and $\mathrm{P} 3$ precursors are processed to the nsps (P2: 2A (except where it is part of P1-2A), 2B and 2C; P3: 3A, 3B, 3C ${ }^{\text {pro }}$ and $3 \mathrm{D}^{\mathrm{pol}}$ ). Processing also generates a number of processing intermediates (e.g., $2 \mathrm{BC}, 3 \mathrm{AB}$ and $3 \mathrm{CD}$ ), which have distinct functions during virus replication [45]. This is important since the processing can have a major effect on the biological activities of the proteins, e.g., $3 \mathrm{D}^{\mathrm{pol}}$ is the functional RNA polymerase whereas $3 C D$ lacks this activity but does have protease activity ( $3 \mathrm{CD}^{\text {pro }}$ ). The $\mathrm{P} 2$ and $\mathrm{P} 3$ proteins (including some processing intermediates) orchestrate vRNA replication and the biochemical and morphological changes that occur inside infected cells. The $2 \mathrm{~A}$ proteins differ significantly in their properties and some picornaviruses encode more than one $2 \mathrm{~A}$ protein, these can have diverse functions (Table 1 ). For example, the enterovirus $2 \mathrm{~A}$ is a protease $\left(2 \mathrm{~A}^{\text {pro }}\right)$ that cleaves the $\mathrm{P} 1 / 2 \mathrm{~A}$ junction thus releasing the $\mathrm{P} 1$ capsid precursor but in other picornaviruses, e.g., kobuviruses, the $2 \mathrm{~A}$ is not a protease and $\mathrm{P} 1$ is separated from $2 \mathrm{~A}$ by $3 \mathrm{CD}^{\text {pro }}$ [46]. In the aphthoviruses (e.g., FMDV) the 2A peptide, which is only 18 residues long, induces a "ribosomal skip" within a NPG/P motif at the $2 \mathrm{~A} / 2 \mathrm{~B}$ junction, such that the polypeptide bond at the G/P junction is not made [47]. The FMDV 2A peptide is closely related to the C-terminus of cardiovirus (and some other) 2A proteins that are believed to employ the same mechanism to separate the capsid precursor P1-2A from the P2 proteins [48].

Early during infection, picornaviruses shut down host-cell cap-dependent translation, which diverts translation away from cellular mRNAs to translation of the vRNA [49]. In addition to being translated, the input vRNA also serves as a template for the synthesis of negative-sense copies of the vRNA. It is widely believed that the process of RNA replication results in the formation of a double-stranded (ds)-RNA product (the replicative form) and then proceeds via the formation of a highly branched structure, termed the replicative intermediate (reviewed in [50]). However, it is possible that the presence of dsRNA in extracted vRNA is essentially a consequence of the presence of complementary positive and negative sense RNAs. It is not clear how the strands of a dsRNA molecule can be separated since single stranded forms of the RNA are required for both translation and RNA replication. It is interesting to note that the $Q \beta$ bacteriophage, with a small positive-sense RNA genome and an RNA dependent RNA polymerase, has been shown to have a mechanism for separating the positive and negative strands of RNA during synthesis (reviewed in [51]). This strand separation mechanism, which limits the length of the dsRNA to only 9 base pairs (bp), requires interaction between the RNA polymerase and the host proteins EF-Tu, EF-Ts and the ribosomal S1 protein. It seems like an elegant mechanism to keep the vRNA 
molecules separate. The production of dsRNA acts as a stimulator of anti-viral responses (see below), which could be counterproductive for the virus. Whatever the precise process of their synthesis, the newly formed negative-sense copies are then used as the template to synthesize more positive-sense vRNA [52], which can either be used to produce more viral proteins or can be packaged into progeny virions. Synthesis of both negative- and positive-sense vRNA is catalyzed by 3D ${ }^{\text {pol }}$, the viral RNA dependent RNA polymerase [53], and takes place within the viral RC, which forms in association with cellular proteins and membranes. In addition, 3D $\mathrm{D}^{\mathrm{pol}}$ also catalyzes VPg uridylylation (i.e., UMP linkage to the hydroxyl group of Tyr 3 within VPg) to generate VPg-pUpU-OH, which serves as the primer for both positive and negative strand vRNA synthesis $[10,11,13,14]$. Most picornaviruses encode a single copy of VPg (3B) (Table 1); however, some have two copies [54], whereas FMDV is unusual and possesses three non-identical copies of VPg $[55,56]$ that all appear to be used for vRNA replication $[29,57]$. Positive-sense vRNA is packaged to form mature virions in a process that is believed to be dependent on packaging signals within the vRNA sequence, and also certain viral nsps and host factors [58-62]. For most picornaviruses, the capsid precursor undergoes post-translational N-terminal myristoylation, which is required for virion/capsid assembly [63-65] and also for VP4-induced membrane translocation of the vRNA during cell entry $[66,67]$. However, myristoylation of P1/P1-2A is not conserved among all picornaviruses and is absent in hepatoviruses and parechoviruses $[68,69]$. Encapsidation of the vRNA is usually accompanied by the final maturation cleavage of the capsid, i.e., autocatalytic conversion of VP0 to VP4 and VP2. However, in some picornaviruses, VP0 remains unprocessed and is present in the mature virion (Table 1) [70-72] while, in assembled FMDV empty capsids, VP0 processing can occur even in the absence of RNA packaging [73,74]. Progeny virions are normally released by cell lysis but may also be released from intact cells via a non-lytic process that involves release of infectious virus particles in membrane enclosed vesicles [75-77].

Picornavirus infection can inhibit cellular protein secretion, which may contribute to evasion of antiviral immunity [78]. Virus infections activate cellular antiviral defense mechanisms and picornaviruses have evolved a number of strategies to interfere with these responses [79-81]. In addition, viral proteins are known to enter the nucleus and inhibit host-cell transcription, which contributes to evasion of the innate cellular antiviral response [82]. Picornaviruses also disrupt nucleo-cytoplasmic trafficking [83-85]. This allows exploitation by these cytoplasmic viruses of proteins that normally reside within the nucleus, such as RNA-binding proteins and proteins that drive mobilization of neutral lipids that are required to generate $\mathrm{RO}[82,86]$.

\section{Picornavirus 3A Proteins}

The 3A proteins of different picornavirus genera vary considerably in length and sequence (Figures 1 and 2) and are therefore often omitted from phylogenetic analyses [1]. Despite being highly divergent, most $3 \mathrm{~A}$ proteins have a shared overall architecture and often have relatively large $\mathrm{N}$-terminal domains with relatively short $\mathrm{C}$-terminal domains that are separated by a single hydrophobic region (or hydrophobic domain (HD)). The Nterminal domains vary in length (e.g., 89 residues, bovine rhinitis B virus 1 (BRBV-1) and 39 residues, hepatitis A virus (HAV)) and are usually longer than the C-terminal domains (Figures 1 and 2). A notable exception is the 3A protein of FMDV where the C-terminal domain is longer (75-76 residues) than the $\mathrm{N}$-terminal domain (ca. 60 residues), and considerably longer than in other picornaviruses [87]. Across the seven FMDV serotypes, the N-terminal region and the HD are highly conserved (Figure 2); however, FMDV 3A is the least conserved nsp at the amino acid (aa) level $[87,88]$ due to high sequence diversity within the C-terminal domain. The function of the extended C-terminal domain of FMDV 3A is unknown but it may be involved in determining host range (see below). For most picornaviruses the HD can be readily assigned (Figures 1 and 2) (this is discussed in more detail below). Although the $3 \mathrm{~A}$ protein of aichi virus A (AiV-A), bovine kobuvirus (AiV-B) and human klassevirus (Salivirus A) are myristoylated at the $\mathrm{N}$-terminal glycine 
(despite not having a canonical myristoylation motif) [89], 3A proteins are typically not post-translationally modified.

\begin{tabular}{|c|c|c|}
\hline \multirow{3}{*}{ TV-A1 } & $\mathrm{N}$-terminal domain & TD \\
\hline & \multirow{2}{*}{\multicolumn{2}{|c|}{ 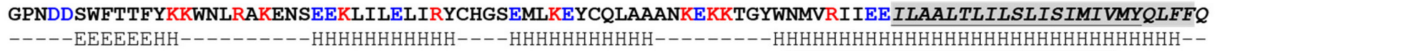 }} \\
\hline & & \\
\hline \multirow[t]{2}{*}{ CPV } & \\
\hline & \multicolumn{2}{|c|}{ 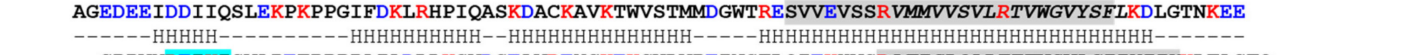 } \\
\hline \multirow[t]{2}{*}{ CVB3 } & \multicolumn{2}{|r|}{ GPPVYREIKISVAPETPPPPAIADLLKSVDSEAVREYCKEKGWLVPEINSTLQIEKHVSRAFICLQALTTFVSVAGIIYIIYKLFAGFQ } \\
\hline & \multirow{2}{*}{\multicolumn{2}{|c|}{ 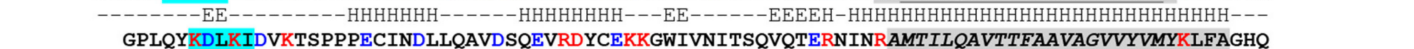 }} \\
\hline \multirow[t]{2}{*}{ PV1 } & & \\
\hline & $\begin{array}{l}\text { GPLQYKDLKIDVKTSPPPECINDLLQAVDSQEVRDYCEKKGWIVNITSQVQTERNINRAMTILQAVTTFAAVAGVVYVMYKLFAGHQ } \\
\text { - }\end{array}$ & -HHHHHHH------HHHHHHHH---EEE----EEEEE-HHHHHHHHHHHHHHHHHHHHHHHHHHHHH--- \\
\hline \multirow[t]{2}{*}{ EV-A71 } & \\
\hline & \multicolumn{2}{|r|}{ GPPKFRPIKICLEEKPAPDAISDLLASVDSEEVRQYCRDQGWIIPETPTNVERHLNRAVLVMQSIATVVAVVSLVYVIYKLFAGFQ } \\
\hline \multirow[t]{2}{*}{ Aiv-A } & \multirow{2}{*}{\multicolumn{2}{|c|}{$\begin{array}{l}\text { GNRVIDAEPREIPLEYADDLLEAMAHHRPVPCSLGLSQAIANNTPIQQISETFWKYRKPIFTCTTFLAVLGFLCSVIPLARSLWKSKQDTPQEPQ } \\
-- \text { EEEE-- }\end{array}$}} \\
\hline & & \\
\hline \multirow[t]{2}{*}{ Aiv-B } & \multicolumn{2}{|r|}{ GAHSERTFETAPSEIDADEVLEILSKSKPAPTHLTLERAIASNAPLSFIDTLWKWRRPVFATTTFLTVLGFVITVLGVAKVLWTKKEDTPDEPQ } \\
\hline & \multicolumn{2}{|r|}{ 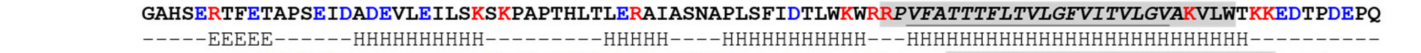 } \\
\hline \multirow[t]{2}{*}{ RV-B14 } & \multicolumn{2}{|r|}{ GPVYKDLEIDVCNTPPSECINDLLKSVDSEEIREYCKKKKWI IPEIPTNIERAMNQASMI INTILMFVSTLGIVYVIYKLFAQTQ } \\
\hline & & 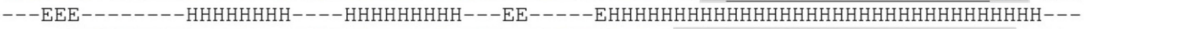 \\
\hline \multirow[t]{2}{*}{$\mathrm{RV}-\mathrm{A} 2$} & & GPIDMKNPPPPAITDLLQSVRTPEVIKYCEGNRWI IPAECKIEKELNLANTIITIIANVIGMARIIYVIYKLFCTLQ \\
\hline & & - HHHHHHHH ---- -HHHHHHHH-------- EEEEHHHHHHHHHHHHHHHHHHHHHHHHHHHHHH--- \\
\hline \multirow[t]{2}{*}{ RV-A16 } & & GPISMDKPPPPAITDLLRSVRTPEVIKYCQDNKWIVPADCQIERDLNIANSIITIIANIISIAGIIYIIYKLFCSLQ \\
\hline & & ---HHHHHHHH-----НHHHHHHH---------EEEEHHHHHHHHHHHHHHHHHHHHHHHHHHHHHH--- \\
\hline \multirow[t]{2}{*}{$\mathrm{RV}-\mathrm{C} 1$} & & GLGDDSTPGFIVDLLSASKDPKVIEFCEKEGWIKQSKHSKIERD FNYVQYCLNCVGSIILILGTVYALYKLMCIAQ \\
\hline & & --------HHHHHHHH-----HHHHHHHH---EEE---EEEEHHHHHHHHHHHHHHHHHHHHHHHHHHHHHHHH -- \\
\hline \multirow[t]{2}{*}{ EMCV-1 } & & GPVDEVSFHSVVQQLKARQQATDEQLEELQEAFAKVQERNSVFSDWLK ISAMLCAATLALSQVVKMAKAVKQMVKPDLVRVQLDEQEQ \\
\hline & & ----- HHHHHHHHHHHHHHH -- HHHHHHHHHHHHHHHHHH-HHHHHHHHHHHHHHHHHHHHHHHHHHHHHHHH ----- EEE \\
\hline \multirow[t]{2}{*}{ TMEV } & & SPPDWQHFENILTCLRQNNAALQDQVDELQEAFTQARERSDFLSDWLKVSAIIFAGIVSLSAVIKLASKFKESIWPTPVRVELSEG \\
\hline & & -- HHHHHHHHHHHH---HHHHHHHHHHHHHHHHHH---HHHHHHHHHHHHHHHHHHHHHHHHHHHHHHHH-----EEEEE- \\
\hline \multirow{2}{*}{ HAV } & & GISDDDNDSAVAEFFQSFPSGEPSNSKLSGFFQSVTNHKWVAVGAAVGILGVLVGGWFVYKHFSRKEEEPIPAE \\
\hline & & \\
\hline
\end{tabular}

Figure 1. 3A protein alignment for selected picornaviruses. Alignment of full-length 3A proteins for selected picornaviruses; Enteroviruses, poliovirus 1 (PV1) (Enterovirus C), coxsackie virus B3 (CVB3) (Enterovirus B), enterovirus A71 (EV-A71) (Enterovirus A), rhinovirus A2 (RV-A2) and rhinovirus A16 (RV-A16) (Rhinovirus A), rhinovirus B14 (RV-B14) (Rhinovirus B), rhinovirus C1 (RV-C1) (Rhinovirus C); Kobuviruses, AiV-A1 (Aichivirus A), AiV-B1 (Aichivirus B); Cardioviruses, encephalomyocarditis -1 (EMCV-1) (Cardiovirus A), Theiler's murine encephalitis virus (TMEV) (Cardiovirus B); Hepatovirus, hepatitis A virus (HAV) (Hepatovirus A); Limnipivirus, carp picornavirus (CPV) (Limnipivirus B); Teschovirus, TV-A1 (Teschovirus A). 3A proteins have a similar organisation that consists of a N-terminal domain, a hydrophobic domain (HD) that includes a predicted membrane-binding region (MBR), followed by a C-terminal domain (CTD). Here, the HD (shown in italics) is loosely defined as a region devoid of charged aa (note for RV-A2 and CPV a single R residue may be present in the HD). The 3A sequences are shown using the single letter aa code and were aligned using the first charged aa (marked by I) before the putative HD (note, for TV-A1 there is no charged aa after the HD). Charged aa are shown in bold red ( $\mathrm{R}$ and $\mathrm{K}$ ) or bold blue text (D and E). Transmembrane binding regions were predicted using TM-PRED [90], TMHMM [91], PHOBIUS [92] and HMMTOP [93]. Grey boxes highlight the aa with the potential to form an MBR identified by at least one of the programs. For some viruses, some programs predicted that the MBR extended beyond the charged aa that flank the HD. Amino acids that were identified by all four programs are underlined and are likely to be involved in forming an MBR. For PV this includes the residues 65-AVTTFAAVAGVVYVMY-80 that were determined experimentally as the MBR by [94]. Note for EMCV-1 and CPV only 3 (TM-PRED, HMMTOP and PHOBIUS) and 1 (TM-PRED) program, respectively, predicted an MBR and therefore, for these viruses, no underlined sequences are shown. The residues that form the Golgi Brefeldin A Resistant Guanine Nucleotide Exchange Factor 1 (GBF1) binding site (residues 6-10 for CVB3 and PV) [95,96] are boxed in light blue. Note that these residues are mostly absent for RV-A2 and RV-A16, and the conserved K-9 (CVB3 and PV) is E-8 in RV-B14. Secondary structure predictions were made using Jpred4 and are indicated under each sequence ( $\mathrm{H}=$ Helix, $\mathrm{E}=$ extended). Accession numbers of the sequences shown: PV1 V01149, CVB3 M88483, EV-A71 MG672481, RV-A2 X02316, RV-A16 L24917, RV-B14 K02121, RV-C1 EF077279, AiV-A AB040749, AiV-B AB084788, EMCV-1 AY296731, TMEV X56019, HAV M14707, CPV KF306267, and TV-A1 AJ011380.

The 3A protein is the N-terminal part of the P3 precursor (3ABCD). For PV, processing of $\mathrm{P} 3$ occurs by two distinct pathways (major and minor). The major pathway generates $3 \mathrm{AB}$ and $3 \mathrm{CD}^{\text {pro }}$ [98], while the minor pathway initially results in 3A and 3BCD [99,100]. The $3 \mathrm{AB}$ and $3 \mathrm{CD}^{\text {pro }}$ precursor proteins are relative stable in infected cells and processed slowly to their mature protein constituents, $3 \mathrm{~A}$ and $3 \mathrm{~B}$, plus $3 \mathrm{C}^{\text {pro }}$ and $3 \mathrm{D}^{\text {pol }}$, respectively [101-103]. Thus, although 3A and 3AB are both present within infected cells, 3A is less abundant than $3 \mathrm{AB}$ especially during the early phase of infection. 


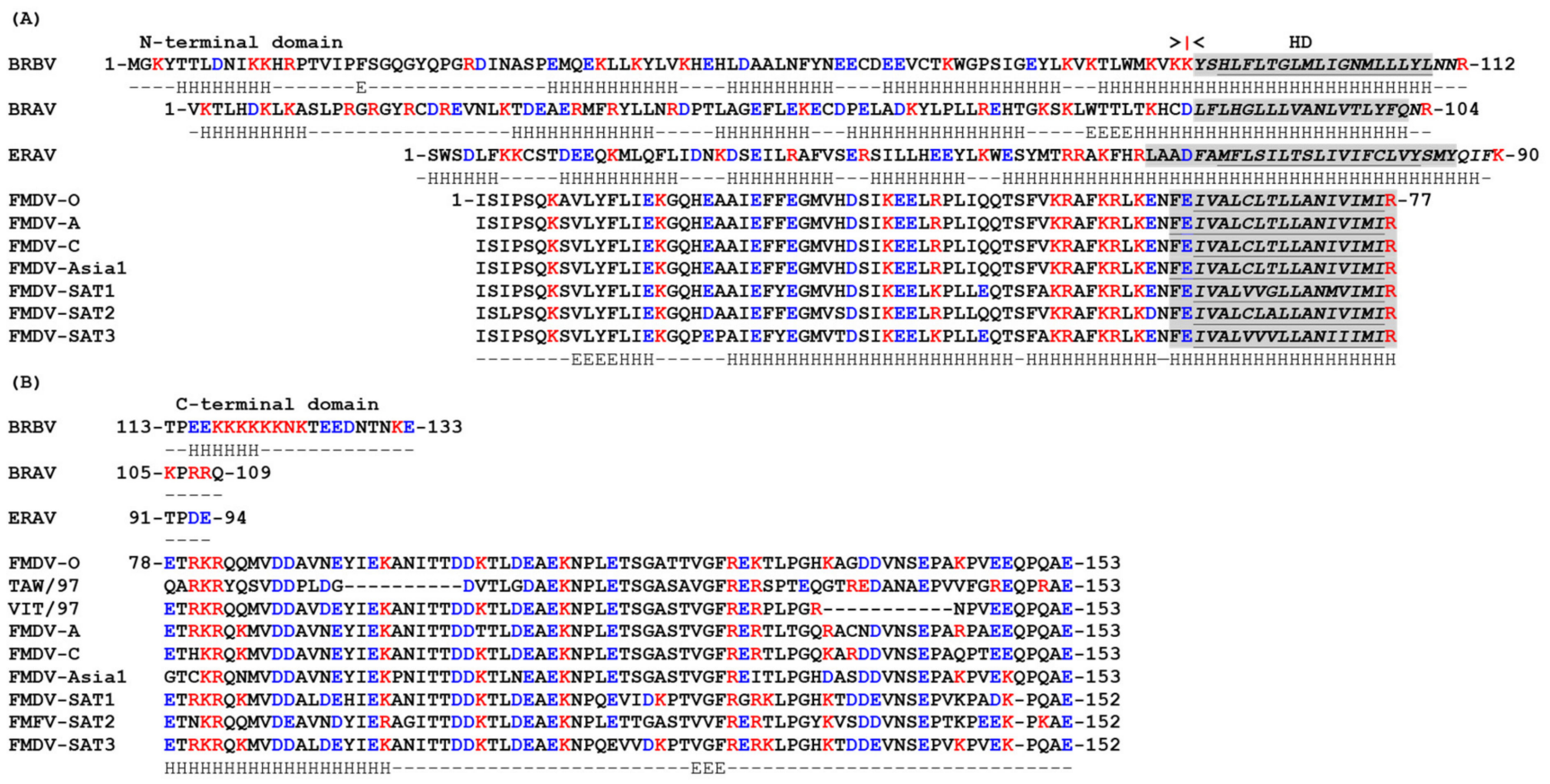

Figure 2. 3A protein alignment for selected aphthoviruses. (A) Alignment of the 3A N-terminal domains and HDs of selected aphthoviruses (all seven serotypes of FMDV, namely FMDV-O, -A, -C, -Asia1, -SAT1, -SAT2 and -SAT3, plus equine rhinitis A virus (ERAV), bovine rhinitis virus A and B (BRAV-1 and BRBV-1). The 3A proteins have a similar organisation that consists of a N-terminal domain, a HD that includes a predicted MBR, followed by a CTD. The sequence annotation and alignment are as described for Figure 1. For BRAV-1 only 3 (TM-PRED, HMMTOP and PHOBIUS) programs predicted an MBR and therefore no underlined sequences are shown. Secondary structure predictions were made using Jpred 4 and are indicated under each sequence $(\mathrm{H}=\mathrm{Helix}, \mathrm{E}=$ extended). Very similar secondary structures were predicted for each FMDV serotype and are represented by FMDV-SAT3. (B) Alignment of the 3A C-terminal domain of selected aphthoviruses (as described for panel A). In addition, the CTDs for FMDV, O/TAW/97 (TAW/97) and O/VIT/2/97 (VIT/97) [87,97] are included to show the position of the internal deletions; the deleted residues are indicated by - (residues 93-102 for O/TAW/97 and 133-142 for O/VIT/2/97). The CTDs of the FMDV-SAT serotypes have one residue less than the other FMDV serotypes. The missing residues are indicated by -. Accession numbers of the sequences shown: FMDV-O AJ539141, FMDV-A AY593752, FMDV-C AY593805, FMDV-Asia1 DQ533483, FMDV-SAT1 AY593840, FMDV-SAT2 AY593849, FMDV-SAT3 AY593850, O/TAW/97 AF308157, O/VIT/2/97 AJ295002, ERAV DQ272578, BRAV-1 KP236128, and BRBV-1 EU236594.

The solution structure of a part of PV 3A (aa 1-59), as determined by nuclear magenetic resonance (NMR) spectroscopy (Figure 3A), shows that the central region of this N-terminal domain forms two amphipathic $\alpha$ helices (aa 23-29, and 32-41) that are joined by a short connecting loop to form a "hairpin" structure [104]. The first 14 and approximately the last 11 residues (aa 48-59 in full-length 3A) of this molecule were unstructured, although it was noted that these regions could potentially form ordered structures when bound to other viral or cellular proteins [104]. In the solution structure, the 3A protein formed dimers with the interface formed by a hydrophobic surface consisting of residues Ile-22, Leu-25, Leu-26, Val-29, Val-34, Tyr-37, Cys-38 and Trp-43. Molecular modelling (based on the NMR structure of PV 3A) suggested that the N-terminal domains of the 3A proteins of FMDV and CVB3 also form dimers and that dimerization is required for vRNA replication $[105,106]$; thus, it is possible that the ability to form homodimers may be a common feature of picornavirus $3 \mathrm{~A}$ proteins. 

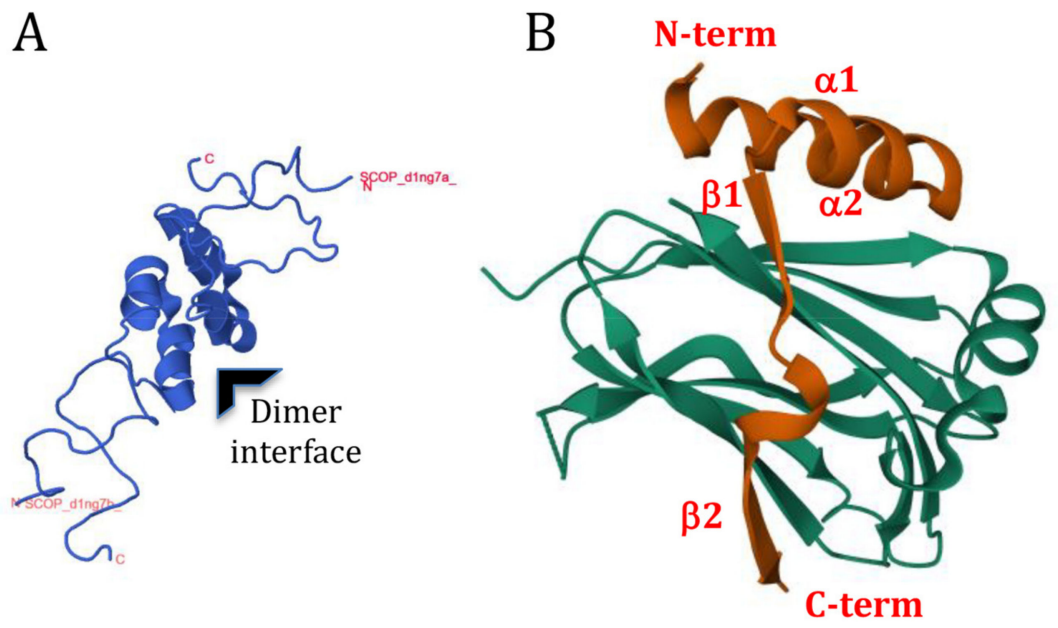

Figure 3. Structure of PV 3A. (A) The NMR structure [104] of a PV 3A (aa 1-59) dimer shown as a cartoon representation (PDB 1NG7). The central region of each $3 \mathrm{~A}$ forms two amphipathic $\alpha$ helices Table 1. PV 3A (red) in a complex with the Golgi Dynamics (GOLD) domain of ACBD3 (green). Electron density could not be assigned for residues 1-14 of 3A. (B) In the complex, 3A formed four secondary elements (two $\alpha$ helices, $\alpha 1$, aa 19-29, and $\alpha 2$, aa 32-41, and two $\beta$ strands, $\beta 1$, aa $44-46$, and $\beta 2$, aa 53-58), which all make contacts with the GOLD domain (PDB 6HLV). 3A is wrapped around the GOLD domain so that the $\mathrm{N}$ - and C-termini of the $\mathrm{N}$-terminal domain make contacts on opposite sides [107]. As in the nuclear magnetic resonance (NMR) structure, hydrophobic residues of $\alpha 1$ and $\alpha 2$ interact with the hydrophobic residues of the other $3 \mathrm{~A}$ molecule that form the 3A dimer interface. When bound to ACBD3, dimerization of 3A drives formation of a 3A:ACBD3 heterotetramer. This allows for the membrane binding regions of the 3A molecules to "staple" ACBD3 to membranes at the RO (see [107] for details).

\section{Viral Binding Partner Proteins}

Evidence for interactions involving $3 \mathrm{~A}$ and $3 \mathrm{AB}$ with other viral nsps (including precursor proteins) primarily comes from studies with PV and AiV using yeast-2-hybrid (Y-2-H) and mammalian-two-hybrid (M-2-H) systems, and from biochemical studies and the use of recombinant viruses [108-112]. Collectively, these studies have shown that although $3 \mathrm{~A}$ and $3 \mathrm{AB}$ likely interact with several different nsps they have different binding profiles, which is consistent with the notion that $3 \mathrm{~A}$ and $3 \mathrm{AB}$ have different roles during picornavirus replication. The protein interaction study results are summarized in Table 2.

\subsection{Dimerization of $P V 3 A$ and $3 A B$}

In both the $\mathrm{Y}-2-\mathrm{H}$ and $\mathrm{M}-2-\mathrm{H}$ systems, $\mathrm{PV} 3 \mathrm{~A}$ was shown to form homodimers andalso to bind to $3 \mathrm{AB}$, whereas $3 \mathrm{AB}$ homodimers were only observed in the $\mathrm{Y}-2-\mathrm{H}$ system and not in the M-2-H system [110,111]. As described above, the NMR structure and mutagenesis studies (and more recent structural analysis; see below) support the case for 3A homodimerization.

\subsection{Interactions between $P V 3 A / 3 A B$ and the $P 2$ Proteins ( $2 B, 2 C$ and $2 B C$ )}

The $3 \mathrm{~A}$ and $3 \mathrm{AB}$ proteins were shown to interact with $2 \mathrm{~B}$ in both the $\mathrm{Y}-2-\mathrm{H}$ and $\mathrm{M}-2-\mathrm{H}$ systems [110-112]. Interactions between $3 \mathrm{~A} / 3 \mathrm{AB}$ and $2 \mathrm{~B}$ may be functionally important, as defective replication due to either aa substitutions within the HD, or the insertion of epitope tags into the $\mathrm{N}$-terminal region of $3 \mathrm{~A}$, could be rescued by compensatory changes within 2B [113,114].

The $2 \mathrm{C}$ protein was identified as a binding partner for $3 \mathrm{~A}$ in both the $\mathrm{Y}-2-\mathrm{H}$ and M-2-H systems (see Table 2 ) but only interacted with $3 \mathrm{AB}$ in the Y-2-H system $[110,111]$ However, an interaction between $2 \mathrm{C}$ and $3 \mathrm{AB}$ has been demonstrated in GST pull-down experiments using purified conjugated proteins [111]. This study also suggested that 
monomeric $3 \mathrm{AB}$, and higher order $3 \mathrm{AB}$ homo-structures, may have distinct functions during $\mathrm{PV}$ replication, as multimerization of $3 \mathrm{AB}$ appeared to reduce binding to $2 \mathrm{C}$ [111]. Evidence for a functional interaction between $2 \mathrm{C}$ and $3 \mathrm{~A}$ during $\mathrm{PV}$ replication comes from studies using recombinant $\mathrm{PV}$ in which the $\mathrm{N}$-terminal residues of $2 \mathrm{C}$ were replaced by the corresponding residues of RV-B14 2C [110]. These viruses replicated poorly; however, near wild-type ( $\mathrm{wt}$ ) levels of replication were restored as a result of substitutions in 3A [110]. $3 \mathrm{~A}$ and $3 \mathrm{AB}$ are also reported to interact with the $2 \mathrm{BC}$ precursor in the $\mathrm{M}-2-\mathrm{H}$ system [110]. However, despite positive interactions involving $3 \mathrm{~A}$ and $3 \mathrm{AB}$ with $2 \mathrm{~B}$ and $2 \mathrm{C}$ (Table 2), binding of $3 \mathrm{~A}$ and $3 \mathrm{AB}$ to $2 \mathrm{BC}$ was not detected in the $\mathrm{Y}-2-\mathrm{H}$ system $[110,112]$.

Table 2. Summary of interactions between $3 \mathrm{~A}$ and $3 \mathrm{AB}$ with other nsps.

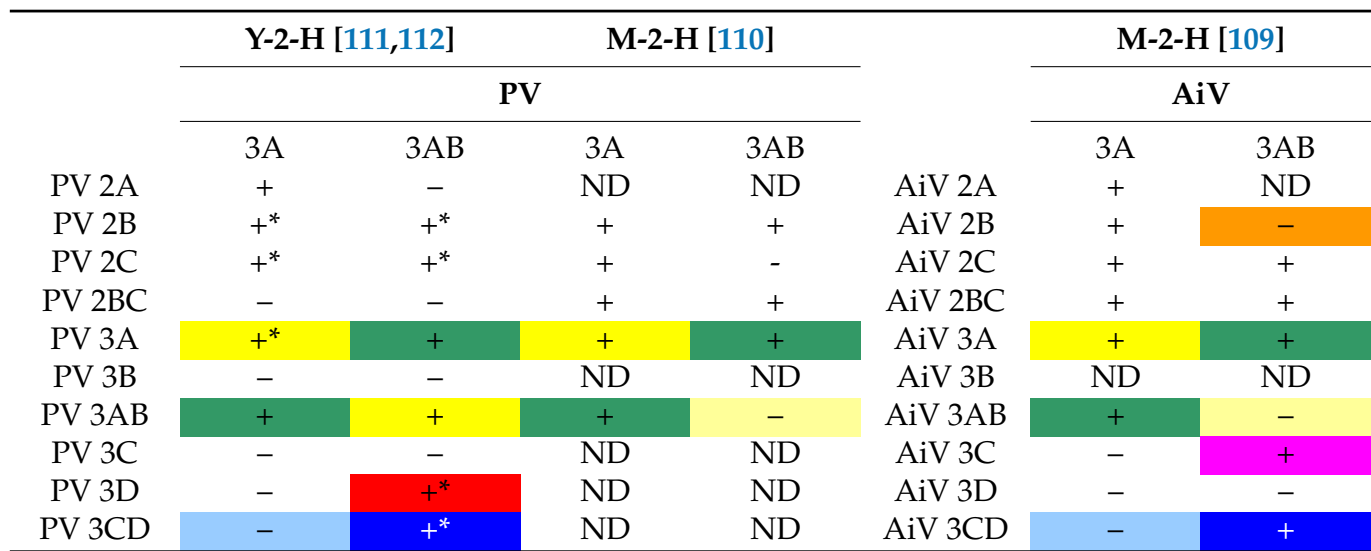

Summary of interactions between $3 \mathrm{~A}$ and $3 \mathrm{AB}$ with the nsps for poliovirus (PV) and aichivirus (AiV) in the yeast-2-hybrid (Y-2-H) and mammalian-2-hybrid (M-2-H) assay systems [109-112]. - indicates no interaction observed; + indicates positive interaction was observed in at least one orientation and in one of the studies. Note for the positive interactions, the strength of the interactions was different (see publications for details). ND, not done. Key similarities and differences between the results, which are discussed in the text, are highlighted Homodimerization interactions for $3 \mathrm{~A}$ and $3 \mathrm{AB}$ are highlighted in yellow (Dark yellow indicates + interaction and light yellow indicates - interaction). 3A:3AB interactions are highlighted in green. For PV and $\mathrm{AiV}$, the $3 \mathrm{AB}$ (but not 3A) interacts with 3CD (Blue highlights; dark blue indicates + interaction and light blue indicates interaction). Only PV $3 \mathrm{AB}$ (and not $\mathrm{AiV} 3 \mathrm{AB}$ or PV / AiV 3A) interacted with 3D (highlighted red). Only AiV 3AB (and not PV 3AB or PV / AiV 3A) interacted with 3C (highlighted purple). Only AiV 3AB did not interact with 2B (highlighted orange). It should be noted that the $\mathrm{Y}-2-\mathrm{H}$ and $\mathrm{M}-2-\mathrm{H}$ assays rely on interactions between individual picornavirus proteins, as part of a fusion protein, within the nucleus of the cell. This is an atypical environment for the picornavirus proteins and could influence the results. However, for PV, the interaction of $3 \mathrm{~A}$ with $3 \mathrm{~A}, 2 \mathrm{~B}$ $2 \mathrm{C}$, and for $3 \mathrm{AB}$ with $2 \mathrm{~B}, 2 \mathrm{C}, 3 \mathrm{D}$ and $3 \mathrm{CD}\left(^{*}\right)$ have been confirmed using other approaches.

\subsection{Interactions between $P V 3 A / 3 A B$ and $3 D^{\text {pol }}, 3 C D^{\text {pro }}$ and $2 A^{\text {pro }}$}

In the $\mathrm{Y}-2-\mathrm{H}$ system, $3 \mathrm{AB}$, but not $3 \mathrm{~A}$, interacted with $3 \mathrm{D}^{\mathrm{pol}}[108,111]$. Substitutions in the $3 \mathrm{~A}$ region of $3 \mathrm{AB}$ that impaired $3 \mathrm{AB}$ homodimerization did not adversely affect the interaction with $3 \mathrm{D}^{\mathrm{pol}}$, which suggests that homodimerization may not be important for $3 \mathrm{AB}$ binding to $3 \mathrm{D}^{\mathrm{pol}}$. The ability of $3 \mathrm{AB}$ (but not $3 \mathrm{~A}$ ) to bind to $3 \mathrm{D}^{\text {pol }}$ is consistent with other studies (see below) that show that $3 \mathrm{AB}$ (but not $3 \mathrm{~A}$ ) can stimulate RNA synthesis by $3 \mathrm{D}^{\mathrm{pol}}$.

Structural studies have identified three distinct 3B-binding sites on 3D ${ }^{\mathrm{pol}}$ [115-117]. Interestingly, two such sites do not involve residues at the active site of $3 \mathrm{D}^{\mathrm{pol}}$ and it has been suggested that when $3 \mathrm{~B}$ is bound at these sites it could be uridylylated, in trans, by another $3 \mathrm{D}^{\mathrm{pol}}$ molecule $[115,117]$. Alternatively, 3B could have a stabilizing role within the uridylylation complex $[115,117,118]$ and it is possible that the $3 \mathrm{~B}$ binding sites that lie outside of the active site could be preferentially occupied by 3B when part of $3 \mathrm{AB}$.

$3 \mathrm{AB}$ also interacted with $3 \mathrm{CD}^{\text {pro }}$ in the Y-2-H system $[108,111]$ and, although the binding appeared weak, this interaction was confirmed in a far-Western blot assay [111]. In addition, $3 \mathrm{AB}$ has been shown to bind $3 \mathrm{D}^{\mathrm{pol}}$ and $3 \mathrm{CD}^{\text {pro }}$ in immunoprecipitation experiments [119]. Furthermore, the ability of $3 \mathrm{AB}$ to bind and form a complex with $3 \mathrm{CD}^{\mathrm{pro}}$ and the $\mathrm{CL}$ at the $5^{\prime}$ end of the PV genome is central to formation of the viral RC 
and this is discussed below. Additionally, in the Y-2-H system PV 3A, but not 3AB, was shown to interact with $2 \mathrm{~A}^{\text {pro }}$ [112].

\subsection{Binding Partners of AiV $3 A$}

In an M-2-H assay, AiV $3 \mathrm{~A}$ interacted with itself and with $3 \mathrm{AB}$ (Table 2). In addition, it bound to $2 \mathrm{~A}, 2 \mathrm{~B}, 2 \mathrm{C}$ and $2 \mathrm{BC}$ but not to $3 \mathrm{C}^{\text {pro }}, 3 \mathrm{D}^{\mathrm{pol}}$ or the $3 \mathrm{CD}^{\text {pro }}$ precursor [109]. 3AB also interacted with $2 \mathrm{C}$ and $2 \mathrm{BC}$, however, in contrast to $3 \mathrm{~A}, 3 \mathrm{AB}$ did not appear to form homodimers or interact with $2 \mathrm{~B}$. Although $3 \mathrm{~A}$ did not interact with $3 \mathrm{C}^{\text {pro }}, 3 \mathrm{D}^{\text {pol }}$ or $3 \mathrm{CD}^{\text {pro }}$, the $\mathrm{AiV} 3 \mathrm{AB}$ did interact with $3 \mathrm{C}^{\text {pro }}$ and $3 \mathrm{CD}^{\text {pro }}$ (but not with $3 \mathrm{D}^{\mathrm{pol}}$ ), which suggests that, as with $\mathrm{PV}$, an interaction between $3 \mathrm{AB}$ and $3 \mathrm{CD}^{\text {pro }}$ may be central to forming the $\mathrm{AiV}$ RC [120]. Other notable differences in the binding partners of PV and AiV 3AB are: (i) in the M-2-H assay PV but not AiV 3AB interacted with 2B, (ii) AiV (in the M-2-H assay) but not PV (in the Y-2-H assay) $3 \mathrm{AB}$ interacted with $3 \mathrm{C}^{\text {pro }}$, and (iii) PV (in the Y-2-H) but not $\mathrm{AiV}$ (in the M-2-H assay) 3AB interacted with 3D ${ }^{\text {pol }}[109,110]$.

\section{Inhibition of Protein Secretion}

Some picornaviruses, (e.g., PV, CVB3 and FMDV) inhibit protein trafficking through the cell $[78,121,122]$. This suppresses cell-surface expression and secretion of proteins involved in the host antiviral response [78,79,122-125]. This process appears to be an advantage in vivo as a recombinant CVB3 incapable of inhibiting protein trafficking was less virulent in mice despite showing near normal replication in cultured cells [95]. For PV and CVB3, inhibition of protein trafficking can be recapitulated by expression of 3A alone [78,122]. However, the ability of $3 \mathrm{~A}$ to inhibit protein trafficking is not universally shared among picornaviruses, as it is 2BC of FMDV, and not 3A, which inhibits protein trafficking [121,126]. Moreover, the 3A proteins of EV-A71, RV (RV-A2 and RV-B14), Theiler's murine encephalomyelitis virus (TMEV), encephalomyocarditis virus (EMCV) and HAV do not have an inhibitory effect $[127,128]$. In contrast to RV-A2 and RV-B14, the $3 \mathrm{~A}$ protein of RV-A16 was reported to inhibit protein trafficking; however, protein secretion is not inhibited in RV-A16-infected cells and the reason for this apparent disparity is unknown [129].

A number of studies have investigated how 3A of enteroviruses (CVB3 and PV) inhibit protein trafficking $[78,128,130]$. Collectively, these studies show that $3 \mathrm{~A}$ blocks anterograde transport between the endoplasmic-reticulum (ER)-Golgi intermediate compartment (ERGIC) and the Golgi by preventing formation of coatomer protein complex I (COPI)-coated transport vesicles. Before describing how 3A is thought to inhibit the secretory pathway, it is worth briefly describing how COPI-coated transport vesicles are formed in the Golgi. The assembly of COPI-coated vesicles is initiated by activation of ARF1 (ADP-ribosylation factor 1) [131]. In the Golgi, activation of ARF1 is triggered by GBF1 (Golgi Brefeldin A Resistant Guanine Nucleotide Exchange Factor 1). As its full name indicates, GBF1 is a guanine nucleotide exchange factor (GEF) that catalyzes GDP/GTP exchange and converts ARF1-GDP (the inactive form) to ARF1-GTP (the active form) [132]. The COPI coat (or coatomer) is then recruited by a direct interaction with ARF1-GTP, and then COPIcoated vesicles subsequently bud from the Golgi. ARF GTPase-activating proteins (GAPs) interact with ARF1-GTP and induce GTP hydrolysis to generate ARF1-GDP in a process that may be enhanced by the COPI coatomer [133]. Normally, GBF1 cycles on and off membranes and each membrane-binding event triggers GDP/GTP exchange and, hence, the activation of ARF1 [133]. Activated ARF1 also shows increased membrane binding, thus, increased membrane association of GBF1 and ARF1 are normally considered to indicate conversion to their active states.

Initial evidence indicating how CVB3 inhibits protein trafficking came from the observations that the N-terminal (aa 1-60) domain of CVB3 3A binds to GBF1 (in a Y-2-H assay and in pull down experiments) and could inhibit its GEF activity [95,96]. Furthermore, expression of 3A reduced cellular levels of activated ARF1 (ARF1-GTP) and this could be overcome by co-expression of GBF1 (along with 3A) [95]. The role of 3A in these studies 
was confirmed by using a serine-insertion modification in 3A immediately after residue 15 (in CVB3 called 3A-ins 16S). This insertion prevents 3A binding to GBF1 and impairs the ability of 3A to: (i) inhibit the GEF activity of GBF1, (ii) reduce cellular levels of ARF1-GTP and (iii) inhibit protein trafficking $[95,96]$. Similar observations to those described above for CVB3 were made for PV 3A, which suggested that their 3A proteins inhibit protein trafficking by the same mechanism [128].

The binding site for GBF1 has been mapped to the N-terminal region of enterovirus $3 \mathrm{~A}$ and deletion of the first $10 \mathrm{~N}$-terminal residues renders $3 \mathrm{~A}$ incapable of inhibiting protein trafficking $[95,124,128]$. Dimerization is required for $3 \mathrm{~A}$ to inhibit protein trafficking [106] and substitutions in 3A that prevent dimerization [106,125] also prevent binding to GBF1 [96]. However, other substitutions in 3A that prevent binding to GBF1 and the ability of $3 \mathrm{~A}$ to inhibit protein trafficking do not affect dimerization $[96,106]$. Based on these observations it was suggested that $3 \mathrm{~A}$ dimerization may be required to present the GBF1-binding site to 3A [96].

In addition to showing that the 3A proteins of RV-A2 and RV-B14 fail to inhibit protein trafficking, Wessels et al. [128] showed that they have a reduced ability to interact with GBF1 due to aa differences within the identified GBF1-binding site (see Figure 1). 3A of RV-A2 did not interact with GBF1 in a Y-2-H assay whereas 3A of RV-B14 made only weak interactions [128]. This suggested that the most likely explanation for the failure of the $3 \mathrm{~A}$ proteins of RV-A2 and RV-B14 to inhibit protein trafficking was an inability or reduced ability to bind GBF1. As noted above, the 3A protein of RV-A16 was reported to inhibit protein trafficking despite the secretory pathway functioning normally in RV-A16-infected cells [129]. Interestingly, as for RV-A2, the 3A protein of RV-A16 also lacks the residues in the $\mathrm{N}$-terminal region that form the GBF1 binding site (Figure 1), and therefore would not be expected to bind to GBF1.

Interestingly, the study by Wessels et al. [95] showed, in FRAP (fluorescence recovery after photo-bleaching) experiments, that membrane association of GBF1 was increased in 3A-transfected cells. This suggested that GBF1 could be activated by 3A. However, Brefeldin A (BFA) inhibits ARF1 activation by forming an inactive complex between GBF1 and ARF1-GDP and thereby stabilizes GBF1 on membranes [134]. Thus, the increased membrane association of GBF1 induced by 3A could indicate that (similar to BFA) 3A inhibits GBF1 when it is membrane associated [95].

Although the 3A proteins of PV and CVB3 inhibit protein secretion, it is not clear if this is also the case for $3 \mathrm{AB}$. An early study reported that $\mathrm{PV} 3 \mathrm{AB}$ does not have an inhibitory effect on protein trafficking [78]. In contrast, a more recent report indicated that $\mathrm{PV} 3 \mathrm{AB}$ can inhibit protein trafficking, but to a lesser extent than 3A [135]. These observations suggest that $3 \mathrm{AB}$ may not be able to bind to GBF1 or may bind with reduced efficiency compared to $3 \mathrm{~A}$. However, problems with the expression of $3 \mathrm{AB}$ have been reported [124] and whether $\mathrm{PV} 3 \mathrm{AB}$ can bind to GBF1 and inhibit protein trafficking is currently not clear.

As discussed further below, picornavirus $3 \mathrm{~A}$ proteins (and certain 3A-containing precursor proteins) have an important role(s) in vRNA replication. However, the roles of $3 \mathrm{~A}$ in vRNA replication and in inhibiting protein trafficking appear distinct, as aa substitutions have been identified in enterovirus $3 \mathrm{~A}$ proteins that attenuate infection but do not reduce the ability of 3A to inhibit protein trafficking $[95,106,124,127]$. Conversely, other changes have been identified that abrogate the ability of $3 \mathrm{~A}$ to inhibit protein trafficking but do not prevent virus replication $[95,106,122-124]$. One such mutant is the 3A-ins $16 \mathrm{~S}$ serineinsertion described above for CVB3 3A. In PV, this insertion mutant is called 3A-2 and, similar to CVB3, the modification results in viable viruses that are unable to inhibit protein trafficking $[95,124,136]$.

The above studies have established that the 3A proteins of PV and CVB3 bind to GBF1 and that CVB3 3A inhibits GBF1 activation. However, enterovirus replication requires the type III phosphatidylinositol 4-kinase (PI4K), PI4KIII $\beta$ (from here onwards termed PI4KB) (see below), and the interaction between $3 \mathrm{~A}$ and GBF1 is thought to provide a mechanism (via GBF1 and ARF1 activation) to recruit PI4KB to the RC. These seemingly contradictory 
outcomes of 3A binding to GBF1 have fueled an on-going conundrum regarding the roles of 3A and GBF1 in enterovirus replication, which is discussed in more detail below.

\section{Membrane Interactions}

$3 \mathrm{~A}$ and $3 \mathrm{AB}$ are membrane-binding proteins and $\mathrm{PV} 3 \mathrm{~A} / 3 \mathrm{AB}$ interacts with membranes when expressed in the absence of other viral proteins [94,102,137-140]. Figures 1 and 2 show an alignment of $3 \mathrm{~A}$ sequences of selected picornaviruses. Although 3A proteins are highly charged, a region devoid of charged residues can be identified towards the $\mathrm{C}$-terminus of the protein, which is consistent with a HD (see above). However, for teschovirus A1 (TV-A1) the HD appears to extend to the C-terminus of the protein (Figure 1). The HD of PV $3 \mathrm{~A}$ is comprised of 22 residues (59-80) and includes the region that anchors $3 \mathrm{~A} / 3 \mathrm{AB}$ to membranes (here called the membrane-binding region (MBR)). For PV 3A, the MBR has been mapped experimentally to residues 65-80 [94]. This is consistent with earlier studies that identified residues within the $\mathrm{C}$-terminal half of the $\mathrm{HD}$ as being critical for PV 3A membrane association [140]. In line with these observations, residues 62-79 were predicted to be part of an MBR by four structure prediction programmes, TM-PRED [90], TMHMM [91], PHOBIUS [92] and HMMTOP [93] (Figure 1). These programs also predict the presence of an MBR for most of the 3A proteins shown in Figure 1. Interestingly, for Carp picornavirus 1 (CPV) only one of them, TM-PRED, predicted an MBR (Figure 1), which suggests that this $3 \mathrm{~A}$ protein may make novel interactions with membranes.

The $3 \mathrm{AB}$ precursor is an efficient substrate for processing when membrane-associated [94]. Models of how $3 \mathrm{AB}$ interacts with membranes have considered the need to maintain the P3 proteins on the cytoplasmic side of the membrane, to facilitate viral polypeptide processing and formation of the viral RC $[94,141]$. Consistent with this, PV 3AB was shown to be orientated parallel to the membrane bilayer such that it only interacts with the outer leaflet (i.e., adopts a monotopic orientation) [94]. Interestingly, the topology of membrane association was different for the mature $3 \mathrm{~A}$ protein, which adopted two alternative orientations; a monotopic orientation (as described for $3 \mathrm{AB}$ ) and a bitopic orientation [94]. The 3B peptide is hydrophilic and effectively extends the length and increases the hydrophilic nature of the C-terminal domain of $3 \mathrm{~A}$, and it is likely that this blocks the ability of $3 \mathrm{AB}$ to fully span the membrane [94]. Furthermore, the observations described above suggest the possibility that a switch between monotopic and bitopic membrane associations may occur on processing of PV 3AB to 3A and 3B [94].

The 3A protein of FMDV is considerably longer (153 residues) than other picornaviruses and has an extended C-terminal domain [87] (Figure 2). However, like other picornaviruses, FMDV $3 \mathrm{~A}$ has three clearly defined regions; $\mathrm{N}$ - and $\mathrm{C}$-terminal domains separated by a HD (residues 61-76). The sequence of the N-terminal and HDs are very highly conserved across FMDV serotypes while, in contrast, the C-terminal domains show rather limited sequence identity [87]. As for PV, the HD of FMDV 3A includes an MBR [142]. The substitution of residues 59 to 76 by a shorter sequence of 8 consecutive Ala residues abrogated FMDV replication, which suggests that the membrane association of FMDV 3A is important for vRNA replication [143] (however, this is a fairly major modification which could influence the protein properties in a variety of ways). Unlike the PV 3A that can fully span cellular membranes, FMDV $3 \mathrm{~A}$ has been shown to adopt a monotopic orientation on membrane binding [142]. Presumably this is because FMDV 3A has a longer C-terminal region that prevents a bitopic membrane association. Thus, due to its longer $\mathrm{C}$-terminal domain, removing $3 \mathrm{~B}$ from FMDV $3 \mathrm{AB}$ may not have the same effect of switching from monotopic to bitopic membrane binding.

\section{Host-Range Determinant}

Some picornaviruses have a restricted host range (e.g., PV) [144], while others such as FMDV have a broad host range that includes economically important livestock (e.g., cattle, buffalo, sheep, goats and pigs) and numerous cloven-hoofed species of wild animal $[145,146]$. Amino acid changes in picornavirus 3A proteins can alter the host range of the virus. 
For example, aa substitutions in 3A allow replication of RV-A1 in mouse cells [147,148] and increase replication of RV-C clinical isolates in cell culture [149]. Changes in 3A have also been implicated in improved growth in cell culture of hepatoviruses [150-153] and have been reported to influence tissue tropism of CVB3 in mice [154].

Substitutions in FMDV 3A are also associated with altered host range. A Gln-44-Arg substitution in the N-terminal domain of the 3A protein of FMDV C-S8c1 allows infection of guinea pigs [155]. The mechanisms that underlie how this change results in replication in guinea pigs' cells are unknown. The Gln- 44 residue is conserved across all FMDV serotypes and lies adjacent to the predicted interface between 3A molecules of a 3A-homodimer where it could make interactions with other viral proteins or with cellular proteins that are involved in FMDV replication. Deletions within the C-terminal domain of FMDV 3A are also linked to determination of host range. Deletion of residues 84-102 in O1Campos O/E, or residues 88-106 in C3 Resende/ Brasil55 were first linked to host specificity as they were lost in viruses that were attenuated for cattle (but not pigs) after passage through chicken embryos during vaccine development [156-159]. A similar deletion in 3A (aa 93-102) was found in a natural field isolate (FMDV O/YUN/TAW/97) that caused an outbreak of FMD in Taiwan in 1997 [160,161]. This outbreak only affected pigs, which suggested that the O/YUN/TAW/97 virus could be attenuated for cattle. In line with this, subsequent studies appeared to link this deletion with attenuation in cattle since recombinant chimeric viruses (based on O/YUN/TAW/97 and a bovine-virulent FMDV) showed that viruses with the 93-102 deletion in 3A had restricted replication in primary bovine cells and were attenuated for cattle [160]. Further studies suggested that the 93-102 deletion in 3A (and a similar deletion of residues 87-106) reduced replication in bovine cells without affecting replication in porcine cells, or virulence for pigs $[87,97,162,163]$. However, analyses of type O FMDVs circulating in South-east Asia (between 1970-1999) identified viruses with the 93-102 deletion in 3A that were initially isolated from cattle; and furthermore, some of these viruses (e.g., O/HKN/21/70) replicated similarly to wt viruses in bovine and porcine primary keratinocytes [87]. This suggested that the 93-102 deletion in 3A may not be solely responsible for the poor replication of O/YUN/TAW/97 in bovine cells. As pointed out by the authors [87], the 3A protein of O/YUN/TAW/97 also had accumulated a large number of other aa substitutions in the C-terminal domain that could also contribute to the inability of O/YUN/TAW/97 to replicate in bovine cells. The study by Pacheco et al. [97] appeared to show that the 87-106 deletion in 3A did not abrogate FMDV replication in an established bovine cell line (LFBK) that had been transfected to express the FMDV receptor, integrin $\alpha \mathrm{v} \beta 6$. However, subsequent analysis has shown that these LFBK cells were actually of porcine origin and the ability of FMDV with the 87-106 deletion in 3A to replicate in bovine cell lines remains to be determined [164].

The FMDVs circulating in South-east Asia [87] also had a second deletion in the Cterminal domain of FMDV 3A that spanned residues 133-143. Similar to the viruses with the 93-102 deletion, viruses with the 133-143 deletion in 3A replicated well in porcine cells [163]. However, the effect of this deletion on FMDV replication in bovine cells is less clear. Two studies have reported that FMDV with the 133-143 deletion could replicate in bovine primary keratinocytes and primary bovine fetal kidney cells [87,165] whereas another study found that replication in secondary bovine kidney cell cultures is severely attenuated [163]. Based on these natural deletions, a recombinant virus with a more extensive deletion in 3A (lacking 52 residues, aa 93-143; so-called 3A super-deleted) has been generated and shown to display severely reduced replication in fetal bovine kidney cells [163]. Interestingly, viruses with this deletion replicate with wt kinetics in fetal porcine kidney cells [163], and caused severe FMD symptoms in pigs, which suggests that almost the entire C-terminal domain of $3 \mathrm{~A}$ is not required for FMDV replication in porcine cells.

FMDV with the 87-106 deletion in 3A has been studied in more detail. In vivo studies have confirmed that viruses with this deletion are virulent for pigs [97] but attenuated for cattle $[97,166]$. Following aerosol inoculation, cattle infected with FMDV carrying this deletion in 3A displayed few or no clinical signs of FMD and did not develop viremia or 
generate neutralizing antibodies [166]. Infectious virus and vRNA were detected in the pharyngeal areas at day 21 post-inoculation [166] suggesting that vRNA replication had occurred but was restricted to these areas. In addition, similar mRNA levels encoding several anti-viral cytokines in nasopharyngeal tissues were seen in animals infected with either the wt virus or the virus with the deletion in 3A. These findings lead the authors to suggest that cattle attenuation of FMDV resulting from the 87-106 deletion in 3A more likely results from reduced intracellular virus replication, rather than differences in the host anti-viral response. However, it is possible that cattle attenuation due to the 87-106 deletion in $3 \mathrm{~A}$ results from the need for $3 \mathrm{~A}$ to combat the antiviral effects of as yet unidentified host restriction factor(s) that function in bovine but not porcine cells.

\section{Nucleic Acid Chaperone Activity}

PV 3AB displays characteristics of a nucleic acid chaperone and promotes (i) sequenceindependent nucleic acid (DNA and RNA) hybridization and (ii) unwinding of nucleic acid secondary structure [167]. The ability of $3 \mathrm{AB}$ to enhance hybridization appears to require $3 \mathrm{~A}$ to coat the target nucleic acid. The $3 \mathrm{~B}$ peptide alone has no activity; however, the chaperone activity of $3 \mathrm{AB}$ appears to be dependent on the $3 \mathrm{~B}$ region, as substitutions within $3 \mathrm{~B}$ abrogated this function [168]. Consistent with these observations, a peptide consisting of $3 \mathrm{~B}$ and the 7 aa from the $\mathrm{C}$-terminal domain of $3 \mathrm{~A}$ (peptide $3 \mathrm{~B}+7$ ) could mimic the chaperone activity of full-length $3 \mathrm{AB}$ indicating that the chaperone activity of $3 \mathrm{AB}$ resides collectively within the C-terminal domain of $3 \mathrm{~A}$ and $3 \mathrm{~B}$ [168]. More recently, the same region of EV-A71 $3 \mathrm{AB}$ has been reported to display RNA chaperone (destabilizing RNA helices and stimulating RNA strand annealing) activity [169]. It is not clear how the chaperone role of $3 \mathrm{AB}$ contributes to enterovirus replication. However, as discussed [167], nucleic acid chaperone activity could enhance recombination or facilitate vRNA replication by promoting unwinding of vRNA templates and/or destabilizing secondary structures and could facilitate packaging.

\section{Interactions with Cellular Proteins}

Picornavirus 3A proteins have been reported to interact (directly or indirectly) with a number of cellular proteins. However, for most of these interactions, the precise role of the cellular protein in facilitating virus replication is currently unclear. The functional consequences for protein secretion resulting from the binding of the $3 \mathrm{~A}$ proteins from PV and CVB3 to GBF1 have been described above. However, GBF1 is also required for enterovirus replication and the role of $3 \mathrm{~A}$ in recruiting GBF1 to the $\mathrm{RC}$ is described in detail below. Similarly, 3A interactions with ACBD3 (Acyl-CoA binding domain containing protein 3), type III phosphatidylinositol 4-kinase (PI4K) and lipid droplet enzymes are associated with vRNA replication and these are also described below. In the next part of the review, we describe interactions between $3 \mathrm{~A}$ and cellular proteins that do not appear to directly influence vRNA replication.

\subsection{LIS1}

Poliovirus 3A has been shown to bind LIS1 (Lissencephaly 1 Protein) in a Y-2-H assay and in pull-down experiments using tagged proteins [170]. LIS1 promotes formation of the dynein-dynactin complex and thereby activates dynein [171,172]. Dynein 1 moves diverse cargos (including organelles, vesicles and RNA) along microtubules and contributes to maintaining the distribution, organization, structural integrity and functions of many cellular organelles [173,174]. The role of LIS1 in PV infection has not been investigated but it has been suggested that binding to LIS1 could contribute, in part, to inhibition of protein trafficking by $3 \mathrm{~A}$, or could be involved in non-lytic virus release [76]. However, an independent study failed to detect LIS1 as a 3A-binding partner in 3A pull-down experiments [113]. This study used recombinant $\mathrm{PV}$ with insertion tags near the $\mathrm{N}$-terminus of 3A; thus, it is possible that such tags impair 3A binding to LIS1. However, given that 
viruses with $3 \mathrm{~A}$ insertion tags were viable, it was suggested that LIS1 may not be required for vRNA replication per se but could serve to promote infection in vivo [113].

\subsection{Dynactin-3}

Dynactin-3 is a subunit of the dynactin complex (that serves as a cofactor for dynein) and is essential for most cellular functions carried out by dynein. The $3 \mathrm{~A}$ protein of FMDV O1 Campos has been reported to bind to dynactin-3 in both $\mathrm{Y}-2-\mathrm{H}$ and $\mathrm{M}-2-\mathrm{H}$ assays [175]. However, attempts to confirm the interaction between $3 \mathrm{~A}$ and dynactin-3 in FMDV-infected cells using immunofluorescence confocal microscopy were inconclusive. In $\mathrm{Y}-2-\mathrm{H}$ experiments, residues within the $\mathrm{C}$-terminal domain of $3 \mathrm{~A}$ were shown to mediate binding to dynactin-3. Specifically, changing residues 89-Ala-Val-Asn-Glu-92 (89-AVNE92) to 89-Pro-Leu-Asp-Glu-92 (89-PLDG-92) abrogated the interaction between $3 \mathrm{~A}$ and dynactin-3. The PLDG motif was chosen as a substitute for 89-AVNE-92 because it is present at the corresponding site in 3A of FMDV O/TAW/97, which was shown not to interact with dynactin-3 in the Y-2-H system. A recombinant FMDV (based on O1 Campos) including the 3A 89-AVNE-92 to 89-PLDG-92 substitutions replicated poorly in primary bovine cell cultures, and only caused mild symptoms of FMD in cattle [175]. Sequencing of viruses isolated from secondary lesions of three cattle infected with the 3A PLDG virus revealed changes at the Pro residue to either Ala (one animal) or Leu (the other two animals). Consistent with these observations, an Ala-89-Leu substitution introduced into $3 \mathrm{~A}$ of O1 Campos did not alter 3A binding to dynactin-3 in a Y-2-H assay, whereas the introduction of Pro at this site (Ala-89-Pro) prevented the interaction. The precise role of dynactin-3 in FMDV infection of cattle remains to be determined, but the failure of the $3 \mathrm{~A}$ PLDG virus to replicate in primary bovine cells suggest that dynactin-3 may be required for FMDV replication. However, the recombinant FMDV including the 3A 89-AVNE-92 to 89-PLDG-92 substitution displayed near wt replication kinetics in a continuous porcine kidney cell line expressing $\alpha \mathrm{v} \beta 6$, which suggests that the interaction between $3 \mathrm{~A}$ and dynactin-3 is not required for FMDV replication in porcine cells. Interestingly, this porcine kidney cell line supports replication of a leaderless FMDV, which suggests that it could have a defective interferon response [176]. Thus, it will be interesting to determine if the 3A PLDG virus can replicate in primary porcine cells and/or retains virulence for pigs. Interestingly, the virus with substitutions within the dynactin binding site has similar growth characteristics to viruses with internal deletions in the C-terminal domain of $3 \mathrm{~A}$ (i.e., poor replication in primary bovine cells and cattle while retaining wt replication in porcine cells). The internal deletions removed the residues that form the dynactin-binding site, which suggests that the interaction between $3 \mathrm{~A}$ and dynactin could contribute to the host range specificity of FMDV [175].

\subsection{Vimentin}

Vimentin is a major intermediate filament and provides a cytoplasmic scaffold for the organization and functions of cellular organelles, and other cellular processes such as cell spreading, migration and signal transduction [177]. In addition, vimentin has been reported to actively support viral infections [178]. FMDV 3A has been identified as a binding partner for vimentin from mass spectrometry analysis of proteins that co-purified with 3A (using an anti-3A antibody) from FMDV-infected primary fetal bovine kidney (FBK) cells [179]. The interaction was also demonstrated by the simultaneous pull-down (using anti-c-Myc agarose beads) of FLAG-tagged vimentin and Myc-tagged FMDV 3A from HEK293T cells co-expressing these proteins. However, labelling for 3A and vimentin showed limited overlap in FMDV-infected pig kidney cells. The interaction with vimentin was reported to involve residues 15-21 of 3A [179]. However, it is not clear what effect the changes introduced into $3 \mathrm{~A}$ (i.e., residues $15-21$ were replaced by 7 consecutive Ala residues) had on the overall structure of $3 \mathrm{~A}$. Recombinant FMDV with these changes in $3 \mathrm{~A}$ could not be rescued suggesting a possible link between $3 \mathrm{~A}$ binding to vimentin and FMDV replication; however, these changes would likely interfere with the other functions 
of $3 \mathrm{~A} / 3 \mathrm{AB}$ during virus replication. FMDV replication was inhibited by overexpression of FLAG-tagged vimentin or by disrupting vimentin with acrylamide, whereas siRNA knockdown of vimentin appeared to enhance FMDV replication. However, these studies need to be reconciled with the observations that vimentin is not normally expressed in epithelial cells, which are the cell type preferentially infected by FMDV in vivo [180,181].

\section{Evasion of the Cellular Antiviral Response}

The innate cellular antiviral response prevents replication of viruses to restrict their spread within the host. Detection of virus infection by the cellular antiviral response is dependent on pathogen-associated molecular patterns (PAMPs) within vRNA. In the cytoplasm, PAMPs are detected by pattern recognition receptors (PRRs), which "sense" vRNA. PRRs include the double-stranded RNA-dependent protein kinase (PKR) and the RIG-I-like receptors (RLRs), RIG-I (Retinoic acid-inducible gene I), MDA5 (Melanoma Differentiation-Associated protein 5) and LGP2 (laboratory of genetics and physiology 2). On binding to PAMPs, RLRs trigger signaling cascades through MAVS (Mitochondrial antiviral signaling protein; also known as VISA; Virus-Induced-Signaling Adapter) that culminate in activation of transcription factors (such as IFN regulatory factor 3 (IRF3), IRF7 and NF-kappa B (NF-қB). These factors then translocate to the nucleus and drive the expression of various antiviral molecules, including the interferons (INFs), which restrict virus replication and orchestrate the adaptive immune response [182,183].

To combat the cellular antiviral response, picornaviruses have evolved a number of strategies. These include: inhibition of host-cell protein synthesis and transcription, preventing nuclear translocation of transcription factors, or inducing degradation (either indirectly by proteasome- and caspase-dependent processes, or directly via virus-encoded proteases) of host proteins that sense infection [82,184-187]. HAV 3A has been implicated as having an indirect role in evading antiviral responses. HAV targets MAVS in infected cells. MAVS is localized to mitochondria and essential for the cellular antiviral immune response to RNA virus infection [188]. During infection by HAV, MAVS is degraded by the protease activity of $3 C^{\text {pro }}$ when part of a larger $3 A B C$ precursor, which associates with mitochondrial membranes via the membrane anchor region of $3 \mathrm{~A}$. In addition, a number of recent studies have reported that the $3 \mathrm{~A}$ proteins of some picornaviruses contribute to evasion of the cell antiviral response by interacting with, or regulating expression of, some of the key proteins involved (see below).

\subsection{ATP1B3}

ATP1B3 (Sodium/potassium-dependent ATPase subunit beta-3) is a regulatory subunit of $\mathrm{Na}+/ \mathrm{K}+-\mathrm{ATPase}$ [189]. Recently, ATP1B3 was proposed to positively regulate IFN expression by activating NF- $\mathrm{B}[190,191]$. In line with such a role, replication of EV-A71 was reduced by overexpression of ATP1B3 and enhanced by ATP1B3 knockdown [190]. This study also reported that EV-A71 3A could bind to ATP1B3 in a Y-2-H assay and in coimmunoprecipitation experiments using epitope tagged proteins expressed in transfected cells. Furthermore, the interaction between endogenous ATP1B3 and 3A was detected in EV-A71-infected human rhabdomyosarcoma cells [190], which suggests that 3A could interfere with the functions of ATP1B3 during infection.

\subsection{RIG-I, MDA5 and MAVS}

FMDV 3A has been reported to bind to RIG-I, MDA5 and MAVS in immunoprecipitation experiments [192]. This study also reported that mRNA and protein levels of RIG-I, MDA5 and MAVS were reduced in cells transfected to express 3A. In addition, 3A was reported to inhibit the IFN- $\beta$ signaling pathway, and phosphorylation and dimerization of IRF3 induced by Sendai virus (SeV). However, this study used human cells and relied solely upon overexpression of $3 \mathrm{~A}$ in isolation from other viral proteins, which may not completely reflect the function of $3 \mathrm{~A}$ in evasion of the cell antiviral response. It would be of interest to determine if 3A interacts with RIG-1, MDA5 and MAVS in FMDV-infected cells derived 
from a natural host of FMDV. Moreover, the above observations need to be reconciled with similar studies that concluded that expression of FMDV 3A (or 3AB) does not influence expression of ISGs in HeLa cells following treatment with IFN $\beta$ [193], and more recent studies which showed that $\mathrm{L}^{\text {pro }}$ targets MDA5 for degradation in FMDV-infected porcine cells [186].

\subsection{DDX56}

The DEAD-box family protein, DDX56 has been proposed to down regulate the IFN signaling pathway by preventing the interaction between IRF3 and IPO5 (a nuclear transport receptor) and thereby reducing IRF3 nuclear import [194]. Recently, FMDV 3A has been reported to cooperate with DDX56 to inhibit the IFN signaling pathway by reducing IRF3 phosphorylation [195], which is also required for nuclear translocation and the antiviral functions of IRF3.

\subsection{G3BP1}

G3BP1 (Ras-GAP SH3-binding protein 1) is an antiviral protein and has been shown to be important for stress granule (SG) formation [196,197]. Assembly of SGs is an important host response to viral infection as they serve as signaling hubs that contribute to the cellular antiviral response [198]. Thus, many viruses including picornaviruses block their assembly during infection (reviewed in [199]). In addition to nucleating SG formation, G3BP1 has been shown to regulate the cell antiviral response via activation of PKR, JNK (Jun Nterminal kinase) signaling and transcription mediated by NFKB [197]. Furthermore, G3BP1 has been shown to interact with RIG-I and dsRNA to induce production of IFN [200]. Recently, FMDV 3A has been reported to interact with porcine G3BP1 [201]. This study also reported that expression of 3A alone induced degradation of G3BP1 by a process that involved LRRC25 (Leucine Rich Repeat Containing 25) and possibly autophagic degradation [201]. However, these observations need to be considered against separate reports that provided evidence that the FMDV 3C ${ }^{\text {pro }}[202,203]$ or alternatively the FMDV L $^{\text {pro }}$ can cause degradation of G3BP1 in FMDV-infected porcine cells [204].

\subsection{RNA Interference}

RNA interference (RNAi) is a gene-silencing mechanism that is conserved through evolution in many diverse organisms and contributes to host defence against pathogens. Consequently, many viruses have evolved viral suppressors of RNAi (VSR) that inhibit the host RNAi silencing. However, the role of RNAi as a component of the cellular antiviral defense response in mammals has been the topic of debate [205]. Recently, the abilities of enterovirus 3A proteins to function as VSRs have been investigated and provided contradictory evidence and conclusions. A recent study has concluded that EV-A71 3A (and 3AB) functions as a potent VSR [206]. This study showed that FLAG-tagged 3A could suppress RNAi-mediated silencing of EGFP expression in HEK293T cells [206]. In addition, EV-A71 3A was shown to bind and protect long dsRNA from processing by Dicer (an RNase III enzyme that processes long precursor dsRNAs to short dsRNAs). A single aa substitution (Asp-23-Ala) (D23A) abrogated the ability of 3A to bind and protect dsRNA from Dicer and also reduced EV-A71 replication. Together these observations suggested that an RNAi response could be triggered on infection by EV-A71 with the 3A D23A mutation and that this could restrict its replication. Consistent with this conclusion, replication of EV-A71 carrying the 3A D23A change could be partially rescued on infection of dicer-deficient cells, or by ectopic expression of wt 3A but not by 3A with the D23A change. Furthermore, EV-A71-derived small RNAs with characteristics of canonical siRNA ( $22 \mathrm{nt}$ long and derived from both strands of the EV-A71 vRNA and enriched for the 5' and $3^{\prime}$ ends of the vRNA) could be detected in cells infected by EV-A71 carrying the 3A D23A substitution, but not after infection with the wt virus. This suggested that EV-A71 3 A could potently inhibit RNAi. Following this study, the 3A protein of CVB3 was also reported to inhibit RNAi [207]. This study also identified a number of residues (24-Asp- 
Leu-Leu-26, 37-Tyr-Cys-38 and Arg-60) that are important for CVB3 3A binding to dsRNA and to suppress siRNA production. Interestingly, these residues are present (although in slightly different positions due to the different lengths of their 3A proteins) in 3A of EV-A71 and other enteroviruses (including PV, see Figure 1), which suggested that the ability of 3A to suppress RNAi could be common among enteroviruses.

In contrast to the above findings, myc-tagged 3A of EV-A71, CVB3 and PV were shown not to suppress RNAi-mediated silencing of firefly luciferase in transfected HeLa cells [208]. In addition, this study showed that infection of HeLa and HEK293T cells by a replication-defective CVB3, with a D24A substitution (equivalent to the D23A change in EV-A71), did not generate canonical virus-derived small RNAs. The small RNAs derived from CVB3 had: (i) a broad size distribution, (ii) a strong bias for positive strands over negative strands and (iii) covered the entire viral genome. Furthermore, replication of CVB3 with the D24A 3A substitution was not improved in AGO-2 knockout cells (which lacked a functional siRNA-mediated RNAi response), which argues against the ability of CVB3 3A to suppress RNAi.

\section{The Viral Replication Complex and vRNA Replication}

Replication of picornavirus vRNA takes place within a RC. The RC forms in close association with membranes in a highly controlled process that involves vRNA translation and viral protein processing, and multiple host proteins [209,210]. The $\mathrm{P} 3$ proteins $(3 \mathrm{~A}, 3 \mathrm{~B}$, $3 \mathrm{C}^{\text {pro }}, 3 \mathrm{D}^{\mathrm{pol}}$ ) and their processing intermediates (e.g., $3 \mathrm{AB}$ and $3 \mathrm{CD}^{\text {pro }}$ ) are the main viral proteins involved in forming the RC and vRNA replication. In line with this, substitutions in the cytoplasmic domain of PV $3 \mathrm{~A}$ (which will also be present in $3 \mathrm{AB}$ ) are lethal and reduced vRNA synthesis [98]. Below, we focus on the roles of $3 \mathrm{~A} / 3 \mathrm{AB}$ in the $\mathrm{RC}$, and the roles of other viral nsps are only described briefly and only when relevant to the functions of $3 \mathrm{~A}$ and $3 \mathrm{AB}$.

The $3 \mathrm{AB}$ and $3 \mathrm{CD}^{\text {pro }}$ precursors of $\mathrm{PV}$ are relatively stable in infected cells (see above) and interact to form a complex with the CL at the $5^{\prime}$ end of positive-sense vRNA that nucleates formation of the $\operatorname{RC}[15,16,119,211-213]$. The interaction of $3 \mathrm{AB}$ with the $\mathrm{CL}$ is dependent on $3 \mathrm{CD}^{\text {pro }}$, as $3 \mathrm{AB}$ does not bind to the $\mathrm{CL}$ alone [211]. The complex of $3 \mathrm{AB}$ and $3 \mathrm{CD}^{\text {pro }}$ can also bind to the $3^{\prime}$-end of plus strand vRNA [211,214]. However, in contrast to the binding to the $\mathrm{CL}, 3 \mathrm{AB}$ can bind to the $3^{\prime}$-end of PV RNA in the absence of $3 \mathrm{CD}^{\text {pro }}$ [211]. A more recent study [215] showed that the initial interaction with the CL is most likely mediated by the full length $\mathrm{P} 3$, which presumably supplies the copies of $3 \mathrm{AB}$ and $3 \mathrm{CD}^{\text {pro }}$ that form the complex. Additional molecules of $\mathrm{P} 3$ are subsequently recruited to the $\mathrm{RC}$, which provides 3Dpol and VPg (3B) for vRNA replication. These observations are consistent with earlier studies that showed that PV RNA with changes in either 3A or 3B (VPg), that rendered viruses replication-defective, could only be rescued in trans by expression of full-length $\mathrm{P} 3$, and not by $3 \mathrm{AB}$ or other 3A- and 3B-containing precursors [141,216]. Similarly, defective replication due to a lesion in $3 \mathrm{~A}$ of an FMDV replicon could be rescued by a "helper" replicon expressing wt 3A when supplied as part of the complete P3 [217].

The $3 \mathrm{AB}$ precursor is a membrane binding protein and it is conceivable that $\mathrm{P} 3$ is tethered to cellular membranes during formation of the RC by the MBR of 3A. As described above, this is most likely mediated by binding only on the cytoplasmic face of the membrane, as this would keep the P3 proteins on the same side of the membrane to facilitate polyprotein processing and formation of the RC. In addition, the ability of $3 \mathrm{AB}$ to bind cell membranes is important for vRNA replication as certain substitutions for the Met at position 79 in the MBR of PV 3A resulted in a specific defect in positive-strand vRNA synthesis (note: VPg uridylylation and negative-strand RNA synthesis occurred normally) [140]. However, this defect was not caused by an inability of 3A to bind membranes, as membrane association of 3A still occurred despite the changes [218]. Other substitutions within the HD of PV 3A cause aberrant processing of precursor proteins and result in non-viable viruses [138]. Together, these observations suggest that a precise interaction of $3 \mathrm{~A} / 3 \mathrm{AB}$ with membranes is required for proper formation and functioning of the PV RC. 
In line with this, when membrane associated, $3 \mathrm{AB}$ binds to $3 \mathrm{D}^{\mathrm{pol}}$ and this interaction is believed to anchor 3D ${ }^{\text {pol }}$ to the RC $[140,219]$. Furthermore, 3AB has been shown to stabilize a complex between an RNA template, primer and $3 \mathrm{D}^{\mathrm{pol}}$ to stimulate the RNA polymerase activity of $3 \mathrm{D}^{\mathrm{pol}}[98,214,220-223]$. In contrast to $3 \mathrm{AB}, 3 \mathrm{~A}$ alone cannot bind or stimulate the polymerase activity of $3 \mathrm{D}^{\mathrm{pol}}[214,224,225]$. This suggested that the $3 \mathrm{D}^{\mathrm{pol}}$ binding and stimulation activity of $3 \mathrm{AB}$ resides mainly within the $3 \mathrm{~B}$ region. However, although $3 \mathrm{~B}$ was shown to enhance $3 \mathrm{D}^{\mathrm{pol}}$ activity, it did so with a reduced efficiency (on a molar basis) compared to $3 \mathrm{AB}[214,221]$, which suggests that the $3 \mathrm{~A}$ and $3 \mathrm{~B}$ regions of $3 \mathrm{AB}$ may have a synergistic effect on $3 \mathrm{D}^{\mathrm{pol}}$ activity.

\section{Uridylylation of VPg (3B)}

$3 \mathrm{AB}$ has been proposed to serve as the VPg donor for uridylylation. VPg is encoded by the $3 \mathrm{~B}$ region of the genome and serves as the primer for vRNA synthesis [13]. To function as a primer, VPg is first uridylylated on a conserved Tyr residue at position 3. VPg uridylylation can be achieved in vitro using the VPg peptide with either poly(A), or the viral cre as the template [50]. It is not known if "free" VPg or a larger VPg-containing precursor (e.g., $3 \mathrm{AB}$ or $3 \mathrm{BC}$ ) serves as the substrate for $\mathrm{VPg}$ uridylylation in vivo. For PV, the $3 \mathrm{AB}$ precursor protein was initially thought to serve as the donor for VPg uridylylation as it is present in relatively high amounts in infected cells [226,227]. However, the relatively high abundance of $3 \mathrm{AB}$ could reflect that it is not used for uridylylation, as this would necessarily be followed by $3 \mathrm{AB}$ processing to $3 \mathrm{~A}$ and VPg-linked vRNA. For PV, some studies have concluded that a free N-terminus of VPg is required for uridylylation $[94,216]$, which also suggests that $3 \mathrm{AB}$ is not the preferred substrate. Consistent with these observations, neither soluble nor membrane bound $3 \mathrm{AB}$ was shown to be a substrate for VPg uridylylation with either a poly(A) or a cre template [94,216,221].

A number of other observations point towards 3BC serving as the substrate for $\mathrm{VPg}$ uridylylation. This includes (i) PV 3BC can serve as a substrate for uridylylation and is more efficiently uridylylated than the "free" VPg peptide $[100,216]$, (ii) preventing cleavage between $3 \mathrm{~A}$ and $3 \mathrm{~B}$ is lethal for PV replication [216], whereas preventing cleavage between $3 \mathrm{~B}$ and $3 \mathrm{C}$ is not [100], and (iii) PV replicons produced vRNA covalently attached to 3BC if cleavage between $3 B$ and $3 C$ is prevented [100]. Similar observations were made for EMCV where 3BC was also linked to vRNA in recombinant viruses where processing of the $3 \mathrm{~B} / 3 \mathrm{C}$ cleavage site was impaired [228]. However, for FMDV, although the 3Bcontaining precursors $3 \mathrm{~B}_{1} \mathrm{~B}_{2} \mathrm{~B}_{3} \mathrm{C}$ and $3 \mathrm{~B}_{3} \mathrm{C}$ could be uridylylated in vitro, free $3 \mathrm{~B}_{3}$ was uridylylated much more efficiently on an equimolar basis, than either of the larger $3 \mathrm{~B}$ precursors [229]. Whether this difference for FMDV is a consequence of having three copies of VPg is unknown, but it suggests that the mechanism of VPg uridylylation for FMDV may differ from that of the enteroviruses.

\section{Formation of Replication Organelles}

During the initial phase of infection, it is likely that the RC assembles on pre-existing membranes of the early secretory pathway [230-237]. However, as infection proceeds, RCs assemble in association with newly formed membranes to generate structures that have been termed RO. Replication organelles are thought to increase the efficiency of vRNA replication by increasing the local concentrations and maintaining the correct spatial associations of viral and cellular proteins and vRNA within the $\operatorname{RC}[233,238]$. Current evidence suggests that RO are novel membrane contact sites (MCS) (MCS are micro-domains formed by close contacts between cellular organelles that allow lipid exchange between apposed membranes) that form between the RC and cellular organelles. Several host proteins are involved in forming RO. Most of these proteins normally function in vesicular membrane traffic and/or non-vesicular lipid-transfer and are recruited to $\mathrm{RO}$ to drive the lipid exchange reactions that give $\mathrm{RO}$ their specific lipid identity. The main host proteins implicated in forming RO are GBF1, ARF1, ACBD3, OSBP (Oxysterol-binding protein), PI4KB and PI4KIII $\alpha$ (from here onwards termed PI4KA). Detailed description of the functions of host 
proteins in $\mathrm{RO}$ is beyond the scope of this review; however, before describing how $3 \mathrm{~A}$ interacts with host proteins to generate $\mathrm{RO}$, it seems appropriate to summarize how host proteins contribute to their formation. RO have been mostly studied using enteroviruses, kobuviruses and cardioviruses; therefore, these viruses will be used as examples.

The membranes of RO formed in cells infected by enteroviruses, kobuviruses and cardioviruses are enriched in phosphatidylinositol 4-phosphate (PI4P) and cholesterol [231,232,234,239,240]. The function(s) of PI4P and cholesterol in the RO are unclear. However, both are needed for efficient vRNA replication and appear to modulate viral polyprotein processing $[233,239,241]$. In addition, PI4P has been proposed to provide a binding-surface for $3 \mathrm{D}^{\mathrm{pol}}$ and/or $3 C^{\text {pro }}[232,242]$. Membrane levels of cholesterol are normally maintained by OSBP [243], which mediates exchange of PI4P for cholesterol between apposed membranes at MCS [244]. In infected cells, OSBP is redirected to RO where it serves the same function and exchanges PI4P for cholesterol $[234,245,246]$, and this is thought to account for the accumulation of most of the cholesterol at RO. Cholesterol is an important component of cellular membranes and regulates fluidity, thickness, and intrinsic curvature of lipid bilayers. The p33 protein of Tomato bushy stunt virus is a membrane binding protein and interacts with cholesterol via CRAC (Cholesterol recognition/interaction amino acid consensus) and CARC (an inverted CRAC) cholesterol-binding motifs that lie within, or adjacent to, its transmembrane domain [247]. Interestingly the HD of PV 3A contains a short sequence 72-Val-Ala-GlyVal-Val-Tyr-Val-Met-Tyr-Lys-81 (the CRAC residues are in bold) that lies within the MBR identified experimentally [94] and shows similarity to a CRAC motif ([Leu/Val]- $X^{1-5}$-[Tyr]$\mathrm{X}^{1-5}$-[Lys/Arg], where $\mathrm{X}$ represents apolar residues compatible with the hydrophobic membrane environment). However, the presence of a CRAC motif does not always indicate cholesterol binding and the ability of PV 3A to bind cholesterol will require experimental validation. High levels of PI4P are maintained in RO by type III PI4K. Despite sharing the need for PI4P for replication, different picornaviruses commandeer different PI4K enzymes for this purpose (Figure 4). Enteroviruses and kobuviruses recruit PI4KB, whereas cardioviruses recruit PI4KA to their RO. How PI4K is redirected to RO has been the subject of many studies and is the main focus of the remainder of this review. However, it should be noted that certain other picornaviruses, such as HAV and FMDV, replicate independently of PI4K (PI4KA and PI4KB), and PI4P is not enriched within RO of FMDV-infected cells $[248,249]$. Thus, it is likely that HAV and FMDV (and some other picornaviruses) have different requirements for host proteins and generate RO by different mechanisms.

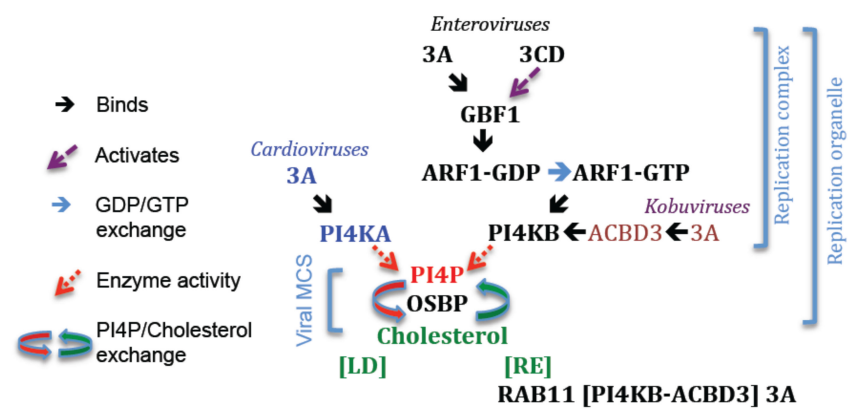

Figure 4. Key steps in forming RO enriched for PI4P and cholesterol. Cardioviruses; PI4KA is recruited to $\mathrm{RO}$ by a direct interaction with $3 \mathrm{~A}$. Kobuviruses; PI4KB is recruited to RO when in a complex with ACBD3 and 3A. Enteroviruses; How PI4KB is recruited to RO is unclear. The roles of 3A, $3 C D$ and GBF1 in recruiting PI4KB to RO are discussed in the main text. At RO, PI4P recruits OSBP, which then drives exchange of PI4P for cholesterol. Cholesterol may be supplied by lipid droplets (LD) or derived from endocytosed cholesterol. For the enteroviruses this involves 3A (at Table 1. at recycling endosomes (RE) and may involve PI4KB and ACBD3. GBF1, Golgi brefeldin A-resistant guanine nucleotide exchange factor 1; ARF1, ADP-ribosylation factor 1; PI4KA, Phosphatidylinositol 4-Kinase III $\alpha$; PI4KB, Phosphatidylinositol 4-Kinase III $\beta$; PI4P, Phosphatidylinositol 4-phosphate; OSBP, Oxysterol-binding protein; MCS, membrane contact site. 


\section{Recruitment of PI4K to Replication Organelles}

In cardiovirus- and enterovirus/kobuvirus-infected cells, PI4P is generated in RO by PI4KA and PI4KB, respectively $[231,232,234,239,240,250,251]$. PI4KA and PI4KB are soluble cytosolic proteins that are normally recruited to cell membranes (PI4KA; to the ER, early Golgi and the plasma membrane, PI4KB; primarily to the Golgi) by direct interactions with specific compartment resident-proteins [252-259]. In addition, PI4KB can be recruited to the Golgi by ARF1 activation, although in this case the cellular protein that tethers PI4KB to the Golgi has not been identified [260]. The 3A proteins of cardioviruses provide a similar function to cellular tethering-proteins and recruit PI4KA to RO via a direct interaction [231]. In immunoprecipitation experiments, the $3 \mathrm{~A}$ proteins of cardioviruses were shown to interact with PI4KA, and in cells co-transfected with PI4KA and either 3A or 3AB, PI4KA was co-localized at $3 \mathrm{~A} / 3 \mathrm{AB}$ positive sites [231]. This suggests that either cardiovirus $3 \mathrm{~A}$ or $3 \mathrm{AB}$ could serve to directly anchor PI4KA in RO. In contrast to cardioviruses, recruitment of PI4KB to enterovirus/kobuvirus RO requires cellular proteins that normally tether PI4KB to the Golgi. Interestingly, although enteroviruses and kobuviruses recruit PI4KB to RO they appear to use different mechanisms (discussed below). For the kobuviruses, 3A has a central role in recruiting PI4KB to $\mathrm{RO}$, whereas for the enteroviruses the role of $3 \mathrm{~A}$ is less clear, and it is possible that recruitment occurs by both 3A-dependent and $3 \mathrm{~A}$-independent processes. The roles of $3 \mathrm{~A}$ and cellular proteins in recruiting PI4KB to RO are described in more detail below.

\section{Recruitment of PI4KB by Subversion of GBF1/ARF1 \\ 16.1. The Case for $3 A$}

The study by Hsu et al. [232], which first showed that PI4P and PI4KB are present in $\mathrm{RO}$ and are required for enterovirus replication was a major advance in understanding how RO form and function. Moreover, this study has since underpinned numerous other studies that have confirmed PI4KA and PI4KB as important host proteins for picornavirus replication. Indeed, for many picornaviruses, PI4P is now considered a marker for the RC/RO [231,232,234,239,240,251]. As well as PI4KB, GBF1 and ARF1 are also present in enterovirus RO [232]. In addition, GBF1, ARF1 and PI4KB were shown to co-localize at membrane sites labelling positive for enterovirus $3 \mathrm{~A}$ in 3A-transfected cells [232]. As the $3 A$ proteins of $P V$ and CVB3 are known to interact directly with GBF1, these observations suggested that $3 \mathrm{~A}$ could recruit PI4KB to RO by subverting the normal cellular pathways (e.g., membrane recruitment of PI4KB by GBF1 induced activation of ARF1) that recruit PI4KB to the Golgi. Interestingly, although PI4KB was present within enterovirus RO, and at sites of 3A-expression in 3A-transfected cells, the COPI coatomer (which binds to activated ARF1) was absent [232]. Observations made earlier also showed that expression of CVB3 3A appeared to inhibit membrane recruitment of the COPI coatomer $[95,128]$. To explain these observations, it was suggested that the interaction between activated ARF1 and the COPI coatomer could be prevented in RO to favour ARF1 recruitment of PI4KB [232].

Before PI4KB was shown to be important for enterovirus replication, there was considerable evidence that GBF1 was also involved. GBF1 became the focus of studies on enterovirus replication primarily because of the observation that BFA inhibited PV replication $[261,262]$. At that time, BFA was known to inhibit ARF1 activation (by preventing GDP/GTP exchange) and induce profound morphological changes in membranes of the secretory pathway [263-265]. Thus, the sensitivity of PV to BFA suggested that membrane or protein components of the secretory pathway (such as GBF1 and ARF proteins) could be required for PV replication. More direct evidence for the requirement for GBF1 in enterovirus replication came from studies which showed that: (i) PV and CVB3 replication can be rescued from BFA-inhibition by overexpression of GBF1, but not by GBF1 lacking GEF activity, and (ii) the ability to overcome BFA-inhibition was improved by including substitutions in the GBF1 catalytic domain that resulted in BFA-resistance [266,267]. Furthermore, enterovirus replication is inhibited by siRNA knockdown of GBF1 [266,267]. 
GBF1 normally cycles between membrane-bound and cytosolic states and preventing its catalytic activity prolongs its interaction with membranes [132,134]. Thus, it was suggested that the failure of catalytically inactive GBF1 to rescue PV replication could result from increased membrane association of GBF1, rather than from a lack of GEF activity [268]. However, a GBF1 mutant with normal membrane cycling dynamics, but an impaired ability to activate ARF1 was unable to rescue PV replication [268], which confirmed that the GEF activity of GBF1 is required for enterovirus replication.

In line with the requirement for GBF1, a number of observations have suggested that ARF proteins are also required for enterovirus replication. A role for ARF proteins was suggested by early studies that reported that synthetic peptides with sequences corresponding to the N-terminal residues of ARF1 could inhibit cell-free replication of PV [261]. More recent studies have shown that the amount of activated ARF1-GTP gradually increases as infection progresses, and that ARF1 locates to the RC in PV-infected cells [232,268,269]. However, it should be noted that other observations have suggested that ARF proteins may not be involved in enterovirus replication. These include: (i) knockdown of ARF1 does not significantly inhibit infection by enteroviruses $[232,267,270]$, and (ii) overexpression of a constitutively active mutant of ARF1 (Q71L-ARF1), when expressed alone or when co-expressed with other constitutively active ARF mutants (ARF3, ARF4 or ARF5), does not rescue enterovirus replication from BFA-inhibition $[266,267,271]$. Collectively the above studies confirmed that catalytically active GBF1 is required for enterovirus replication and supported a model in which recruitment of PI4KB to enterovirus RO is initiated by $3 \mathrm{~A}$, and most likely dependent on activation of ARF1. However, as described above (Section 6), some enterovirus 3A proteins are thought to inhibit the GEF activity of GBF1 (and therefore ARF1 activation) and this provides a mechanism to inhibit the secretory pathway $[95,128]$. Thus, the role of enterovirus 3A in inhibiting GBF1 and the secretory pathway appears at odds with the mechanisms proposed for 3A-mediated recruitment of GBF1, ARF1 and PI4KB to RO.

The role of enterovirus $3 \mathrm{~A}$ in recruiting PI4KB to $\mathrm{RO}$ has also been challenged by other evidence that suggests the existence of a 3A-independent mechanism(s) for recruiting $\mathrm{PI} 4 \mathrm{~KB}$ to $\mathrm{RO}$. This comes primarily from studies that used $3 \mathrm{~A}$ proteins with a serineinsertion after residue 15 (called 3A-ins 16S, in CVB3; and 3A-2, in PV 3A), which no longer bind GBF1 and are incapable of inhibiting protein secretion. One such study showed that membrane association of ARF proteins was increased to similar levels on translation of full-length PV RNAs with either the wt 3A sequence or with the 3A-2 mutation [272]. This suggested that 3A may not have a direct role in recruiting GBF1/ARF1, and therefore PI4KB to RO [268]. Moreover, despite rendering 3A incapable of binding to GBF1 [96], viruses (and sub-genomic replicons) with the 3A-2 (PV) or 3A-ins 16S (CVB3) substitutions are viable [96,123], which shows that 3A binding to GBF1 is not required for enterovirus replication. Furthermore, these viruses remained sensitive to BFA and could be rescued from BFA-inhibition by overexpression of GBF1 [267,268]. Similar to PV with the 3A-2 change, recombinant PVs [113] with an epitope (myc or FLAG) tag inserted into the Nterminal region of 3A are also viable despite the tags preventing 3A binding to GBF1. Furthermore, the 3A-tagged viruses were shown to be sensitive to BFA and could be rescued from BFA-inhibition by expression of GBF1. However, although enteroviruses with 3A-ins 16S, 3A-2 or epitope tags in 3A are viable they show a slightly delayed and/or a reduced level of replication $[113,266,268]$. It was suggested that these characteristics could be explained if the serine insertions/tags weaken, rather that completely block $3 \mathrm{~A}$ binding to GBF1 $[113,266]$. This could also explain how GBF1 can rescue replication of viruses (and replicons) carrying such mutations from BFA. However, the serine/tag insertions will also be present in the $3 \mathrm{AB}$ precursor, which is essential for vRNA replication and formation of the RC [98]. Thus, it is possible that introducing changes into 3A could reduce vRNA replication by influencing the interactions of $3 \mathrm{~A}$ and/or $3 \mathrm{AB}$ with other viral or cellular proteins within the RC. 
Additional evidence that supports the existence of a 3A-independent mechanism for recruitment of PI4KB to enterovirus RO comes from studies with RV-A2. The 3A protein of RV-A2 does not bind to GBF1 [273]. However, RV-A2 replication requires PI4KB [234] and is sensitive to BFA $[273,274]$ and can be rescued from BFA-inhibition by overexpression of a BFA-resistant GBF1 [273]. Moreover, GBF1 locates to RO in RV-A2-infected cells [273]. Collectively, these observations suggest that RV-A2 replication is dependent on GBF1 despite the inability of 3A to bind to GBF1 [273].

Consistent with the model in which 3A binding to GBF1 triggers recruitment of PI4KB to RO, Belov et al. [266] showed that translation of PV replicon RNA with a wt 3A sequence caused an increased membrane association of GBF1. They also showed that translation of PV RNA with the 3A-2 modification also increased the amount of membrane-associated GBF1; however, to a lesser extent than for the replicon RNA with a wt 3A sequence. This suggested that 3A-2 could either bind to GBF1 with a lower affinity than wt 3A, or that GBF1 was recruited to membranes by a different viral protein. In addition to enhancing GBF1 membrane binding, translation of wt PV RNA also induced membrane association of ARF1; however, in contrast to other studies that showed that enterovirus $3 \mathrm{~A}$ prevents membrane association of COPI, they also observed increased membrane association of $\alpha$-COP (a component of the COPI coatomer) [266]. This suggested that 3A binding to GBF1 could trigger ARF1 activation and membrane recruitment of COPI. These observations appear to contradict the following: (i) the model proposed by Hsu et al. [232] in which 3A-mediated recruitment of GBF1/ARF1 to RO leads to the preferential recruitment of PI4KB over COPI, and (ii) the proposed role for $3 \mathrm{~A}$ in inhibiting protein secretion [95], i.e., $3 \mathrm{~A}$ binds to GBF1 and inhibits its GEF activity, and hence, ARF1 activation and COPI recruitment. The reasons why COPI membrane association appears to decrease $[95,128,232]$ or increase $[266,275]$ on expression of enterovirus $3 \mathrm{~A}$ are currently unknown but could be the result of the different experimental approaches. To reconcile their results with the ability of $3 \mathrm{~A}$ to inhibit protein secretion, it has been suggested that GBF1 may provide a function when in the RC that differs to it normal cellular functions [276], or that 3A could inhibit protein secretion indirectly by sequestering GBF1 at the RC [266], and thereby reduce the amount available for the secretory pathway. However, an alternative explanation was proposed by Altan-Bonnet and Balla [277] who suggested that 3A may inhibit formation of COPI-coated vesicles at a late stage of formation. During COPI vesicle formation, the preformed COPI coatomer interacts with activated ARF1 (ARF-GTP). However, before it engages ARF1-GTP, the COPI coatomer transiently associates with GBF1 and this occurs before GDP/GTP exchange and ARF1 activation [278]. Thus, it is interesting to speculate that 3A binding to GBF1 stabilizes a complex between GBF1 and ARF1-GDP, which cannot proceed to GDP/GTP exchange but can still interact with COPI coatomer. A similar study also showed that expression of CVB3 3A induced membrane association of GBF1, ARF1 and $\alpha \mathrm{COP}$ [275]. In addition, this study showed that expression of CVB3 3A also induced increased membrane association of PI4KB, which also suggested that 3A binding to GBF1 could trigger ARF1 activation. However, subsequent studies have shown that enterovirus $3 \mathrm{~A}$ can recruit PI4KB to $\mathrm{RO}$ when in a complex with ACBD3, which normally tethers PI4KB to Golgi membranes (see below); thus, the ability of 3A to bind to ACBD3 could account for the increased membrane association of PI4KB induced by 3A [275].

Interestingly, more recent studies have shown that expression of PV $3 \mathrm{~A}$ (or $3 \mathrm{AB}$ ) in isolation reduced PI4P levels [242,245]. These observations were unexpected and also suggest that 3A may not be involved in recruiting functionally active PI4KB to RO and are discussed in more detail below. In retrospect, although the study by Hsu et al. [232] showed that GBF1, ARF1 and PI4KB were recruited to the same membrane sites as 3A, the level of PI4P in 3A-transfected cells was not determined, and a direct link between 3A and enrichment of PI4P at RO was not demonstrated. 


\subsection{The Case for $3 C D^{\text {pro }}$}

Most studies investigating the mechanism of PI4KB recruitment to enterovirus RO have focused on $3 \mathrm{~A}$. However, PV $3 \mathrm{CD}^{\text {pro }}$ has also been implicated in activating the GBF1/ARF1/PI4KB pathway. Studies by Belov et al. [272,279] showed that expression of PV $3 C^{\text {pro }}$ increase membrane association of activated ARF proteins. More recently, expression of PV $3 C^{\text {pro }}$ was shown to induce membrane proliferation and PI4P synthesis [242]. The increased level of PI4P induced by $3 C^{\text {pro }}$ appeared to require GBF1, ARF1 and PI4KB as it could be inhibited by BFA (or by golgicide A) or PIK93 (an inhibitor of PI4KB), and was accompanied by an increased level of ARF1-GTP (i.e., ARF1 activation). Interestingly, whereas 3A specifically induced membrane association of GBF1, the expression of $\mathrm{PV} 3 \mathrm{CD}^{\text {pro }}$ preferentially increased membrane association of two other ARF GEFs, namely BIG1 (brefeldin A-inhibited guanine nucleotide-exchange factor 1) and BIG2 and did not induce membrane association of GBF1 [269]. These observations suggested that BIG1/2 could be involved in enterovirus replication; however, a number of other studies have concluded that neither BIG1 nor BIG2 (BIG1/2) are involved in this process $[95,266,267,280]$. A recent study has identified a functional link between GBF1 and BIG1/2 [281]. This showed that activation of GBF1 enhanced membrane recruitment of BIG1/2 by a process that involved the GBF1-activated ARF proteins, ARF4 and ARF5. This suggests the possibility that the increased membrane association of BIG1 and BIG2 induced by $3 C^{\text {pro }}$ could be a consequence of increased activity of GBF1, rather than reflecting the need for BIG1 and BIG2 for enterovirus replication. Consistent with this possibility, a recent study has shown that ARF4 and ARF5 are located within enterovirus $\mathrm{RO}$ [282].

The study by Banerjee et al. [242] also showed that when expressed alone PV 3A or $3 \mathrm{AB}$ reduced the amount of PI4P in cells. This observation is consistent with an earlier study that also concluded that expression of PV $3 \mathrm{~A}$ (and to a lesser extent $3 \mathrm{AB}$ ) reduced levels of PI4P [245]. These observations suggest that PV 3A does not activate (or indirectly facilitate activation of PI4KB. Interestingly, the reduction in PI4P caused by $3 \mathrm{AB}$ could be overcome by co-expression with $3 C^{\text {pro }}$ [242]. As the authors point out, this was not unexpected as PI4P levels are increased in PV infected cells [283], thus the positive effect of $3 \mathrm{CD}^{\text {pro }}$ on PI4P synthesis would be expected to dominate over the inhibitory effect of $3 \mathrm{AB}$. Furthermore, $3 \mathrm{AB}$ and $3 \mathrm{CD}^{\text {pro }}$ are relatively abundant in PV-infected cells and form a complex with the $5^{\prime}-\mathrm{CL}$ and it is possible that $3 \mathrm{AB}$, when bound to $3 \mathrm{CD}^{\text {pro }}$, may no longer inhibit PI4P synthesis. In contrast, the inhibitory effect of 3A on PI4P levels was not overcome by co-expression with $3 \mathrm{CD}^{\text {pro }}$. In PV-infected cells, $3 \mathrm{~A}$ is produced by the minor $\mathrm{P} 3$ processing pathway and is present at relatively low levels compared to $3 \mathrm{CD}^{\text {pro }}$, especially during the early phase of infection $[99,100,284]$. Thus, it is possible that during a natural infection the inhibitory effect of $3 \mathrm{~A}$ on PI4P levels may be outweighed by the ability of $3 \mathrm{CD}^{\text {pro }}$ to induce PI4P synthesis, especially during the early phase of infection when the levels of $3 \mathrm{~A}$ are low.

\section{3A and the Great Escapes}

As discussed above, GBF1 is required for replication of enteroviruses, which can therefore be inhibited by BFA. Studies using expression of viral nsps in isolation have shown that $3 \mathrm{CD}^{\text {pro }}$ (but not $3 \mathrm{~A}$ ) increased levels of PI4P and this could also be inhibited by BFA $[241,242,244,307]$. However, PVs with resistance to BFA have been isolated but they did not have aa changes in $3 \mathrm{CD}^{\text {pro }}$ but instead had single aa substitutions in $2 \mathrm{C}$ (Val to Ile at residue 80) or $3 \mathrm{~A}$ (Ala to Val at residue 27) [285]. PVs with either change were able to replicate in the presence of BFA, but replication was improved further for viruses with both changes. The molecular mechanisms that underlie how changes in $2 \mathrm{C}$ and/or $3 \mathrm{~A}$ can overcome inhibition of PV replication by BFA are currently unclear. A study by Arita [245] reported that PV P2 proteins interacted with PI4KB in an M-2-H assay (2B, 2C and 2BC) and a proximity ligation assay $(2 \mathrm{BC})$, and that cells transfected to express $2 \mathrm{BC}$ had increased levels of PI4P. However, 2BC was not immunoprecipitated with FLAG-tagged PI4KB, 
and the increased level of PI4P in 2BC-transfected cells was not prevented by inhibition of PI4KB. Nevertheless, these observations suggest that 2C/2BC may interact with PI4KB and that the aa changes seen in the 2C of BFA-resistant PV isolates could potentially allow for more efficient recruitment of PI4KB to the RC in the presence of BFA.

Additionally, as discussed above, replication of several picornaviruses is dependent on PI4KB and OSBP, and thus inhibitors of PI4KB and OSBP also restrict their replication [234,286-292]. Enteroviruses with resistance to inhibitors of PI4KB and OSBP have been isolated and carry single aa changes in 3A. CVB3 isolates that are resistant to PI4KB inhibitors have Val-45-Ala, Ile-54-Phe or His-57-Tyr substitutions whereas PVs that are resistant to PI4KB inhibitors have an Ala-70-Thr change [287,288,293,294]. These changes in CVB3 3A did not restore PI4KB activity but allow for replication independently of PI4KB [287]. The same aa changes in CVB3 3A were seen in virus isolates that were selected to be resistant to OSBP inhibitors [289,292], which highlights the strong link between PI4KB and OSBP during enterovirus replication. Recently, the mechanism by which the His-57-Tyr change in 3A overcomes inhibitors of PI4KB and OSBP has been identified [295]. Using a replication-independent expression system, both types of inhibitors were shown to cause defective processing of wt $3 \mathrm{AB}$, and that the His-57-Tyr change in $3 \mathrm{~A}$ corrected this defect and restored normal $3 \mathrm{AB}$ processing. These results show that inhibition of either PI4KB or OSBP impairs processing at the boundary between $3 \mathrm{~A}$ and $3 \mathrm{~B}$ and suggest that correct $3 \mathrm{AB}$ processing is dependent on cholesterol. In line with these observations, Arita [291] showed that the Ala-70-Thr change in PV 3A, that results in resistance to PI4KB inhibitors, increased the level of $3 \mathrm{~A}$, and decreased the level of $3 \mathrm{AB}$ during infection. In addition, other aa changes in 3A (Thr-14-Met and His-86-Tyr) have been identified in PVs that are resistant to PI4KB inhibitors. When combined, these changes confer similar resistance to PI4KB inhibitors as the Ala-70-Thr change and also enhance the level of $3 \mathrm{~A}$. This suggested that restoring aberrant $3 \mathrm{AB}$ processing in the presence of PI4KB inhibitors (and possibly OSBP inhibitors) could be a common mechanism used by enteroviruses to overcome inhibition of PI4KB. A more recent study, by Arita and Bigay [296], showed that aa changes (Glu-53-Asp and Arg-54-Trp) in 3A allowed for PV replication in PI4KB ${ }^{\mathrm{ko}}$ cells. Similar to the aa changes in 3A in PI4KB-resistant CVB3 isolates, these changes also allowed PV replication in the presence of an OSBP inhibitor. In addition, these changes appeared to enhance processing of $3 \mathrm{AB}$.

EMCV requires PI4KA for replication [231]. EMCV isolates that are less dependent on PI4KA have been isolated using cells that expressed a low level of PI4KA and support limited replication of wt EMCV [297]. Viruses that showed improved growth in these cells were less sensitive to inhibition of PI4KA (by AL-9) and also carried a single aa change (Ala to Val) at either residue 32 or 34 in 3A. Viruses with these changes in 3A do not require other PI4K isoforms (PI4K2A, PI4K2B or PI4KB) and their replication was independent of PI4P. In RO, PI4P serves to recruit OSBP and cholesterol, however, when cells were infected with the mutant viruses (with the changes in 3A) in the presence of AL-9, co-localization of $3 \mathrm{~A}$ with OSBP and cholesterol was greatly reduced [297]. This suggests that EMCV isolates with changes in $3 \mathrm{~A}$ do not require high levels of cholesterol for infection. Interestingly, unlike CVB3 where the same aa changes in 3A result in resistance to both PI4KB and OSBP inhibition [287-290]. EMCV with changes in 3A that allowed for PI4KA independent replication remained sensitive to OSBP inhibitors. These observations show that replication of EMCV with the above changes in $3 \mathrm{~A}$ remain dependent on OSBP and suggest that OSBP may provide another non-canonical function during EMCV replication [297].

\section{Recruitment of PI4KB by Subversion of ACBD3}

Similar to the enteroviruses, AiV replication is dependent on PI4KB and generates RO enriched with PI4P and cholesterol [258]. However, AiV is insensitive to BFA and does not require GBF1 for replication [258], which suggests that AiV recruits PI4KB to RO by a GBF1/ARF1-independent mechanism. PI4KB can be recruited to the Golgi via interactions with several different Golgi-resident proteins [254-256,259,298,299], including ACBD3, 
which interacts directly with PI4KB [258,300]. In 2012, two independent studies showed that $\mathrm{ACBD} 3$ relocates to $\mathrm{AiV} R \mathrm{R}$ and is required for virus replication $[89,258]$. In addition, these studies showed that AiV 3A binds to ACBD3 $[89,258]$. Furthermore, although AiV $3 \mathrm{~A}$ did not directly interact with PI4KB it was co-purified along with ACBD3 when using strep-tagged $3 \mathrm{~A}$ as bait $[89,258]$. This indicated that ACBD3 could simultaneously bind to AiV $3 \mathrm{~A}$ and PI4KB, and that this could facilitate delivery of PI4KB to RO $[89,258]$. Interestingly, substitutions in $3 \mathrm{~A}$ were identified that prevented co-purification of PI4KB without appearing to affect the interaction with $\mathrm{ACBD} 3$, which suggested the possibility that AiV 3A could make weak or transient interactions with PI4KB that are stabilized by ACBD3 [89]. The ACBD3 protein consists of two central domains (a charged amino acid region, termed the CAR domain, and a glutamine-rich domain, termed the Q-domain) that are flanked by an N-terminal acyl-CoA-binding domain and a C-terminal Golgi Dynamics (GOLD) domain. The binding sites for 3A and PI4KB have been mapped to the GOLD- and Q-domains of ACBD3, respectively [89,258], which explains how ACBD3 can simultaneously bind to 3A and PI4KB. ACBD3 lacks intrinsic membrane binding capability and is targeted to Golgi membranes through an interaction between the GOLD domain and giantin, which is a member of the Golgin family of proteins that regulate Golgi architecture and function $[301,302]$. However, giantin is not present in AiV RO, which suggests that $3 \mathrm{~A}$ can displace giantin from the GOLD domain and that this may facilitate recruitment of ACBD3 to RO.

In addition to identifying ACBD3 as a binding partner of AiV 3A, the study by Greninger et al. [89] (and the subsequent study by Greninger et al. [303]) also showed that PV 3A could interact with ACBD3. Furthermore, these studies suggested that ACBD3 was required for PV replication, as replication was inhibited by ACBD3 knockdown. Following these observations, other studies gave conflicting results, as knockdown of ACBD3 was reported to enhance PV infection [304] and did not appear to influence replication of CVB3 or RVs $[273,275]$. However, follow-up studies have shown conclusively that ACBD3 is essential for enterovirus replication, as replication of EV-A71 and CVB3 was severely impaired in $\mathrm{ACBD} 3$ knockout $\left(\mathrm{ACBD} 3^{\mathrm{KO}}\right.$ ) cells and could be restored by exogenous expression of ACBD3 [251,305,306]. In addition, 3A, ACBD3 and PI4KB were located at EV-A71 RO [251]. A more recent study, that also used $\mathrm{ACBD} 3^{\mathrm{KO}}$ cells, confirmed that ACBD3 is required for replication of a number of human enteroviruses (EV-A71, CVB3, PV, EV-D68, RV-A2 and RV-B14) [307]. Furthermore, in 3A-transfected cells, enterovirus 3A was co-localized with ACBD3 and PI4KB, whereas in $3 \mathrm{~A}$-transfected $\mathrm{ACBD} 3^{\mathrm{KO}}$ cells no co-localization with PI4KB was observed. These observations are similar to those made for AiV $3 \mathrm{~A}$ and suggest that PI4KB may be recruited to RO by enterovirus $3 \mathrm{~A}$ when in a complex with ACBD3 [307]. However, Horova et al. [107] showed that when expressed in isolation, EV-D68 3A does not increase levels of PI4P. Based on these observations, it was proposed that for enteroviruses either another viral protein(s) is required to co-operate with 3A to increase PI4KB activity during infection [107] or, alternatively, that ACBD3 could provide a scaffold function for the correct positioning (and function) of $3 \mathrm{~A}$ in the $\mathrm{RC} / \mathrm{RO}$, rather than serving to recruit active PI4KB [307].

The crystal structures of the N-terminal domains (i.e., 3A truncated at the HD) of the AiV-A and AiV-B 3A proteins have been determined when in a complex with the ACBD3 GOLD domain. This showed that these $3 \mathrm{~A}$ proteins adopt a similar overall structure when bound to the GOLD domain despite sharing a low sequence similarity [308] (see Figure 1). In the complex, the $3 \mathrm{~A} \mathrm{~N}$-terminal domain adopts an ordered conformation and wraps around the GOLD domain so that the $\mathrm{N}$ - and C-termini of the N-terminal domain make contacts on opposite sides [308]. Should full-length 3A bind to the GOLD domain in the same way, then this configuration would allow the N-terminal myristate group and the MBR of the AiV 3A to simultaneously engage with a single bilayer and thereby effectively "staple" ACBD3 to the membrane. Crystal structures have also been solved for the 3A proteins from enteroviruses (PV, EV-A71, EV-D68, and RV-B14) in complex with the GOLD domain [107] (Figure 3). The overall structures of these complexes were highly similar to 
each other despite wide aa sequence variation across the 3A proteins. Electron density could not be assigned for the first $15 \mathrm{~N}$-terminal residues of the crystalized enterovirus $3 \mathrm{~A}$ proteins, which suggests that this region is flexible and does not adopt a stable conformation when $3 \mathrm{~A}$ is bound to ACBD3. This is different to the AiV 3A:GOLD complex where residues close to the $\mathrm{N}$-terminus of $3 \mathrm{~A}$ make contacts with the GOLD domain. The $\mathrm{N}$-terminal residues of enterovirus 3A (but not AiV 3A) include the binding site for GBF1 and it is likely that the above difference reflects the need for some enterovirus $3 \mathrm{~A}$ proteins to interact with GBF1 [107]. The rest of the enterovirus 3A polypeptide formed four distinct structural elements (two $\alpha$ helices and two $\beta$ strands) that were conserved in all four structures and each contributed to interaction with the GOLD domain. Mutagenesis studies confirmed that all four secondary elements are important for binding to ACBD3 and for enterovirus replication. Consistent with the ability of PV 3A to form homodimers [104], 3A made contacts with a second $3 \mathrm{~A}$ molecule when bound to ACBD3. In agreement with the NMR structure, the $3 \mathrm{~A}$ dimerization interface was mainly formed by hydrophobic interactions between residues of the central $\alpha$-helices, and Ala substitution of the main residues (Leu25, Val29, Val34, and Tyr37) involved in forming the interface impaired dimerization and also replication of EV-D68 [107]. In the NMR structure, the N-terminal domain of PV 3A appeared largely unstructured apart from the two central $\alpha$ helices [104]. However, in the EV-D68 3A:GOLD complex, the C-terminal residues of the N-terminal domain adopted an ordered conformation. This suggested that this region could become ordered on binding to the GOLD domain. However, it is also possible that this region of enterovirus $3 \mathrm{~A}$ is normally ordered within the context of full-length 3A.

A comparison of the $\mathrm{AiV}$ and enterovirus 3A:GOLD complexes showed that despite having diverse sequences and distinct secondary structures, the $3 \mathrm{~A}$ proteins of these viruses bind to the same regions of the GOLD domain [107]. Furthermore, the GOLD domain most likely interacts with membranes in a similar conformation as when in a complex with the different $3 \mathrm{~A}$ proteins. ACBD3 serves as a scaffold for a number of protein complexes associated with the Golgi and the GOLD domain interacts with several different proteins $[309,310]$. Thus, the inherent ability of the GOLD domain to bind several diverse cellular proteins may account for the ability to interact with distinct $3 \mathrm{~A}$ proteins of different picornaviruses [89]. However, although the $3 \mathrm{~A}$ proteins of enteroviruses and kobuviruses interact with the same region of the GOLD domain, they interact in reverse orientations which suggests that the $3 \mathrm{~A}$ proteins of different picornavirus genera have evolved the ability to interact with ACBD3 independently [107].

PI4P levels are increased in kobuvirus RO; however, it is not clear if simply recruiting PI4KB generates PI4P or if the kinase activity of the bound PI4KB is also up-regulated. Regulation of the enzymatic activity of PI4KB is not completely understood [298]. However, PI4KB activity is regulated (in part) through membrane recruitment. In an in vitro assay, the kinase activity of PI4KB was increased by ACBD3 but only when ACBD3 was anchored on artificial vesicles via a His-tag [300]. This suggested that ACBD3 does not directly influence the kinase activity of PI4KB but regulates its activity by positioning it on membranes in close proximity to its substrate [300]. Earlier studies had also reported that ACBD3 alone could not stimulate PI4KB kinase activity [240]. In addition, this study also reported that $\mathrm{AiV} 3 \mathrm{~A}$ (and $3 \mathrm{AB}$ ) alone does not stimulate PI4KB kinase activity. However, in the presence of both ACBD3 (at $\geq 5$-fold molar excess relative to PI4KB) and 3A (at 25-fold molar excess relative to PI4KB), kinase activity was increased [240]. However, subsequent studies by McPhail et al. [311] concluded that AiV 3A can enhance the kinase activity of PI4KB in the absence of ACBD3 when $3 \mathrm{~A}$ is membrane associated. This study used His-tagged AiV 3A (residues 1-59), which was anchored on the surfaces of artificial vesicles using DGS-NTA(Ni) (1,2-dioleoyl-sn-glycero-3-[(N-(5-amino-1-carboxypentyl)iminodiacetic acid) succinyl] (nickel salt)). When the assay was carried out on vesicles lacking DGS-NTA(Ni) neither ACBD3 nor 3A (when they were added either individually or together) induced kinase activity. However, when $3 \mathrm{~A}$ was anchored to the DGS-NTA(Ni) vesicles, a dosedependent activation of PI4KB was observed and this was enhanced when ACBD3 was 
included in the assay. These observations suggest that, when membrane bound, AiV 3A may be able to interact directly with PI4KB and stimulate its kinase activity, and this is further enhanced by ACBD3. Thus, ACBD3 may not only facilitate recruitment of PI4KB to $\mathrm{RO}$ by $\mathrm{AiV} 3 \mathrm{~A}$ but may also provide a mechanism to accelerate PI4P synthesis at RO.

For AiV, a link between 3A expression and increased PI4P was demonstrated as PI4P levels were increased in 3A-transfected cells [258]. In contrast (as mentioned above), expression of enterovirus $3 \mathrm{~A}$ in isolation either reduces or does not influence PI4P levels $[242,245,307]$. The reason(s) why the 3A proteins of AiV and PV affect levels of PI4P differently are currently unknown. As noted above, PV and AiV 3A bind to ACBD3 in opposite orientations and this could conceivably alter the interaction between ACBD3 and PI4KB in such a way as to differentially influence the enzyme activity of PI4KB, and hence PI4P levels. Other studies have also suggested that AiV and PV 3A proteins interact differently with ACBD3. The study by Greninger et al. [89] showed that ACBD3 and PI4KB could be readily co-purified along with strep-tagged $\mathrm{AiV} 3 \mathrm{~A}$ in pull down experiments (under standard assay conditions), whereas only ACBD3 was co-purified when the assay was carried out using strep-tagged 3A of several enteroviruses. These results suggested that the interaction between ACBD3 and PI4KB may be stabilized by AiV 3A, but not by enterovirus 3A. Consistent with this conclusion, PI4KB was co-purified along with ACBD3 by enterovirus strep-tagged 3A proteins when the assay conditions were changed (to rapid-capture conditions) to better detect transient interactions. Differences in how AiV and PV 3A bind to ACBD3 have also been demonstrated using TCB1D22 (a putative Rab GAP) [312], which competes with PI4KB for overlapping binding sites on the Q-domain of ACBD3. In pull-down experiments using TBC1D22 tagged with V5 as bait, 3A was readily co-purified along with ACBD3 from cells transfected to express FLAG-tagged PV $3 A$ [303]. However, when the experiment was repeated using cells transfected to express FLAG-tagged AiV 3A, although 3A was co-purified it was present at a greatly reduced level relative to ACBD3. These results suggested that TBCD1D22 could reduce the strength of the interaction between AiV 3A and ACBD3 [303]. Based on these observations, it was postulated that during infection, AiV 3A may displace TBC1D22 from ACBD3 to favour binding to PI4KB with a concomitant increased production of PI4P.

Finally, it has also been suggested that the apparent inability of enterovirus 3A proteins to stimulate the kinase activity of PI4KB when bound to ACBD3 results from the requirement for binding to GBF1 [107]. Interestingly, although PI4KB was not co-purified with ACBD3 in the experiments described above using enterovirus strep-tagged 3A (under the standard assay conditions), GBF1 was co-purified with it [89]. In these experiments, it was not possible to conclude if ACBD3 and GBF1 simultaneously bind to a single molecule of $3 \mathrm{~A}$, or if they were bound to separate $3 \mathrm{~A}$ proteins. However, in the enterovirus $3 \mathrm{~A} / \mathrm{GOLD}$ domain complex the N-terminal residues of 3A that form the GBF1 binding site were apparently disordered, which suggests that this region could remain available to bind to GBF1 when 3A is bound to ACBD3 [107]. For RV-B14 3A, GBF1 was not pulled down with ACBD3 under the standard assay conditions but it was under rapid capture assay conditions [89]. This is in line with the observations that 3A of RV-B14 shows a reduced ability to bind to GBF1 (compared to the 3A proteins of PV and CVB3) [128]. This observation provides additional interest as 3A of RV-B14 has been shown not to inhibit protein trafficking through the secretory pathway $[127,128]$.

As described above, enterovirus 3A proteins binds to ACBD3, yet expression of 3A alone does not increase PI4P levels [107,307]. These observations suggested that ACBD3 could play a role in enterovirus replication independent of its ability to recruit and stimulate the kinase activity of PI4KB. Consistent with this, ACBD3 has been shown to bind to 3A proteins of other picornaviruses that do not require PI4KB for replication (e.g., HAV) [303]. This points to a role for ACBD3 in replication of some picornaviruses that is independent of the ability to bind to PI4KB. As noted above, cholesterol is important for picornavirus vRNA replication and polyprotein processing and is enriched in enterovirus $\mathrm{RO}$ by a process that involves cholesterol shuttling mediated by OSBP. However, other mechanisms 
are also thought to channel cholesterol to $\mathrm{RO}$ including the re-routing of endocytosed cholesterol from recycling endosomes (RE) [239]. In enterovirus-infected cells, RE are recruited to $\mathrm{RO}$ by a process facilitated by an interaction between PI4KB (at the RC/RO) and Rab11 (on RE) [239]. In cells transfected to express CVB3 3A, Rab11 was localized to sites where the $3 \mathrm{~A}$ protein was present, which suggests that $3 \mathrm{~A}$ is sufficient to target RE to the RC/RO [239]. Rab11 is an effector protein of PI4KB and binds to PI4KB independently of its kinase activity [255]. Similarly, the interaction between PI4KB and Rab11 in CVB3infected cells does not require the kinase activity of PI4KB [239]. Thus, it was suggested that by binding to Rab11, PI4KB could play a "scaffold" role in bridging the RC/RO and $\mathrm{RE}$, and this could facilitate targeting endocytosed cholesterol to generate $\mathrm{RO}$ membranes. As CVB3 3A and PI4KB bind to ACBD3 (see above), it is possible that ACBD3 could also play a role in bridging $R E$ to the $R C$.

\section{Lipid Droplets}

Lipid droplets (LDs) are distinct cellular organelles bounded by a single phospholipid monolayer that store neutral lipids to provide energy and also for membrane homeostasis [313]. Lipid droplets establish MCS with many different organelles to facilitate nonvesicular lipid transfer between their membranes [313,314]. Recently, enteroviruses have been shown to establish novel MCS between the RC and LD [86,234,315] and this is thought to provide the lipids for forming RO. In PV-infected cells, 2C and 2BC located to LD and it was suggested that the ability of $2 \mathrm{C}$ to self-oligomerize [316] (and/or to interact with $2 \mathrm{BC}$ ) could allow for formation of a "molecular bridge" that maintains the close spatial association of the RC with LD [315]. PV 3A has been shown to bind to $2 \mathrm{C}$ and $2 \mathrm{BC}$ and there is also evidence for a functional interaction between $2 \mathrm{C}$ and $3 \mathrm{~A}$ during $\mathrm{PV}$ replication $[110,111]$. Furthermore, co-expression of $3 \mathrm{~A}$ and $2 \mathrm{BC}$ induces formation of membrane structures that are similar to RO in PV-infected cells [236]. Interestingly, the ability of $3 \mathrm{AB}$ to interact with only the outer leaflet of membranes (a monotopic interaction) may allow for 3AB (but not 3A) to target LD [317]. Thus, by interacting with other viral proteins it can be speculated that $3 \mathrm{AB}$ could also participate in maintaining the close association between the RC and LD.

The study by Laufman et al. [315] also showed that PV 3A and 3AB interact with adipose triglyceride lipase (ATGL) and hormone sensitive lipase (HSL). These are LDassociated enzymes involved in lipid metabolism and it was suggested that by binding to 3A they could promote mobilization of lipid stores for generating RO. Although GBF1 preferentially locates to the Golgi, it also localizes to other organelles such as LD where it facilitates delivery of LD-associated proteins, including ATGL, to the LD membrane [133,318-320]. Furthermore, GBF1 has been reported to bind to ATGL and this may contribute to its localization to LD [318]. It has been suggested that the interaction between $3 \mathrm{~A}$ and ATGL could be mediated by an interaction with GBF1 [321]. Thus, it will be interesting to determine if GBF1 contributes to picornavirus replication when located on LD.

\section{Conclusions}

As described above, many exciting papers have led to picornavirus $3 \mathrm{~A}$ and $3 \mathrm{AB}$ proteins being assigned diverse roles in the viral replication cycle, such as inhibiting protein trafficking (3A), presenting VPg for uridylylation (3AB) and the recruitment of PI4KB to RO (3A/3AB). However, some of these roles have recently been challenged and may be carried out by other viral nsps, and there is much still to learn about the role(s) of $3 \mathrm{~A} / 3 \mathrm{AB}$ in picornavirus replication.

Perhaps the most intriguing conundrum in enterovirus replication concerns the role of GBF1. Although the precise role of GBF1 remains to be determined, its GEF activity appears to be essential for enterovirus replication, yet the ability of 3A to inhibit its GEF activity is thought to provide a mechanism for some enteroviruses to inhibit protein trafficking. GBF1 is central to the formation of transport vesicles in the early secretory pathway, so inhibition of its GEF activity would be expected to inhibit protein trafficking. However, 
GBF1 exists as a cytosolic pool and is also recruited to other cellular sites including LD, where it regulates the recruitment of LD-associated proteins [319]. Interestingly, LD are currently thought to be a major source of lipids for formation of RO. It will be interesting to determine if different enterovirus nsps interact with different cellular pools of GBF1, potentially at different stages of replication, with different functional outcomes for its GEF activity. It is conceivable that this could be achieved (at least, in part) by the spatial and temporal regulation of nsps during infection. With this in mind, fully processed $3 \mathrm{~A}$ is present at a relatively low level during the early phase of infection and may be preferentially recruited to different membrane sites than $3 \mathrm{AB}$ due to different membrane interactions (monotopic or bitopic). Furthermore, at least two different labelling patterns (relative to the RC) for 3A have been identified in PV-infected cells [282], which suggest the possibility that a distinct pool of $3 \mathrm{~A}$ may be spatially segregated from the RC.

The $3 \mathrm{~A}$ proteins of several picornaviruses bind to ACBD3. An intriguing observation is that the $3 \mathrm{~A}$ protein of kobuviruses and enteroviruses appear to have evolved the ability to bind to ACBD3 independently with different outcomes for virus replication. The interaction between AiV 3A and ACBD3 redirects PI4KB to RO where it generates PI4P, whereas although enterovirus $3 \mathrm{~A}$ interactions with ACBD3 appear to redirect PI4KB to the RC it does not induce PI4P synthesis. Unravelling the details of the consequences of the interaction between enterovirus 3A and ACBD3 will undoubtedly herald new lines of investigation and insights into enterovirus replication.

The roles of the $3 \mathrm{~A}$ proteins produced by other picornaviruses are still poorly understood. For example, HAV 3A binds to ACBD3, but HAV does not require either PI4KA or PI4KB for replication suggesting that the interaction between $3 \mathrm{~A}$ and ACBD3 provides a novel, but as yet unidentified, function during HAV replication. Similarly, little is known about the role of FMDV 3A in its replication, including the role of its extended C-terminal domain. FMDV $3 A$ does not bind to ACBD3, and FMDV replication is insensitive to BFA (which implies replication does not require GBF1) and does not depend on PI4KA or PI4KB. Thus, it is likely that the 3A proteins of HAV and FMDV will interact with different host proteins (compared to enteroviruses and kobuviruses) and will provide distinct functions during virus replication. As with PV 3A, within FMDV-infected cells, the 3A appears to segregate into at least two distinct populations, which are either associated or not with the RC [248], and it will be interesting to determine if this reflects a separation of independent functional pools of $3 \mathrm{~A}$ (or $3 \mathrm{~A}$ and $\mathrm{BAB}$ ) at different membrane locations.

A direct role for $3 \mathrm{~A}$ in evading the cellular innate antiviral responses within infectedcells remains to be clarified and this activity will need to be combined with understanding of the role of viral proteases in antagonizing the cellular antiviral response [185,186,322], and with the global reductions in cellular transcription [82] and translation [323] that occur in picornavirus-infected cells. Each of these processes contributes significantly to the downregulation of cellular innate immunity. Finally, it is likely that as new picornaviruses are discovered novel roles for $3 \mathrm{~A} / 3 \mathrm{AB}$ will be uncovered, which will undoubtedly surprise.

Author Contributions: Conceptualization, T.J. and G.J.B.; writing-original draft preparation, T.J. and G.J.B.; writing-review and editing, T.J. and G.J.B. Both authors have read and agreed to the published version of the manuscript.

Funding: This research received no external funding

Data Availability Statement: No new data are reported, only a review of previously published material.

Conflicts of Interest: The authors declare no conflict of interest.

\section{References}

1. Zell, R. Picornaviridae-the ever-growing virus family. Arch. Virol. 2018, 163, 299-317. [CrossRef]

2. Tapparel, C.; Siegrist, F.; Petty, T.J.; Kaiser, L. Picornavirus and enterovirus diversity with associated human diseases. Infect. Genet. Evol. 2013, 14, 282-293. [CrossRef] [PubMed]

3. Knight-Jones, T.; Rushton, J. The economic impacts of foot and mouth disease-What are they, how big are they and where do they occur? Prev. Veter Med. 2013, 112, 161-173. [CrossRef] [PubMed] 
4. Alexandersen, S.; Knowles, N.J.; Belsham, G.J.; Dekker, A.; Nfon, C.; Zhang, Z.; Koenen, F. Picornaviruses. In Diseases of Swine; Wiley: Hoboken, NJ, USA, 2019; pp. 641-684.

5. Zell, R.; Delwart, E.; Gorbalenya, A.E.; Hovi, T.; King, A.M.Q.; Knowles, N.J.; Lindberg, A.M.; Pallansch, M.A.; Palmenberg, A.C.; Reuter, G.; et al. ICTV Virus Taxonomy Profile: Picornaviridae. J. Gen. Virol. 2017, 98, 2421-2422. [CrossRef]

6. Belsham, G.J. Divergent picornavirus IRES elements. Virus Res. 2009, 139, 183-192. [CrossRef]

7. Lange, J.; Groth, M.; Fichtner, D.; Granzow, H.; Keller, B.; Walther, M.; Platzer, M.; Sauerbrei, A.; Zell, R. Virus isolate from carp: Genetic characterization reveals a novel picornavirus with two aphthovirus 2A-like sequences. J. Gen. Virol. 2014, 95, 80-90. [CrossRef]

8. Reuter, G.; Boros, Á.; Földvári, G.; Szekeres, S.; Mátics, R.; Kapusinszky, B.; Delwart, E.; Pankovics, P. Dicipivirus (family Picornaviridae) in wild Northern white-breasted hedgehog (Erinaceus roumanicus). Arch. Virol. 2018, 163, 175-181. [CrossRef] [PubMed]

9. Yang, X.; Cheng, A.; Wang, M.; Jia, R.; Sun, K.; Pan, K.; Yang, Q.; Wu, Y.; Zhu, D.; Chen, S.; et al. Structures and Corresponding Functions of Five Types of Picornaviral 2A Proteins. Front. Microbiol. 2017, 8, 1373. [CrossRef]

10. Ambros, V.; Baltimore, D. Protein is linked to the $5^{\prime}$ end of poliovirus RNA by a phosphodiester linkage to tyrosine. J. Biol. Chem. 1978, 253, 5263-5266. [CrossRef]

11. Flanegan, J.B.; Petterson, R.F.; Ambros, V.; Hewlett, N.J.; Baltimore, D. Covalent linkage of a protein to a defined nucleotide sequence at the 5'-terminus of virion and replicative intermediate RNAs of poliovirus. In Proceedings of the Proceedings of the National Academy of Sciences; Proc. Natl. Acad. Sci. USA 1977, 74, 961-965. [CrossRef] [PubMed]

12. Lee, Y.F.; Nomoto, A.; Detjen, B.M.; Wimmer, E. A protein covalently linked to poliovirus genome RNA. Proc. Natl. Acad. Sci. USA 1977, 74, 59-63. [CrossRef]

13. Paul, A.V.; Van Boom, J.H.; Filippov, D.V.; Wimmer, E. Protein-primed RNA synthesis by purified poliovirus RNA polymerase. Nat. Cell Biol. 1998, 393, 280-284. [CrossRef] [PubMed]

14. Rothberg, P.G.; Harris, T.J.; Nomoto, A.; Wimmer, E. O4-(5'-uridylyl)tyrosine is the bond between the genome-linked protein and the RNA of poliovirus. Proc. Natl. Acad. Sci. USA 1978, 75, 4868-4872. [CrossRef] [PubMed]

15. Andino, R.; Rieckhof, G.; Achacoso, P.; Baltimore, D. Poliovirus RNA synthesis utilizes an RNP complex formed around the $5^{\prime}$-end of viral RNA. EMBO J. 1993, 12, 3587-3598. [CrossRef]

16. Barton, D.J.; O'Donnell, B.J.; Flanegan, J.B. $5^{\prime}$ cloverleaf in poliovirus RNA is a cis-acting replication element required for negative-strand synthesis. EMBO J. 2001, 20, 1439-1448. [CrossRef]

17. Kloc, A.; Segundo, F.D.-S.; Schafer, E.A.; Rai, D.K.; Kenney, M.; Santos, T.D.L.; Rieder, E. Foot-and-mouth disease virus 5'-terminal $\mathrm{S}$ fragment is required for replication and modulation of the innate immune response in host cells. Virology 2017, 512, 132-143. [CrossRef] [PubMed]

18. Martínez-Salas, E.; Francisco-Velilla, R.; Fernandez-Chamorro, J.; Lozano, G.; Diaz-Toledano, R. Picornavirus IRES elements: RNA structure and host protein interactions. Virus Res. 2015, 206, 62-73. [CrossRef]

19. Vogt, D.A.; Andino, R. An RNA Element at the $5^{\prime}$-End of the Poliovirus Genome Functions as a General Promoter for RNA Synthesis. PLoS Pathog. 2010, 6, e1000936. [CrossRef]

20. Herold, J.; Andino, R. Poliovirus RNA Replication Requires Genome Circularization through a Protein-Protein Bridge. Mol. Cell 2001, 7, 581-591. [CrossRef]

21. Ogram, S.A.; Flanegan, J.B. Non-template functions of viral RNA in picornavirus replication. Curr. Opin. Virol. 2011, 1, 339-346. [CrossRef]

22. Sarnow, P. Role of $3^{\prime}$-end sequences in infectivity of poliovirus transcripts made in vitro. J. Virol. 1989, 63, 467-470. [CrossRef]

23. Serrano, P. The $3^{\prime}$ end of the foot-and-mouth disease virus genome establishes two distinct long-range RNA-RNA interactions with the 5' end region. J. Gen. Virol. 2006, 87, 3013-3022. [CrossRef]

24. Van Ooij, M.J.M. Polyadenylation of genomic RNA and initiation of antigenomic RNA in a positive-strand RNA virus are controlled by the same cis-element. Nucleic Acids Res. 2006, 34, 2953-2965. [CrossRef] [PubMed]

25. Wang, J.; Bakkers, J.M.J.E.; Galama, J.M.D.; Slot, H.J.B.; Pilipenko, E.V.; Agol, V.I.; Melchers, W.J.G. Structural requirements of the higher order RNA kissing element in the enteroviral 3'UTR. Nucleic Acids Res. 1999, 27, 485-490. [CrossRef] [PubMed]

26. Goodfellow, I.; Chaudhry, Y.; Richardson, A.; Meredith, J.; Almond, J.W.; Barclay, W.; Evans, D.J. Identification of a cis-Acting Replication Element within the Poliovirus Coding Region. J. Virol. 2000, 74, 4590-4600. [CrossRef]

27. Mason, P.W.; Bezborodova, S.V.; Henry, T.M. Identification and Characterization of a cis-Acting Replication Element (cre) Adjacent to the Internal Ribosome Entry Site of Foot-and-Mouth Disease Virus. J. Virol. 2002, 76, 9686-9694. [CrossRef] [PubMed]

28. McKnight, K.L.; Lemon, S.M. The rhinovirus type 14 genome contains an internally located RNA structure that is required for viral replication. RNA 1998, 4, 1569-1584. [CrossRef]

29. Nayak, A.; Goodfellow, I.G.; Belsham, G.J. Factors Required for the Uridylylation of the Foot-and-Mouth Disease Virus 3B1, 3B2, and 3B3 Peptides by the RNA-Dependent RNA Polymerase (3Dpol) In Vitro. J. Virol. 2005, 79, 7698-7706. [CrossRef]

30. Paul, A.V.; Rieder, E.; Kim, D.W.; Van Boom, J.H.; Wimmer, E. Identification of an RNA Hairpin in Poliovirus RNA That Serves as the Primary Template in the In Vitro Uridylylation of VPg. J. Virol. 2000, 74, 10359-10370. [CrossRef]

31. Belsham, G.J.; Bostock, C.J. Studies on the Infectivity of Foot-and-Mouth Disease Virus RNA using Microinjection. J. Gen. Virol. 1988, 69, 265-274. [CrossRef] 
32. Holland, J.J.; Bassett, D.W. Evidence for cytoplasmic replication of poliovirus ribonucleic acid. Virology 1964, $23,164-172$. [CrossRef]

33. Tuthill, T.J.; Bubeck, D.; Rowlands, D.J.; Hogle, J.M. Characterization of Early Steps in the Poliovirus Infection Process: ReceptorDecorated Liposomes Induce Conversion of the Virus to Membrane-Anchored Entry-Intermediate Particles. J. Virol. 2006, 80, 172-180. [CrossRef]

34. Bergamini, G.; Preiss, T.; Hentze, M.W. Picornavirus IRESes and the poly(A) tail jointly promote cap-independent translation in a mammalian cell-free system. RNA 2000, 6, 1781-1790. [CrossRef] [PubMed]

35. García-Nuñez, S.; Gismondi, M.I.; König, G.; Berinstein, A.; Taboga, O.; Rieder, E.; Martínez-Salas, E.; Carrillo, E. Enhanced IRES activity by the 3'UTR element determines the virulence of FMDV isolates. Virology 2014, 448, 303-313. [CrossRef]

36. De Quinto, S.L. IRES-driven translation is stimulated separately by the FMDV $3^{\prime}$-NCR and poly(A) sequences. Nucleic Acids Res. 2002, 30, 4398-4405. [CrossRef]

37. Simoes, E.A.; Sarnow, P. An RNA hairpin at the extreme 5' end of the poliovirus RNA genome modulates viral translation in human cells. J. Virol. 1991, 65, 913-921. [CrossRef] [PubMed]

38. Clarke, B.E.; Sangar, D.V. Processing and Assembly of Foot-and-Mouth Disease Virus Proteins Using Subgenomic RNA. J. Gen. Virol. 1988, 69, 2313-2325. [CrossRef] [PubMed]

39. Kräusslich, H.-G.; Nicklin, M.J.; Lee, C.-K.; Wimmer, E. Polyprotein processing in picornavirus replication. Biochimestry 1988, 70, 119-130. [CrossRef]

40. Lawson, M.A.; Semler, B.L. Picornavirus Protein Processing-Enzymes, Substrates, and Genetic Regulation. Curr. Topics Microbiol. Immunol. 1990, 161, 49-87. [CrossRef]

41. Pallansch, M.A.; Kew, O.M.; Semler, B.L.; Omilianowski, D.R.; Anderson, C.W.; Wimmer, E.; Rueckert, R.R. Protein processing map of poliovirus. J. Virol. 1984, 49, 873-880. [CrossRef]

42. Strebel, K.; Beck, E. A second protease of foot-and-mouth disease virus. J. Virol. 1986, 58, 893-899. [CrossRef]

43. Parks, G.D.; Duke, G.M.; Palmenberg, A.C. Encephalomyocarditis virus 3C protease: Efficient cell-free expression from clones which link viral 5' noncoding sequences to the P3 region. J. Virol. 1986, 60, 376-384. [CrossRef] [PubMed]

44. Sasaki, J.; Taniguchi, K. Aichi Virus 2A Protein Is Involved in Viral RNA Replication. J. Virol. 2008, 82, 9765-9769. [CrossRef] [PubMed]

45. Palmenberg, A.C. Proteolytic Processing of Picornaviral Polyprotein. Annu. Rev. Microbiol. 1990, 44, 603-623. [CrossRef] [PubMed]

46. Sasaki, J.; Ishikawa, K.; Taniguchi, K. 3CD, but not 3C, cleaves the VP1/2A site efficiently during Aichi virus polyprotein processing through interaction with 2A. Virus Res. 2012, 163, 592-598. [CrossRef] [PubMed]

47. Donnelly, M.L.L.; Luke, G.; Mehrotra, A.; Li, X.; Hughes, L.E.; Gani, D.; Ryan, M.D. Analysis of the aphthovirus 2A/2B polyprotein 'cleavage' mechanism indicates not a proteolytic reaction, but a novel translational effect: A putative ribosomal 'skip'. J. Gen. Virol. 2001, 82, 1013-1025. [CrossRef] [PubMed]

48. Palmenberg, A.C.; Parks, G.D.; Hall, D.J.; Ingraham, R.H.; Seng, T.W.; Pallai, P.V. Proteolytic processing of the cardioviral P2 region: Primary 2A/2B cleavage in clone-derived precursors. Virology 1992, 190, 754-762. [CrossRef]

49. Belsham, G.J.; Jackson, R.J. Translation initiation on picornavirus RNA. In Translational Control of Gene Expression; Monograph 39; Sonenberg, N., Hershey, J.W.B., Mathews, M.B., Eds.; Cold Spring Harbor Laboratory Press: Cold Spring Harbor, NY, USA, 2000; pp. 869-900.

50. Paul, A.V.; Wimmer, E. Initiation of protein-primed picornavirus RNA synthesis. Virus Res. 2015, 206, 12-26. [CrossRef]

51. Takeshita, D.; Yamashita, S.; Tomita, K. Molecular insights into replication initiation by Q $\beta$ replicase using ribosomal protein S1. Nucleic Acids Res. 2014, 42, 10809-10822. [CrossRef]

52. Pilipenko, E.V.; Poperechny, K.V.; Maslova, S.V.; Melchers, W.J.; Slot, H.J.; Agol, V.I. Cis-element, oriR, involved in the initiation of (-) strand poliovirus RNA: A quasi-globular multi-domain RNA structure maintained by tertiary ('kissing') in-teractions. EMBO J. 1996, 15, 5428-5436. [CrossRef]

53. Flanegan, J.B.; Baltimore, D. Poliovirus-specific primer-dependent RNA polymerase able to copy poly(A). Proc. Natl. Acad. Sci. USA 1977, 74, 3677-3680. [CrossRef]

54. Kapoor, A.; Victoria, J.; Simmonds, P.; Wang, C.; Shafer, R.W.; Nims, R.; Nielsen, O.; Delwart, E. A Highly Divergent Picornavirus in a Marine Mammal. J. Virol. 2007, 82, 311-320. [CrossRef]

55. Forss, S.; Schaller, H. A tandem repeat gene in a picornavirus. Nucleic Acids Res. 1982, 10, 6441-6450. [CrossRef] [PubMed]

56. Forss, S.; Strebel, K.; Beck, E.; Schaller, H. Nucleotide sequence and genome organization of foot-and-mouth disease virus. Nucleic Acids Res. 1984, 12, 6587-6601. [CrossRef]

57. King, A.M.; Sangar, D.V.; Harris, T.J.; Brown, F. Heterogeneity of the genome-linked protein of foot-and-mouth disease virus. J. Virol. 1980, 34, 627-634. [CrossRef]

58. Logan, G.; Newman, J.; Wright, C.F.; Lasecka-Dykes, L.; Haydon, D.T.; Cottam, E.M.; Tuthill, T.J. Deep Sequencing of Foot-andMouth Disease Virus Reveals RNA Sequences Involved in Genome Packaging. J. Virol. 2017, 92. [CrossRef] [PubMed]

59. Ma, H.-C.; Liu, Y.; Wang, C.; Strauss, M.; Rehage, N.; Chen, Y.-H.; Altan-Bonnet, N.; Hogle, J.; Wimmer, E.; Mueller, S.; et al. An Interaction between Glutathione and the Capsid Is Required for the Morphogenesis of C-Cluster Enteroviruses. PLoS Pathog. 2014, 10, e1004052. [CrossRef] [PubMed] 
60. Sasaki, J.; Nagashima, S.; Taniguchi, K. Aichi Virus Leader Protein Is Involved in Viral RNA Replication and Encapsidation. J. Virol. 2003, 77, 10799-10807. [CrossRef]

61. Sasaki, J.; Taniguchi, K. The 5'-End Sequence of the Genome of Aichi Virus, a Picornavirus, Contains an Element Critical for Viral RNA Encapsidation. J. Virol. 2003, 77, 3542-3548. [CrossRef] [PubMed]

62. Wang, C.; Jiang, P.; Sand, C.; Paul, A.V.; Wimmer, E. Alanine Scanning of Poliovirus 2CATPaseReveals New Genetic Evidence that Capsid Protein/2CATPaseInteractions Are Essential for Morphogenesis. J. Virol. 2012, 86, 9964-9975. [CrossRef] [PubMed]

63. Chow, M.; Newman, J.F.E.; Filman, D.; Hogle, J.M.; Rowlands, D.J.; Brown, F. Myristylation of picornavirus capsid protein VP4 and its structural significance. Nat. Cell Biol. 1987, 327, 482-486. [CrossRef]

64. Ramljak, I.C.; Stanger, J.; Real-Hohn, A.; Dreier, D.; Wimmer, L.; Redlberger-Fritz, M.; Fischl, W.; Klingel, K.; Mihovilovic, M.D.; Blaas, D.; et al. Cellular N-myristoyltransferases play a crucial picornavirus genus-specific role in viral assembly, virion maturation, and infectivity. PLoS Pathog. 2018, 14, e1007203. [CrossRef]

65. Paul, A.V.; Schultz, A.; Pincus, S.E.; Oroszlan, S.; Wimmer, E. Capsid protein VP4 of poliovirus is N-myristoylated. Proc. Natl. Acad. Sci. USA 1987, 84, 7827-7831. [CrossRef]

66. Hogle, J.M. Poliovirus Cell Entry: Common Structural Themes in Viral Cell Entry Pathways. Annu. Rev. Microbiol. 2002, 56, 677-702. [CrossRef] [PubMed]

67. Panjwani, A.; Strauss, M.; Gold, S.; Wenham, H.; Jackson, T.; Chou, J.J.; Rowlands, D.J.; Stonehouse, N.J.; Hogle, J.M.; Tuthill, T.J. Capsid Protein VP4 of Human Rhinovirus Induces Membrane Permeability by the Formation of a Size-Selective Multimeric Pore. PLoS Pathog. 2014, 10, e1004294. [CrossRef] [PubMed]

68. Stanway, G.; Kalkkinen, N.; Roivainen, M.; Ghazi, F.; Khan, M.; Smyth, M.; Meurman, O.; Hyypiä, T. Molecular and biological characteristics of echovirus 22, a representative of a new picornavirus group. J. Virol. 1994, 68, 8232-8238. [CrossRef] [PubMed]

69. Tesar, M.; Jia, X.-Y.; Summers, D.F.; Ehrenfeld, E. Analysis of a Potential Myristoylation Site in Hepatitis A Virus Capsid Protein VP4. Virology 1993, 194, 616-626. [CrossRef] [PubMed]

70. Basavappa, R.; Filman, D.J.; Syed, R.; Flore, O.; Icenogle, J.P.; Hogle, J.M. Role and mechanism of the maturation cleavage of VP0 in poliovirus assembly: Structure of the empty capsid assembly intermediate at $2.9 \AA$ resolution. Protein Sci. 1994, 3, 1651-1669. [CrossRef]

71. Stanway, G.; Hyypia, T. Parechoviruses. J. Virol. 1999, 73, 5249-5254. [CrossRef]

72. Yamashita, T.; Sakae, K.; Tsuzuki, H.; Suzuki, Y.; Ishikawa, N.; Takeda, N.; Miyamura, T.; Yamazaki, S. Complete Nucleotide Sequence and Genetic Organization of Aichi Virus, a Distinct Member of the PicornaviridaeAssociated with Acute Gastroenteritis in Humans. J. Virol. 1998, 72, 8408-8412. [CrossRef]

73. Curry, S.; Fry, E.; Blakemore, W.; Abu-Ghazaleh, R.; Jackson, T.; King, A.; Lea, S.; Newman, J.; Stuart, D. Dissecting the roles of VP0 cleavage and RNA packaging in picornavirus capsid stabilization: The structure of empty capsids of foot-and-mouth disease virus. J. Virol. 1997, 71, 9743-9752. [CrossRef] [PubMed]

74. Gullberg, M.; Muszynski, B.; Organtini, L.J.; Ashley, R.E.; Hafenstein, S.L.; Belsham, G.J.; Polacek, C. Assembly and characterization of foot-and-mouth disease virus empty capsid particles expressed within mammalian cells. J. Gen. Virol. 2013, 94, 1769-1779. [CrossRef] [PubMed]

75. Robinson, S.M.; Tsueng, G.; Sin, J.; Mangale, V.; Rahawi, S.; McIntyre, L.L.; Williams, W.; Kha, N.; Cruz, C.; Hancock, B.M.; et al. Coxsackievirus B Exits the Host Cell in Shed Microvesicles Displaying Autophagosomal Markers. PLoS Pathog. 2014, 10, e1004045. [CrossRef]

76. Taylor, M.P.; Burgon, T.B.; Kirkegaard, K.; Jackson, W.T. Role of Microtubules in Extracellular Release of Poliovirus. J. Virol. 2009, 83, 6599-6609. [CrossRef] [PubMed]

77. Van Der Grein, S.G.; Defourny, K.A.Y.; Rabouw, H.H.; Galiveti, C.R.; Langereis, M.A.; Wauben, M.H.M.; Arkesteijn, G.J.A.; Van Kuppeveld, F.J.M.; Hoen, E.N.M.N. ‘T Picornavirus infection induces temporal release of multiple extracellular vesicle subsets that differ in molecular composition and infectious potential. PLoS Pathog. 2019, 15, e1007594. [CrossRef]

78. Doedens, J.; Kirkegaard, K. Inhibition of cellular protein secretion by poliovirus proteins 2B and 3A. EMBO J. 1995, 14, 894-907. [CrossRef]

79. Deitz, S.B.; Dodd, D.A.; Cooper, S.; Parham, P.; Kirkegaard, K. MHC I-dependent antigen presentation is inhibited by poliovirus protein 3A. Proc. Natl. Acad. Sci. USA 2000, 97, 13790-13795. [CrossRef]

80. Feng, Q.; Langereis, M.A.; Van Kuppeveld, F.J. Induction and suppression of innate antiviral responses by picornaviruses. Cytokine Growth Factor Rev. 2014, 25, 577-585. [CrossRef]

81. Zhang, Y.; Li, J.; Li, Q. Immune Evasion of Enteroviruses Under Innate Immune Monitoring. Front. Microbiol. 2018, 9, 1866. [CrossRef]

82. Flather, D.; Semler, B.L. Picornaviruses and nuclear functions: Targeting a cellular compartment distinct from the replication site of a positive-strand RNA virus. Front. Microbiol. 2015, 6, 594. [CrossRef]

83. Gustin, K.E. Effects of poliovirus infection on nucleo-cytoplasmic trafficking and nuclear pore complex composition. EMBO J. 2001, 20, 240-249. [CrossRef]

84. Gustin, K.E.; Sarnow, P. Inhibition of Nuclear Import and Alteration of Nuclear Pore Complex Composition by Rhinovirus. J. Virol. 2002, 76, 8787-8796. [CrossRef] [PubMed]

85. Lidsky, P.V.; Hato, S.; Bardina, M.V.; Aminev, A.G.; Palmenberg, A.C.; Sheval, E.V.; Polyakov, V.Y.; Van Kuppeveld, F.J.M.; Agol, V.I. Nucleocytoplasmic Traffic Disorder Induced by Cardioviruses. J. Virol. 2006, 80, 2705-2717. [CrossRef] 
86. Viktorova, E.G.; Nchoutmboube, J.A.; Ford-Siltz, L.A.; Iverson, E.; Belov, G.A. Phospholipid synthesis fueled by lipid droplets drives the structural development of poliovirus replication organelles. PLoS Pathog. 2018, 14, e1007280. [CrossRef]

87. Knowles, N.J.; Davies, P.R.; Henry, T.; O’Donnell, V.; Pacheco, J.M.; Mason, P.W. Emergence in Asia of Foot-and-Mouth Disease Viruses with Altered Host Range: Characterization of Alterations in the 3A Protein. J. Virol. 2001, 75, 1551-1556. [CrossRef] [PubMed]

88. Yoon, S.H.; Lee, K.-N.; Park, J.-H.; Kim, H. Molecular epidemiology of foot-and-mouth disease virus serotypes A and O with emphasis on Korean isolates: Temporal and spatial dynamics. Arch. Virol. 2011, 156, 817-826. [CrossRef]

89. Greninger, A.L.; Knudsen, G.M.; Betegon, M.; Burlingame, A.L.; DeRisi, J.L. The 3A Protein from Multiple Picornaviruses Utilizes the Golgi Adaptor Protein ACBD3 To Recruit PI4KIII. J. Virol. 2012, 86, 3605-3616. [CrossRef] [PubMed]

90. Hofmann, K.; Stoffel, W. TMbase-A database of membrane spanning proteins segments. Biol. Chem. Hoppe Seyler 1993, $374,166$.

91. Krogh, A.; Larsson, B.; von Heijne, G.; Sonnhammer, E.L. Predicting transmembrane protein topology with a hidden markov model: Application to complete genomes11Edited by F. Cohen. J. Mol. Biol. 2001, 305, 567-580. [CrossRef]

92. Käll, L.; Krogh, A.; Sonnhammer, E.L. Advantages of combined transmembrane topology and signal peptide prediction-The Phobius web server. Nucleic Acids Res. 2007, 35, W429-W432. [CrossRef]

93. Tusnady, G.E.; Simon, I. The HMMTOP transmembrane topology prediction server. Bioinformatics 2001, 17, 849-850. [CrossRef]

94. Fujita, K.; Krishnakumar, S.S.; Franco, D.; Paul, A.V.; London, E.; Wimmer, E. Membrane Topography of the Hydrophobic Anchor Sequence of Poliovirus 3A and 3AB Proteins and the Functional Effect of 3A/3AB Membrane Association upon RNA Replication. Biochemestry 2007, 46, 5185-5199. [CrossRef]

95. Wessels, E.; Duijsings, D.; Niu, T.-K.; Neumann, S.; Oorschot, V.M.; de Lange, F.; Lanke, K.H.; Klumperman, J.; Henke, A.; Jackson, C.L.; et al. A Viral Protein that Blocks Arf1-Mediated COP-I Assembly by Inhibiting the Guanine Nucleotide Exchange Factor GBF1. Dev. Cell 2006, 11, 191-201. [CrossRef]

96. Wessels, E.; Duijsings, D.; Lanke, K.H.W.; Melchers, W.J.G.; Jackson, C.L.; Van Kuppeveld, F.J.M. Molecular Determinants of the Interaction between Coxsackievirus Protein 3A and Guanine Nucleotide Exchange Factor GBF1. J. Virol. 2007, 81, 5238-5245. [CrossRef] [PubMed]

97. Pacheco, J.M.; Gladue, D.P.; Holinka, L.G.; Arzt, J.; Bishop, E.; Smoliga, G.; Pauszek, S.J.; Bracht, A.J.; O’Donnell, V.; Fernandez-Sainz, I.; et al. A partial deletion in non-structural protein $3 \mathrm{~A}$ can attenuate foot-and-mouth disease virus in cattle. Virology 2013, 446, 260-267. [CrossRef]

98. Xiang, W.; Cuconati, A.; Paul, A.V.; Cao, X.; Wimmer, E. Molecular dissection of the multifunctional poliovirus RNA-binding protein 3AB. RNA 1995, 1, 892-904. [PubMed]

99. Lawson, M.A.; Semler, B.L. Alternate poliovirus nonstructural protein processing cascades generated by primary sites of 3C proteinase cleavage. Virology 1992, 191, 309-320. [CrossRef]

100. Pathak, H.B.; Oh, H.S.; Goodfellow, I.G.; Arnold, J.J.; Cameron, C.E. Picornavirus Genome Replication. J. Biol. Chem. 2008, 283, 30677-30688. [CrossRef]

101. Leong, L.E.-C.; Cornell, C.T.; Semler, B.L. Processing Determinants and Functions of Cleavage Products of Picornavirus Polyproteins. In Molecular Biology of Picornavirus; American Society for Microbiology Press: Washington, DC, USA, 2014 ; pp. $185-197$.

102. O'Donnell, V.K.; Pacheco, J.M.; Henry, T.M.; Mason, P.W. Subcellular Distribution of the Foot-and-Mouth Disease Virus 3A Protein in Cells Infected with Viruses Encoding Wild-Type and Bovine-Attenuated Forms of 3A. Virology 2001, 287, 151-162. [CrossRef] [PubMed]

103. Paul, A.V. Possible Unifying Mechanism of Picornavirus Genome Replication. In Molecular Biology of Picornavirus; American Society for Microbiology Press: Washington, DC, USA, 2014; pp. 225-246.

104. Strauss, D.M.; Glustrom, L.W.; Wuttke, D.S. Towards an Understanding of the Poliovirus Replication Complex: The Solution Structure of the Soluble Domain of the Poliovirus 3A Protein. J. Mol. Biol. 2003, 330, 225-234. [CrossRef]

105. González-Magaldi, M.; Postigo, R.; De La Torre, B.G.; Vieira, Y.A.; Rodríguez-Pulido, M.; López-Viñas, E.; Gómez-Puertas, P.; Andreu, D.; Kremer, L.; Rosas, M.F.; et al. Mutations That Hamper Dimerization of Foot-and-Mouth Disease Virus 3A Protein Are Detrimental for Infectivity. J. Virol. 2012, 86, 11013-11023. [CrossRef]

106. Wessels, E.; Notebaart, R.A.; Duijsings, D.; Lanke, K.; Vergeer, B.; Melchers, W.J.G.; van Kuppeveld, F.J.M. Structure-Function Analysis of the Coxsackievirus Protein 3A. J. Biol. Chem. 2006, 281, 28232-28243. [CrossRef]

107. Horova, V.; Lyoo, H.; Różycki, B.; Chalupska, D.; Smola, M.; Humpolickova, J.; Strating, J.R.P.M.; Van Kuppeveld, F.J.M.; Boura, E.; Klima, M. Convergent evolution in the mechanisms of ACBD3 recruitment to picornavirus replication sites. PLoS Pathog. 2019, 15, e1007962. [CrossRef]

108. Hope, D.A.; Diamond, S.E.; Kirkegaard, K. Genetic dissection of interaction between poliovirus 3D polymerase and viral protein 3AB. J. Virol. 1997, 71, 9490-9498. [CrossRef]

109. Ishikawa, K.; Sasaki, J.; Taniguchi, K. Overall linkage map of the nonstructural proteins of Aichi virus. Virus Res. 2010, 147, 77-84. [CrossRef] [PubMed]

110. Teterina, N.L.; Levenson, E.; Rinaudo, M.S.; Egger, D.; Bienz, K.; Gorbalenya, A.E.; Ehrenfeld, E. Evidence for Functional Protein Interactions Required for Poliovirus RNA Replication. J. Virol. 2006, 80, 5327-5337. [CrossRef] [PubMed]

111. Xiang, W.; Cuconati, A.; Hope, D.; Kirkegaard, K.; Wimmer, E. Complete Protein Linkage Map of Poliovirus P3 Proteins: Interaction of Polymerase 3Dpol with VPg and with Genetic Variants of 3AB. J. Virol. 1998, 72, 6732-6741. [CrossRef] [PubMed] 
112. Yin, J.; Liu, Y.; Wimmer, E.; Paul, A.V. Complete protein linkage map between the P2 and P3 non-structural proteins of poliovirus. J. Gen. Virol. 2007, 88, 2259-2267. [CrossRef] [PubMed]

113. Teterina, N.L.; Pinto, Y.; Weaver, J.D.; Jensen, K.S.; Ehrenfeld, E. Analysis of Poliovirus Protein 3A Interactions with Viral and Cellular Proteins in Infected Cells. J. Virol. 2011, 85, 4284-4296. [CrossRef]

114. Towner, J.S.; Brown, D.M.; Nguyen, J.H.; Semler, B.L. Functional conservation of the hydrophobic domain of polypeptide 3AB between human rhinovirus and poliovirus. Virol. 2003, 314, 432-442. [CrossRef]

115. Chen, C.; Wang, Y.; Shan, C.; Sun, Y.; Xu, P.; Zhou, H.; Yang, C.; Shi, P.-Y.; Rao, Z.; Zhang, B.; et al. Crystal Structure of Enterovirus 71 RNA-Dependent RNA Polymerase Complexed with Its Protein Primer VPg: Implication for a trans Mechanism of VPg Uridylylation. J. Virol. 2013, 87, 5755-5768. [CrossRef]

116. Ferrer-Orta, C.; Arias, A.; Agudo, R.; Pérez-Luque, R.; Escarmís, C.; Domingo, E.; Verdaguer, N. The structure of a protein primer-polymerase complex in the initiation of genome replication. EMBO J. 2006, 25, 880-888. [CrossRef]

117. Gruez, A.; Selisko, B.; Roberts, M.; Bricogne, G.; Bussetta, C.; Jabafi, I.; Coutard, B.; De Palma, A.M.; Neyts, J.; Canard, B. The Crystal Structure of Coxsackievirus B3 RNA-Dependent RNA Polymerase in Complex with Its Protein Primer VPg Confirms the Existence of a Second VPg Binding Site on Picornaviridae Polymerases. J. Virol. 2008, 82, 9577-9590. [CrossRef]

118. Ferrer-Orta, C.; Ferrero, D.; Verdaguer, N. RNA-Dependent RNA Polymerases of Picornaviruses: From the Structure to Regulatory Mechanisms. Viruses 2015, 7, 4438-4460. [CrossRef]

119. Molla, A.; Harris, K.S.; Paul, A.V.; Shin, S.H.; Mugavero, J.; Wimmer, E. Stimulation of poliovirus proteinase 3Cpro-related proteolysis by the genome-linked protein VPg and its precursor 3AB. J. Biol. Chem. 1994, 269, 27015-27020. [CrossRef]

120. Nagashima, S.; Sasaki, J.; Taniguchi, K. Interaction between Polypeptide 3ABC and the $5^{\prime}$-Terminal Structural Elements of the Genome of Aichi Virus: Implication for Negative-Strand RNA Synthesis. J. Virol. 2008, 82, 6161-6171. [CrossRef]

121. Moffat, K.; Howell, G.; Knox, C.; Belsham, G.J.; Monaghan, P.; Ryan, M.D.; Wileman, T. Effects of Foot-and-Mouth Disease Virus Nonstructural Proteins on the Structure and Function of the Early Secretory Pathway: 2BC but Not 3A Blocks Endoplasmic Reticulum-to-Golgi Transport. J. Virol. 2005, 79, 4382-4395. [CrossRef] [PubMed]

122. Wessels, E.; Duijsings, D.; Notebaart, R.A.; Melchers, W.J.G.; Van Kuppeveld, F.J.M. A Proline-Rich Region in the Coxsackievirus 3A Protein Is Required for the Protein To Inhibit Endoplasmic Reticulum-to-Golgi Transport. J. Virol. 2005, 79, 5163-5173. [CrossRef] [PubMed]

123. Dodd, D.A.; Giddings, T.H., Jr.; Kirkegaard, K. Poliovirus 3A Protein Limits Interleukin-6 (IL-6), IL-8, and Beta Interferon Secretion during Viral Infection. J. Virol. 2001, 75, 8158-8165. [CrossRef] [PubMed]

124. Doedens, J.R.; Giddings, T.H.; Kirkegaard, K. Inhibition of endoplasmic reticulum-to-Golgi traffic by poliovirus protein 3A: Genetic and ultrastructural analysis. J. Virol. 1997, 71, 9054-9064. [CrossRef]

125. Neznanov, N.; Kondratova, A.; Chumakov, K.M.; Angres, B.; Zhumabayeva, B.; Agol, V.I.; Gudkov, A.V. Poliovirus Protein 3A Inhibits Tumor Necrosis Factor (TNF)-Induced Apoptosis by Eliminating the TNF Receptor from the Cell Surface. J. Virol. 2001, 75, 10409-10420. [CrossRef]

126. Moffat, K.; Knox, C.; Howell, G.; Clark, S.J.; Yang, H.; Belsham, G.J.; Ryan, M.D.; Wileman, T. Inhibition of the Secretory Pathway by Foot-and-Mouth Disease Virus 2BC Protein Is Reproduced by Coexpression of 2B with 2C, and the Site of Inhibition Is Determined by the Subcellular Location of 2C. J. Virol. 2006, 81, 1129-1139. [CrossRef] [PubMed]

127. Choe, S.S.; Dodd, D.A.; Kirkegaard, K. Inhibition of cellular protein secretion by picornaviral 3A proteins. Virology 2005, 337, 18-29. [CrossRef]

128. Wessels, E.; Duijsings, D.; Lanke, K.H.W.; Van Dooren, S.H.J.; Jackson, C.L.; Melchers, W.J.G.; Van Kuppeveld, F.J.M. Effects of Picornavirus 3A Proteins on Protein Transport and GBF1-Dependent COP-I Recruitment. J. Virol. 2006, 80, 11852-11860. [CrossRef]

129. Mousnier, A.; Swieboda, D.; Pinto, A.; Guedán, A.; Rogers, A.V.; Walton, R.; Johnston, S.L.; Solari, R. Human Rhinovirus 16 Causes Golgi Apparatus Fragmentation without Blocking Protein Secretion. J. Virol. 2014, 88, 11671-11685. [CrossRef]

130. Beske, O.; Reichelt, M.; Taylor, M.P.; Kirkegaard, K.; Andino, R. Poliovirus infection blocks ERGIC-to-Golgi trafficking and induces microtubule-dependent disruption of the Golgi complex. J. Cell Sci. 2007, 120, 3207-3218. [CrossRef]

131. Szul, T.; Sztul, E. COPII and COPI Traffic at the ER-Golgi Interface. Physiol. 2011, 26, 348-364. [CrossRef] [PubMed]

132. Szul, T.; Garcia-Mata, R.; Brandon, E.; Shestopal, S.; Alvarez, C.; Sztul, E. Dissection of Membrane Dynamics of the ARF-Guanine Nucleotide Exchange Factor GBF1. Traffic 2005, 6, 374-385. [CrossRef] [PubMed]

133. Sztul, E.; Chen, P.-W.; Casanova, J.E.; Cherfils, J.; Dacks, J.B.; Lambright, D.G.; Lee, F.-J.S.; Randazzo, P.A.; Santy, L.C.; Schürmann, A.; et al. ARF GTPases and their GEFs and GAPs: Concepts and challenges. Mol. Biol. Cell 2019, 30, 1249-1271. [CrossRef] [PubMed]

134. Niu, T.-K.; Pfeifer, A.C.; Lippincott-Schwartz, J.; Jackson, C.L. Dynamics of GBF1, a Brefeldin A-Sensitive Arf1 Exchange Factor at the Golgi. Mol. Biol. Cell 2005, 16, 1213-1222. [CrossRef]

135. Arita, M.; Wakita, T.; Shimizu, H. Valosin-Containing Protein (VCP/p97) Is Required for Poliovirus Replication and Is Involved in Cellular Protein Secretion Pathway in Poliovirus Infection. J. Virol. 2012, 86, 5541-5553. [CrossRef] [PubMed]

136. Berstein, H.D.; Baltimore, D. Poliovirus mutant that contains a cold-sensitive defect in viral RNA synthesis. J. Virol. 1988, 62, 2922-2928. [CrossRef] [PubMed]

137. Datta, U.; Dasgupta, A. Expression and subcellular localization of poliovirus VPg-precursor protein 3AB in eukaryotic cells: Evidence for glycosylation in vitro. J. Virol. 1994, 68, 4468-4477. [CrossRef] 
138. Giachetti, C.; Hwang, S.S.; Semler, B.L. cis-acting lesions targeted to the hydrophobic domain of a poliovirus membrane protein involved in RNA replication. J. Virol. 1992, 66, 6045-6057. [CrossRef]

139. Semler, B.L.; Anderson, C.W.; Hanecak, R.; Dorner, L.F.; Wimmer, E. A membrane-associated precursor to poliovirus VPg identified by immunoprecipitation with antibodies directed against a synthetic heptapeptide. Cell 1982, 28, 405-412. [CrossRef]

140. Towner, J.S.; Ho, T.V.; Semler, B.L. Determinants of Membrane Association for Poliovirus Protein 3AB. J. Biol. Chem. 1996, 271, 26810-26818. [CrossRef]

141. Towner, J.S.; Mazanet, M.M.; Semler, B.L. Rescue of Defective Poliovirus RNA Replication by 3AB-Containing Precursor Polyproteins. J. Virol. 1998, 72, 7191-7200. [CrossRef]

142. González-Magaldi, M.; Martín-Acebes, M.A.; Kremer, L.; Sobrino, F. Membrane Topology and Cellular Dynamics of Foot-andMouth Disease Virus 3A Protein. PLoS ONE 2014, 9, e106685. [CrossRef]

143. Lotufo, C.M.; Wilda, M.; Giraldez, A.N.; Grigera, P.R.; Mattion, N.M. Relevance of the N-terminal and major hydrophobic domains of non-structural protein 3A in the replicative process of a DNA-launched foot-and-mouth disease virus replicon. Arch. Virol. 2018, 163, 1769-1778. [CrossRef]

144. Racaniello, V.R. One hundred years of poliovirus pathogenesis. Virology 2006, 344, 9-16. [CrossRef] [PubMed]

145. Arzt, J.; Baxt, B.; Grubman, M.J.; Jackson, T.; Juleff, N.; Rhyan, J.; Rieder, E.; Waters, R.; Rodriguez, L.L. The Pathogenesis of Foot-and-Mouth Disease II: Viral Pathways in Swine, Small Ruminants, and Wildlife; Myotropism, Chronic Syndromes, and Molecular Virus-Host Interactions. Transbound. Emerg. Dis. 2011, 58, 305-326. [CrossRef]

146. Weaver, G.V.; Domenech, J.; Thiermann, A.R.; Karesh, W.B. Foot and Mouth Disease: A Look from the Wild Side. J. Wildl. Dis. 2013, 49, 759-785. [CrossRef]

147. Harris, J.R.; Racaniello, V.R. Amino Acid Changes in Proteins 2B and 3A Mediate Rhinovirus Type 39 Growth in Mouse Cells. J. Virol. 2005, 79, 5363-5373. [CrossRef] [PubMed]

148. Rasmussen, A.L.; Racaniello, V.R. Selection of rhinovirus 1A variants adapted for growth in mouse lung epithelial cells. Virology 2011, 420, 82-88. [CrossRef] [PubMed]

149. Bochkov, Y.A.; Watters, K.; Basnet, S.; Sijapati, S.; Hill, M.; Palmenberg, A.C.; Gern, J.E. Mutations in VP1 and 3A proteins improve binding and replication of rhinovirus C15 in HeLa-E8 cells. Virology 2016, 499, 350-360. [CrossRef]

150. Graff, J.; Kasang, C.; Normann, A.; Pfisterer-Hunt, M.; Feinstone, S.M.; Flehmig, B. Mutational Events in Consecutive Passages of Hepatitis A Virus Strain GBM during Cell Culture Adaptation. Virology 1994, 204, 60-68. [CrossRef] [PubMed]

151. Graff, J.; Normann, A.; Feinstone, S.M.; Flehmig, B. Nucleotide sequence of wild-type hepatitis A virus GBM in comparison with two cell culture-adapted variants. J. Virol. 1994, 68, 548-554. [CrossRef] [PubMed]

152. Lemon, S.M.; Murphy, P.C.; Shields, P.A.; Ping, L.H.; Feinstone, S.M.; Cromeans, T.; Jansen, R.W. Antigenic and genetic variation in cytopathic hepatitis A virus variants arising during persistent infection: Evidence for genetic recombination. J. Virol. 1991, 65, 2056-2065. [CrossRef]

153. Morace, G.; Pisani, G.; Beneduce, F.; Divizia, M.; Pana, A. Mutations in the 3A genomic region of two cytopathic strains of hepatitis A virus isolated in Italy. Virus Res. 1993, 28, 187-194. [CrossRef]

154. Massilamany, C.; Gangaplara, A.; Basavalingappa, R.H.; Rajasekaran, R.A.; Vu, H.; Riethoven, J.-J.; Steffen, D.; Pattnaik, A.K.; Reddy, J. Mutations in the 5' NTR and the Non-Structural Protein 3A of the Coxsackievirus B3 Selectively Attenuate Myocarditogenicity. PLoS ONE 2015, 10, e0131052. [CrossRef]

155. Núñez, J.I.; Baranowski, E.; Molina, N.; Ruiz-Jarabo, C.M.; Sánchez, C.; Domingo, E.; Sobrino, F. A Single Amino Acid Substitution in Nonstructural Protein 3A Can Mediate Adaptation of Foot-and-Mouth Disease Virus to the Guinea Pig. J. Virol. 2001, 75, 3977-3983. [CrossRef] [PubMed]

156. Giraudo, A.T.; Beck, E.; Strebel, K.; De Mello, P.A.; La Torre, J.; Scodeller, E.A.; Bergmann, I.E. Identification of a nucleotide deletion in parts of polypeptide 3A in two independent attenuated aphthovirus strains. Virology 1990, 177, 780-783. [CrossRef]

157. Giraudo, A.T.; Sagedahl, A.; Bergmann, I.E.; La Torre, J.L.; Scodeller, E.A. Isolation and characterization of recombinants between attenuated and virulent aphthovirus strains. J. Virol. 1987, 61, 419-425. [CrossRef]

158. Parisi, J.M.; Giomi, P.C.; Grigera, P.; Mello, P.A.; Bergmann, I.E.; La Torre, J.L.; Scodeller, E.A. Biochemical characterization of an aphthovirus type 01 strain campos attenuated for cattle by serial passages in chicken embryos. Virology 1985, 147, 61-71. [CrossRef]

159. Sagedahl, A.; Giraudo, A.T.; De Mellod, P.A.; Bergmann, I.E.; La Torre, J.; Scodeller, E.A. Biochemical characterization of an aphthovirus type C3 strain resende attenuated for cattle by serial passages in chicken embryos. Virology 1987, 157, 366-374. [CrossRef]

160. Beard, C.W.; Mason, P.W. Genetic Determinants of Altered Virulence of Taiwanese Foot-and-Mouth Disease Virus. J. Virol. 2000, 74, 987-991. [CrossRef] [PubMed]

161. Dunn, C.S.; Donaldson, A.I. Natural adaption to pigs of a Taiwanese isolate of foot-and-mouth disease virus. Veter Rec. 1997, 141, 174-175. [CrossRef] [PubMed]

162. Li, S.; Gao, M.; Zhang, R.; Song, G.; Song, J.; Liu, D.; Cao, Y.; Li, T.; Ma, B.; Liu, X.; et al. A mutant of infectious Asia 1 serotype foot-and-mouth disease virus with the deletion of 10-amino-acid in the 3A protein. Virus Genes 2010, 41, 406-413. [CrossRef]

163. Pacheco, J.M.; Henry, T.M.; O’Donnell, V.K.; Gregory, J.B.; Mason, P.W. Role of Nonstructural Proteins 3A and 3B in Host Rangeand Pathogenicity of Foot-and-Mouth Disease Virus. J. Virol. 2003, 77, 13017-13027. [CrossRef] [PubMed] 
164. Larocco, M.; Krug, P.W.; Kramer, E.; Ahmed, Z.; Pacheco, J.M.; Duque, H.; Baxt, B.; Rodriguez, L.L. Correction for LaRocco et al., A Continuous Bovine Kidney Cell Line Constitutively Expressing Bovine $\alpha \mathrm{V} \beta 6$ Integrin Has Increased Susceptibility to Foot-and-Mouth Disease Virus. J. Clin. Microbiol. 2015, 53, 755. [CrossRef]

165. Ma, X.; Li, P.; Bai, X.; Sun, P.; Bao, H.; Lu, Z.; Cao, Y.; Li, D.; Chen, Y.; Qiao, Z.; et al. Sequences outside that of residues 93-102 of $3 \mathrm{~A}$ protein can contribute to the ability of foot-and-mouth disease virus (FMDV) to replicate in bovine-derived cells. Virus Res. 2014, 191, 161-171. [CrossRef]

166. Stenfeldt, C.; Arzt, J.; Pacheco, J.M.; Gladue, D.P.; Smoliga, G.R.; Silva, E.B.; Rodriguez, L.L.; Borca, M.V. A partial deletion within foot-and-mouth disease virus non-structural protein $3 \mathrm{~A}$ causes clinical attenuation in cattle but does not prevent subclinical infection. Virology 2018, 516, 115-126. [CrossRef]

167. DeStefano, J.J.; Titilope, O. Poliovirus Protein 3AB Displays Nucleic Acid Chaperone and Helix-Destabilizing Activities. J. Virol. 2006, 80, 1662-1671. [CrossRef] [PubMed]

168. Gangaramani, D.R.; Eden, E.L.; Shah, M.; DeStefano, J.J. The twenty-nine amino acid C-terminal cytoplasmic domain of poliovirus $3 \mathrm{AB}$ is critical for nucleic acid chaperone activity. RNA Biol. 2010, 7, 820-829. [CrossRef]

169. Tang, F.; Xia, H.; Wang, P.; Yang, J.; Zhao, T.; Zhang, Q.; Hu, Y.; Zhou, X. The identification and characterization of nucleic acid chaperone activity of human enterovirus 71 nonstructural protein 3AB. Virology 2014, 464-465, 353-364. [CrossRef]

170. Kondratova, A.A.; Neznanov, N.; Kondratov, R.V.; Gudkov, A.V. Poliovirus Protein 3A Binds and Deregulates LIS1, Causing Block of Membrane Protein Trafficking and Deregulation of Cell Division. Cell Cycle 2005, 4, 1403-1410. [CrossRef]

171. Htet, Z.M.; Gillies, J.P.; Baker, R.W.; Leschziner, A.E.; DeSantis, M.E.; Reck-Peterson, S.L. LIS1 promotes the formation of activated cytoplasmic dynein-1 complexes. Nat. Cell Biol. 2020, 22, 518-525. [CrossRef]

172. Toropova, K.; Zou, S.; Roberts, A.J.; Redwine, W.B.; Goodman, B.S.; Reck-Peterson, S.L.; E Leschziner, A. Lis1 regulates dynein by sterically blocking its mechanochemical cycle. eLife 2014, 3. [CrossRef] [PubMed]

173. Egan, M.J.; Tan, K.; Reck-Peterson, S.L. Lis1 is an initiation factor for dynein-driven organelle transport. J. Cell Biol. 2012, 197, 971-982. [CrossRef]

174. Reck-Peterson, S.L.; Redwine, W.B.; Vale, R.D.; Carter, A.P. The cytoplasmic dynein transport machinery and its many cargoes. Nat. Rev. Mol. Cell Biol. 2018, 19, 382-398. [CrossRef] [PubMed]

175. Gladue, D.P.; O’Donnell, V.; Baker-Bransetter, R.; Pacheco, J.M.; Holinka, L.G.; Arzt, J.; Pauszek, S.; Fernandez-Sainz, I.; Fletcher, P.; Brocchi, E.; et al. Interaction of Foot-and-Mouth Disease Virus Nonstructural Protein 3A with Host Protein DCTN3 Is Important for Viral Virulence in Cattle. J. Virol. 2013, 88, 2737-2747. [CrossRef]

176. Santos, T.D.L.; Botton, S.D.A.; Weiblen, R.; Grubman, M.J. The Leader Proteinase of Foot-and-Mouth Disease Virus Inhibits the Induction of Beta Interferon mRNA and Blocks the Host Innate Immune Response. J. Virol. 2006, 80, 1906-1914. [CrossRef] [PubMed]

177. Lowery, J.; Kuczmarski, E.R.; Herrmann, H.; Goldman, R.D. Intermediate Filaments Play a Pivotal Role in Regulating Cell Architecture and Function. J. Biol. Chem. 2015, 290, 17145-17153. [CrossRef] [PubMed]

178. Zhang, Y.; Wen, Z.; Shi, X.; Liu, Y.-J.; Eriksson, J.E.; Jiu, Y. The diverse roles and dynamic rearrangement of vimentin during viral infection. J. Cell Sci. 2021, 134, jcs250597. [CrossRef]

179. Ma, X.; Ling, Y.; Li, P.; Sun, P.; Cao, Y.; Bai, X.; Li, K.; Fu, Y.; Zhang, J.; Li, D.; et al. Cellular Vimentin Interacts with Foot-and-Mouth Disease Virus Nonstructural Protein 3A and Negatively Modulates Viral Replication. J. Virol. 2020, 94. [CrossRef] [PubMed]

180. Dash, P.; Barnett, P.V.; Denyer, M.S.; Jackson, T.; Stirling, C.M.A.; Hawes, P.C.; Simpson, J.L.; Monaghan, P.; Takamatsu, H.-H. Foot-and-Mouth Disease Virus Replicates Only Transiently in Well-Differentiated Porcine Nasal Epithelial Cells. J. Virol. 2010, 84, 9149-9160. [CrossRef] [PubMed]

181. Gilles, C.; Polette, M.; Zahm, J.M.; Tournier, J.M.; Volders, L.; Foidart, J.M.; Birembaut, P. Vimentin contributes to human mammary epithelial cell migration. J. Cell Sci. 1999, 112, 4615-4625. [PubMed]

182. Borden, E.C.; Sen, G.C.; Uze, G.; Silverman, R.H.; Ransohoff, R.M.; Foster, G.R.; Stark, G.R. Interferons at age 50: Past, current and future impact on biomedicine. Nat. Rev. Drug Discov. 2007, 6, 975-990. [CrossRef]

183. Hur, S. Double-Stranded RNA Sensors and Modulators in Innate Immunity. Annu. Rev. Immunol. 2019, 37, 349-375. [CrossRef]

184. Barral, P.M.; Morrison, J.M.; Drahos, J.; Gupta, P.; Sarkar, D.; Fisher, P.B.; Racaniello, V.R. MDA-5 Is Cleaved in Poliovirus-Infected Cells. J. Virol. 2007, 81, 3677-3684. [CrossRef]

185. Feng, Q.; Langereis, M.A.; Lork, M.; Nguyen, M.; Hato, S.V.; Lanke, K.; Emdad, L.; Bhoopathi, P.; Fisher, P.B.; Lloyd, R.E.; et al. Enterovirus 2Apro Targets MDA5 and MAVS in Infected Cells. J. Virol. 2014, 88, 3369-3378. [CrossRef]

186. Pulido, M.R.; Martínez-Salas, E.; Sobrino, F.; Sáiz, M. MDA5 cleavage by the Leader protease of foot-and-mouth disease virus reveals its pleiotropic effect against the host antiviral response. Cell Death Dis. 2020, 11, 1-13. [CrossRef]

187. Wang, Y.; Ma, L.; Stipkovits, L.; Szathmary, S.; Li, X.; Liu, Y. The Strategy of Picornavirus Evading Host Antiviral Responses: Non-structural Proteins Suppress the Production of IFNs. Front. Microbiol. 2018, 9, 2943. [CrossRef]

188. Kumar, H.; Kawai, T.; Kato, H.; Sato, S.; Takahashi, K.; Coban, C.; Yamamoto, M.; Uematsu, S.; Ishii, K.J.; Takeuchi, O.; et al. Essential role of IPS-1 in innate immune responses against RNA viruses. J. Exp. Med. 2006, 203, 1795-1803. [CrossRef] [PubMed]

189. Malik, N.; Canfield, V.A.; Beckers, M.-C.; Gros, P.; Levenson, R. Identification of the Mammalian Na,K-ATPase $\beta 3$ Subunit. J. Biol. Chem. 1996, 271, 22754-22758. [CrossRef] [PubMed]

190. Lu, Y.; Hou, H.; Wang, F.; Qiao, L.; Wang, X.; Yu, J.; Liu, W.; Sun, Z. ATP1B3: A virus-induced host factor against EV71 replication by up-regulating the production of type-I interferons. Virology 2016, 496, 28-34. [CrossRef] 
191. Zheng, B.; Zhang, J.; Zheng, T.; Wang, H.; Li, Z.; Huan, C.; Ning, S.; Wang, Y.; Zhang, W. ATP1B3 cooperates with BST-2 to promote hepatitis B virus restriction. J. Med Virol. 2020, 92, 201-209. [CrossRef] [PubMed]

192. Li, D.; Lei, C.; Xu, Z.; Yang, F.; Liu, H.; Zhu, Z.; Li, S.; Liu, X.; Shu, H.; Zheng, H. Foot-and-mouth disease virus non-structural protein 3A inhibits the interferon- $\beta$ signaling pathway. Sci. Rep. 2016, 6, 21888. [CrossRef]

193. Du, Y.; Bi, J.; Liu, J.; Liu, X.; Wu, X.; Jiang, P.; Yoo, D.; Zhang, Y.; Wu, J.; Wan, R.; et al. 3Cpro of Foot-and-Mouth Disease Virus Antagonizes the Interferon Signaling Pathway by Blocking STAT1/STAT2 Nuclear Translocation. J. Virol. 2014, 88, 4908-4920. [CrossRef]

194. Li, D.; Fu, S.; Wu, Z.; Yang, W.; Ru, Y.; Shu, H.; Liu, X.; Zheng, H. DDX56 inhibits type I interferon by disrupting assembly of IRF3-IPO5 to inhibit IRF3 nucleus import. J. Cell Sci. 2020, 133, jcs230409. [CrossRef]

195. Fu, S.-Z.; Yang, W.-P.; Ru, Y.; Zhang, K.-S.; Wang, Y.; Liu, X.-T.; Li, D.; Zheng, H.-X. DDX56 cooperates with FMDV 3A to enhance FMDV replication by inhibiting the phosphorylation of IRF3. Cell. Signal. 2019, 64, 109393. [CrossRef]

196. Reineke, L.C.; Kedersha, N.; Langereis, M.A.; Van Kuppeveld, F.J.M.; Lloyd, R.E. Stress Granules Regulate Double-Stranded RNA-Dependent Protein Kinase Activation through a Complex Containing G3BP1 and Caprin1. mBio 2015, 6, e02486. [CrossRef]

197. Reineke, L.C.; Lloyd, R.E. The Stress Granule Protein G3BP1 Recruits Protein Kinase R To Promote Multiple Innate Immune Antiviral Responses. J. Virol. 2015, 89, 2575-2589. [CrossRef]

198. Onomoto, K.; Yoneyama, M.; Fung, G.; Kato, H.; Fujita, T. Antiviral innate immunity and stress granule responses. Trends Immunol. 2014, 35, 420-428. [CrossRef] [PubMed]

199. Eiermann, N.; Haneke, K.; Sun, Z.; Stoecklin, G.; Ruggieri, A. Dance with the Devil: Stress Granules and Signaling in Antiviral Responses. Viruses 2020, 12, 984. [CrossRef]

200. Kim, S.S.-Y.; Sze, L.; Lam, K.-P. The stress granule protein G3BP1 binds viral dsRNA and RIG-I to enhance interferon- $\beta$ response. J. Biol. Chem. 2019, 294, 6430-6438. [CrossRef]

201. Yang, W.; Li, D.; Ru, Y.; Bai, J.; Ren, J.; Zhang, J.; Li, L.; Liu, X.; Zheng, H. Foot-and-Mouth Disease Virus 3A Protein Causes Upregulation of Autophagy-Related Protein LRRC25 To Inhibit the G3BP1-Mediated RIG-Like Helicase-Signaling Pathway. J. Virol. 2020, 94. [CrossRef]

202. Galan, A.; Lozano, G.; Piñeiro, D.; Martinez-Salas, E. G3BP1 interacts directly with the FMDV IRES and negatively regulates translation. FEBS J. 2017, 284, 3202-3217. [CrossRef] [PubMed]

203. Ye, X.; Pan, T.; Wang, D.; Fang, L.; Ma, J.; Zhu, X.; Shi, Y.; Zhang, K.; Zheng, H.; Chen, H.; et al. Foot-and-Mouth Disease Virus Counteracts on Internal Ribosome Entry Site Suppression by G3BP1 and Inhibits G3BP1-Mediated Stress Granule Assembly via Post-Translational Mechanisms. Front. Immunol. 2018, 9, 1142. [CrossRef]

204. Visser, L.J.; Medina, G.N.; Rabouw, H.H.; De Groot, R.J.; Langereis, M.A.; Santos, T.D.L.; Van Kuppeveld, F.J.M. Foot-and-Mouth Disease Virus Leader Protease Cleaves G3BP1 and G3BP2 and Inhibits Stress Granule Formation. J. Virol. 2018, 93, 93. [CrossRef] [PubMed]

205. Maillard, P.V.; Van Der Veen, A.G.; Poirier, E.Z.; Sousa, C.R.E. Slicing and dicing viruses: Antiviral RNA interference in mammals. EMBO J. 2019, 38. [CrossRef]

206. Qiu, Y.; Xu, Y.; Zhang, Y.; Zhou, H.; Deng, Y.-Q.; Li, X.-F.; Miao, M.; Zhang, Q.; Zhong, B.; Hu, Y.; et al. Human Virus-Derived Small RNAs Can Confer Antiviral Immunity in Mammals. Immunology 2017, 46, 992-1004. [CrossRef]

207. Mu, J.; Zhang, H.; Li, T.; Shu, T.; Qiu, Y.; Zhou, X. The 3A protein of coxsackievirus B3 acts as a viral suppressor of RNA interference. J. Gen. Virol. 2020, 101, 1069-1078. [CrossRef]

208. Schuster, S.; Overheul, G.J.; Bauer, L.; Van Kuppeveld, F.J.M.; Van Rij, R.P. No evidence for viral small RNA production and antiviral function of Argonaute 2 in human cells. Sci. Rep. 2019, 9, 1-11. [CrossRef]

209. Gamarnik, A.V.; Andino, R. Switch from translation to RNA replication in a positive-stranded RNA virus. Genes Dev. 1998, 12, 2293-2304. [CrossRef] [PubMed]

210. Novak, J.E.; Kirkegaard, K. Coupling between genome translation and replication in an RNA virus. Genes Dev. 1994, 8, $1726-1737$. [CrossRef] [PubMed]

211. Harris, K.S.; Xiang, W.; Alexander, L.; Lane, W.S.; Paul, A.V.; Wimmer, E. Interaction of poliovirus polypeptide 3CDpro with the 5 and $3^{\prime}$ termini of the poliovirus genome. Identification of viral and cellular cofactors needed for efficient binding. J. Biol. Chem. 1994, 269, 27004-27014. [CrossRef]

212. Parsley, T.B.; Towner, J.S.; Blyn, L.B.; Ehrenfeld, E.; Semler, B.L. Poly (rC) binding protein 2 forms a ternary complex with the 5 '-terminal sequences of poliovirus RNA and the viral 3CD proteinase. RNA 1997, 3, 1124-1134. [PubMed]

213. Xiang, W.; Harris, K.S.; Alexander, L.; Wimmer, E. Interaction between the 5 '-terminal cloverleaf and $3 \mathrm{AB} / 3 \mathrm{CDpro}$ of poliovirus is essential for RNA replication. J. Virol. 1995, 69, 3658-3667. [CrossRef] [PubMed]

214. Paul, A.V.; Cao, X.; Harris, K.S.; Lama, J.; Wimmer, E. Studies with poliovirus polymerase 3Dpol. Stimulation of poly(U) synthesis in vitro by purified poliovirus protein 3AB. J. Biol. Chem. 1994, 269, 29173-29181. [CrossRef]

215. Spear, A.R.; Ogram, S.A.; Morasco, B.J.; Smerage, L.E.; Flanegan, J.B. Viral precursor protein P3 and its processed products perform discrete and essential functions in the poliovirus RNA replication complex. Virology 2015, 485, 492-501. [CrossRef] [PubMed]

216. Liu, Y.; Franco, D.; Paul, A.V.; Wimmer, E. Tyrosine 3 of Poliovirus Terminal Peptide VPg(3B) Has an Essential Function in RNA Replication in the Context of Its Precursor Protein, 3AB. J. Virol. 2007, 81, 5669-5684. [CrossRef] 
217. Herod, M.R.; Loundras, E.-A.; Ward, J.C.; Tulloch, F.; Rowlands, D.J.; Stonehouse, N.J. Employing transposon mutagenesis to investigate foot-and-mouth disease virus replication. J. Gen. Virol. 2015, 96, 3507-3518. [CrossRef] [PubMed]

218. Teterina, N.L.; Rinaudo, M.S.; Ehrenfeld, E. Strand-Specific RNA Synthesis Defects in a Poliovirus with a Mutation in Protein 3A. J. Virol. 2003, 77, 12679-12691. [CrossRef]

219. Lyle, J.M.; Clewell, A.; Richmond, K.; Richards, O.C.; Hope, D.A.; Schultz, S.C.; Kirkegaard, K. Similar Structural Basis for Membrane Localization and Protein Priming by an RNA-dependent RNA Polymerase. J. Biol. Chem. 2002, $277,16324-16331$. [CrossRef] [PubMed]

220. Lama, J.; Paul, A.; Harris, K.; Wimmer, E. Properties of purified recombinant poliovirus protein $3 a B$ as substrate for viral proteinases and as co-factor for RNA polymerase 3Dpol. J. Biol. Chem. 1994, 269, 66-70. [CrossRef]

221. Plotch, S.J.; Palant, O. Poliovirus protein $3 \mathrm{AB}$ forms a complex with and stimulates the activity of the viral RNA polymerase, 3Dpol. J. Virol. 1995, 69, 7169-7179. [CrossRef] [PubMed]

222. Richards, O.C.; Ehrenfeld, E. Effects of Poliovirus 3AB Protein on 3D Polymerase-catalyzed Reaction. J. Biol. Chem. 1998, 273, 12832-12840. [CrossRef]

223. Rodriguez-Wells, V. Primer-dependent synthesis by poliovirus RNA-dependent RNA polymerase (3Dpol). Nucleic Acids Res. 2001, 29, 2715-2724. [CrossRef]

224. Lama, J.; Sanz, M.A.; Rodrguez, P.L. A Role for 3AB Protein in Poliovirus Genome Replication. J. Biol. Chem. 1995, 270, 14430-14438. [CrossRef]

225. Strauss, D.M.; Wuttke, D.S. Characterization of Protein-Protein Interactions Critical for Poliovirus Replication: Analysis of $3 A B$ and VPg Binding to the RNA-Dependent RNA Polymerase. J. Virol. 2007, 81, 6369-6378. [CrossRef]

226. Takegami, T.; Kuhn, R.J.; Anderson, C.W.; Wimmer, E. Membrane-dependent uridylylation of the genome-linked protein VPg of poliovirus. Proc. Natl. Acad. Sci. USA 1983, 80, 7447-7451. [CrossRef] [PubMed]

227. Takegami, T.; Semler, B.L.; Anderson, C.W.; Wimmer, E. Membrane fractions active in poliovirus RNA replication contain VPg precursor polypeptides. Virol. 1983, 128, 33-47. [CrossRef]

228. Hall, D.J.; Palmenberg, A.C. Cleavage site mutations in the encephalomyocarditis virus P3 region lethally abrogate the normal processing cascade. J. Virol. 1996, 70, 5954-5961. [CrossRef]

229. Nayak, A.; Goodfellow, I.G.; Woolaway, K.E.; Birtley, J.; Curry, S.; Belsham, G.J. Role of RNA Structure and RNA Binding Activity of Foot-and-Mouth Disease Virus 3C Protein in VPg Uridylylation and Virus Replication. J. Virol. 2006, 80, 9865-9875. [CrossRef]

230. Bienz, K.; Egger, D.; Pasamontes, L. Association of polioviral proteins of the P2 genomic region with the viral replication complex and virus-induced membrane synthesis as visualized by electron microscopic immunocytochemistry and autoradiography. Virology 1987, 160, 220-226. [CrossRef]

231. Dorobantu, C.M.; Albulescu, L.; Harak, C.; Feng, Q.; Van Kampen, M.; Strating, J.R.P.M.; Gorbalenya, A.E.; Lohmann, V.; Van Der Schaar, H.M.; Van Kuppeveld, F.J.M. Modulation of the Host Lipid Landscape to Promote RNA Virus Replication: The Picornavirus Encephalomyocarditis Virus Converges on the Pathway Used by Hepatitis C Virus. PLoS Pathog. 2015, 11, e1005185. [CrossRef] [PubMed]

232. Hsu, N.-Y.; Ilnytska, O.; Belov, G.; Santiana, M.; Chen, Y.-H.; Takvorian, P.M.; Pau, C.; Van Der Schaar, H.; Kaushik-Basu, N.; Balla, T.; et al. Viral Reorganization of the Secretory Pathway Generates Distinct Organelles for RNA Replication. Cell 2010, 141, 799-811. [CrossRef] [PubMed]

233. Melia, C.E.; Van Der Schaar, H.M.; Lyoo, H.; Limpens, R.W.; Feng, Q.; Wahedi, M.; Overheul, G.J.; Van Rij, R.P.; Snijder, E.J.; Koster, A.J.; et al. Escaping Host Factor PI4KB Inhibition: Enterovirus Genomic RNA Replication in the Absence of Replication Organelles. Cell Rep. 2017, 21, 587-599. [CrossRef] [PubMed]

234. Roulin, P.S.; Lötzerich, M.; Torta, F.; Tanner, L.B.; Van Kuppeveld, F.J.; Wenk, M.R.; Greber, U.F. Rhinovirus Uses a Phosphatidylinositol 4-Phosphate/Cholesterol Counter-Current for the Formation of Replication Compartments at the ER-Golgi Interface. Cell Host Microbe 2014, 16, 677-690. [CrossRef] [PubMed]

235. Rust, R.C.; Landmann, L.; Gosert, R.; Tang, B.L.; Hong, W.; Hauri, H.-P.; Egger, D.; Bienz, K. Cellular COPII Proteins Are Involved in Production of the Vesicles That Form the Poliovirus Replication Complex. J. Virol. 2001, 75, 9808-9818. [CrossRef] [PubMed]

236. Suhy, D.A.; Giddings, T.H.; Kirkegaard, K. Remodeling the Endoplasmic Reticulum by Poliovirus Infection and by Individual Viral Proteins: An Autophagy-Like Origin for Virus-Induced Vesicles. J. Virol. 2000, 74, 8953-8965. [CrossRef]

237. Van Der Schaar, H.M.; Dorobantu, C.M.; Albulescu, L.; Strating, J.R.; Van Kuppeveld, F.J. Fat(al) attraction: Picornaviruses Usurp Lipid Transfer at Membrane Contact Sites to Create Replication Organelles. Trends Microbiol. 2016, 24, 535-546. [CrossRef] [PubMed]

238. Nagy, P.D.; Strating, J.R.P.M.; Van Kuppeveld, F.J.M. Building Viral Replication Organelles: Close Encounters of the Membrane Types. PLoS Pathog. 2016, 12, e1005912. [CrossRef]

239. Ilnytska, O.; Santiana, M.; Hsu, N.-Y.; Du, W.-L.; Chen, Y.-H.; Viktorova, E.G.; Belov, G.; Brinker, A.; Storch, J.; Moore, C.; et al. Enteroviruses Harness the Cellular Endocytic Machinery to Remodel the Host Cell Cholesterol Landscape for Effective Viral Replication. Cell Host Microbe 2013, 14, 281-293. [CrossRef] [PubMed]

240. Ishikawa-Sasaki, K.; Sasaki, J.; Taniguchi, K. A Complex Comprising Phosphatidylinositol 4-Kinase III, ACBD3, and Aichi Virus Proteins Enhances Phosphatidylinositol 4-Phosphate Synthesis and Is Critical for Formation of the Viral Replication Complex. J. Virol. 2014, 88, 6586-6598. [CrossRef] 
241. Albulescu, L.; Wubbolts, R.; Van Kuppeveld, F.J.M.; Strating, J.R.P.M. Cholesterol shuttling is important for RNA replication of coxsackievirus B3 and encephalomyocarditis virus. Cell. Microbiol. 2015, 17, 1144-1156. [CrossRef]

242. Banerjee, S.; Aponte-Diaz, D.; Yeager, C.; Sharma, S.D.; Ning, G.; Oh, H.S.; Han, Q.; Umeda, M.; Hara, Y.; Wang, R.Y.L.; et al. Hijacking of multiple phospholipid biosynthetic pathways and induction of membrane biogenesis by a picornaviral $3 \mathrm{CD}$ protein. PLoS Pathog. 2018, 14, e1007086. [CrossRef]

243. Antonny, B.; Bigay, J.; Mesmin, B. The Oxysterol-Binding Protein Cycle: Burning Off PI(4)P to Transport Cholesterol. Annu. Rev. Biochem. 2018, 87, 809-837. [CrossRef]

244. Mesmin, B.; Bigay, J.; Von Filseck, J.M.; Lacas-Gervais, S.; Drin, G.; Antonny, B. A Four-Step Cycle Driven by PI(4)P Hydrolysis Directs Sterol/PI(4)P Exchange by the ER-Golgi Tether OSBP. Cell 2013, 155, 830-843. [CrossRef]

245. Arita, M. Phosphatidylinositol-4 kinase III beta and oxysterol-binding protein accumulate unesterified cholesterol on poliovirusinduced membrane structure. Microbiol. Immunol. 2014, 58, 239-256. [CrossRef]

246. Ishikawa-Sasaki, K.; Nagashima, S.; Taniguchi, K.; Sasaki, J. Model of OSBP-Mediated Cholesterol Supply to Aichi Virus RNA Replication Sites Involving Protein-Protein Interactions among Viral Proteins, ACBD3, OSBP, VAP-A/B, and SAC1. J. Virol. 2018, 92, e01952-17. [CrossRef] [PubMed]

247. Xu, K.; Nagy, P.D. Sterol Binding by the Tombusviral Replication Proteins Is Essential for Replication in Yeast and Plants. J. Virol. 2017, 91, 91. [CrossRef] [PubMed]

248. Berryman, S.; Moffat, K.; Harak, C.; Lohmann, V.; Jackson, T. Foot-and-mouth disease virus replicates independently of phosphatidylinositol 4-phosphate and type III phosphatidylinositol 4-kinases. J. Gen. Virol. 2016, 97, 1841-1852. [CrossRef]

249. Esser-Nobis, K.; Harak, C.; Schult, P.; Kusov, Y.; Lohmann, V. Novel perspectives for hepatitis A virus therapy revealed by comparative analysis of hepatitis C virus and hepatitis A virus RNA replication. Hepatology 2015, 62, 397-408. [CrossRef]

250. Spickler, C.; Lippens, J.; Laberge, M.K.; Desmeules, S.; Bellavance, É.; Garneau, M.; Guo, T.; Hucke, O.; Leyssen, P.; Neyts, J.; et al Phosphatidylinositol 4-Kinase III Beta Is Essential for Replication of Human Rhinovirus and Its Inhibition Causes a Lethal PhenotypeIn Vivo. Antimicrob. Agents Chemother. 2013, 57, 3358-3368. [CrossRef] [PubMed]

251. Xiao, X.; Lei, X.; Zhang, Z.; Ma, Y.; Qi, J.; Wu, C.; Xiao, Y.; Li, L.; He, B.; Wang, J. Enterovirus 3A Facilitates Viral Replication by Promoting Phosphatidylinositol 4-Kinase III $\beta-A C B D 3$ Interaction. J. Virol. 2017, 91, e00791-17. [CrossRef] [PubMed]

252. Chung, J.; Nakatsu, F.; Baskin, J.M.; De Camilli, P. Plasticity of PI 4 KIII $\alpha$ interactions at the plasma membrane. EMBO Rep. 2015, 16, 312-320. [CrossRef]

253. Clayton, E.L.; Minogue, S.; Waugh, M.G. Mammalian phosphatidylinositol 4-kinases as modulators of membrane trafficking and lipid signaling networks. Prog. Lipid Res. 2013, 52, 294-304. [CrossRef]

254. Daboussi, L.; Costaguta, G.; Ghukasyan, R.; Payne, G.S. Conserved role for Gga proteins in phosphatidylinositol 4-kinase localization to the trans-Golgi network. Proc. Natl. Acad. Sci. USA 2017, 114, 3433-3438. [CrossRef]

255. De Graaf, P.; Zwart, W.T.; Van Dijken, R.A.; Deneka, M.; Schulz, T.K.; Geijsen, N.; Coffer, P.J.; Gadella, B.M.; Verkleij, A.J.; Van Der Sluijs, P.; et al. Phosphatidylinositol 4-Kinase $\beta$ Is Critical for Functional Association of rab11 with the Golgi Complex. Mol. Biol. Cell 2004, 15, 2038-2047. [CrossRef]

256. Hausser, A.; Link, G.; Hoene, M.; Russo, C.; Selchow, O.; Pfizenmaier, K. Phospho-specific binding of 14-3-3 proteins to phosphatidylinositol 4-kinase III $\beta$ protects from dephosphorylation and stabilizes lipid kinase activity. J. Cell Sci. 2006, 119, 3613-3621. [CrossRef] [PubMed]

257. Haynes, L.P.; Thomas, G.M.H.; Burgoyne, R.D. Interaction of Neuronal Calcium Sensor-1 and ADP-ribosylation Factor 1 Allows Bidirectional Control of Phosphatidylinositol 4-Kinase $\beta$ and trans-Golgi Network-Plasma Membrane Traffic. J. Biol. Chem. 2005, 280, 6047-6054. [CrossRef]

258. Sasaki, J.; Ishikawa, K.; Arita, M.; Taniguchi, K. ACBD3-mediated recruitment of PI4KB to picornavirus RNA replication sites. EMBO J. 2011, 31, 754-766. [CrossRef] [PubMed]

259. Zhao, X.; Várnai, P.; Tuymetova, G.; Balla, A.; Tóth, Z.E.; Oker-Blom, C.; Roder, J.; Jeromin, A.; Balla, T. Interaction of Neuronal Calcium Sensor-1 (NCS-1) with Phosphatidylinositol 4-Kinase $\beta$ Stimulates Lipid Kinase Activity and Affects Membrane Trafficking in COS-7 Cells. J. Biol. Chem. 2001, 276, 40183-40189. [CrossRef]

260. Godi, A.; Pertile, P.; Meyers, R.; Marra, P.; Di Tullio, G.; Iurisci, C.; Luini, A.; Corda, D.; De Matteis, M.A. ARF mediates recruitment of PtdIns-4-OH kinase- $\beta$ and stimulates synthesis of PtdIns(4,5)P2 on the Golgi complex. Nat. Cell Biol. 1999, 1, 280-287. [CrossRef] [PubMed]

261. Cuconati, A.; Molla, A.; Wimmer, E. Brefeldin A Inhibits Cell-Free, De Novo Synthesis of Poliovirus. J. Virol. 1998, 72, 6456-6464. [CrossRef]

262. Maynell, L.A.; Kirkegaard, K.; Klymkowsky, M.W. Inhibition of poliovirus RNA synthesis by brefeldin A. J. Virol. 1992, 66, 1985-1994. [CrossRef]

263. Donaldson, J.G.; Finazzi, D.; Klausner, R.D. Brefeldin A inhibits Golgi membrane-catalysed exchange of guanine nucleotide onto ARF protein. Nat. Cell Biol. 1992, 360, 350-352. [CrossRef]

264. Helms, J.B.; Rothman, J.E. Inhibition by brefeldin A of a Golgi membrane enzyme that catalyses exchange of guanine nucleotide bound to ARF. Nat. Cell Biol. 1992, 360, 352-354. [CrossRef]

265. Klausner, R.D.; Donaldson, J.G.; Lippincott-Schwartz, J. Brefeldin A: Insights into the control of membrane traffic and organelle structure. J. Cell Biol. 1992, 116, 1071-1080. [CrossRef] [PubMed] 
266. Belov, G.A.; Feng, Q.; Nikovics, K.; Jackson, C.L.; Ehrenfeld, E. A Critical Role of a Cellular Membrane Traffic Protein in Poliovirus RNA Replication. PLoS Pathog. 2008, 4, e1000216. [CrossRef] [PubMed]

267. Lanke, K.H.W.; Van Der Schaar, H.M.; Belov, G.A.; Feng, Q.; Duijsings, D.; Jackson, C.L.; Ehrenfeld, E.; Van Kuppeveld, F.J.M. GBF1, a Guanine Nucleotide Exchange Factor for Arf, Is Crucial for Coxsackievirus B3 RNA Replication. J. Virol. 2009, 83, 11940-11949. [CrossRef] [PubMed]

268. Viktorova, E.G.; Gabaglio, S.; Meissner, J.M.; Lee, E.; Moghimi, S.; Sztul, E.; Belov, G.A. A Redundant Mechanism of Recruitment Underlies the Remarkable Plasticity of the Requirement of Poliovirus Replication for the Cellular ArfGEF GBF1. J. Virol. 2019, 93. [CrossRef]

269. Belov, G.A.; Altan-Bonnet, N.; Kovtunovych, G.; Jackson, C.L.; Lippincott-Schwartz, J.; Ehrenfeld, E. Hijacking Components of the Cellular Secretory Pathway for Replication of Poliovirus RNA. J. Virol. 2006, 81, 558-567. [CrossRef]

270. Ferlin, J.; Farhat, R.; Belouzard, S.; Cocquerel, L.; Bertin, A.; Hober, D.; Dubuisson, J.; Rouillé, Y. Investigation of the role of GBF1 in the replication of positive-sense single-stranded RNA viruses. J. Gen. Virol. 2018, 99, 1086-1096. [CrossRef]

271. Wang, J.; Du, J.; Jin, Q. Class I ADP-Ribosylation Factors Are Involved in Enterovirus 71 Replication. PLoS ONE 2014, 9, e99768. [CrossRef]

272. Belov, G.A.; Fogg, M.H.; Ehrenfeld, E. Poliovirus Proteins Induce Membrane Association of GTPase ADP-Ribosylation Factor. J. Virol. 2005, 79, 7207-7216. [CrossRef]

273. Dorobantu, C.M.; Ford-Siltz, L.A.; Sittig, S.P.; Lanke, K.H.W.; Belov, G.A.; Van Kuppeveld, F.J.M.; Van Der Schaar, H.M. GBF1and ACBD3-Independent Recruitment of PI4KIII $\beta$ to Replication Sites by Rhinovirus 3A Proteins. J. Virol. 2015, 89, 1913-1918. [CrossRef]

274. Irurzun, A.; Perez, L.; Carrasco, L. Involvement of membrane traffic in the replication of poliovirus genomes: Effects of brefeldin A. Virology 1992, 191, 166-175. [CrossRef]

275. Dorobantu, C.M.; Van Der Schaar, H.M.; Ford, L.A.; Strating, J.R.P.M.; Ulferts, R.; Fang, Y.; Belov, G.; Van Kuppeveld, F.J.M.; Sandri-Goldin, R.M. Recruitment of PI4KIII to Coxsackievirus B3 Replication Organelles Is Independent of ACBD3, GBF1, and Arf1. J. Virol. 2013, 88, 2725-2736. [CrossRef]

276. Belov, G.A.; Kovtunovych, G.; Jackson, C.L.; Ehrenfeld, E. Poliovirus replication requires the N-terminus but not the catalytic Sec7 domain of ArfGEF GBF1. Cell. Microbiol. 2010, 12, 1463-1479. [CrossRef] [PubMed]

277. Altan-Bonnet, N.; Balla, T. Phosphatidylinositol 4-kinases: Hostages harnessed to build panviral replication platforms. Trends Biochem. Sci. 2012, 37, 293-302. [CrossRef] [PubMed]

278. Deng, Y.; Golinelli-Cohen, M.; Smirnova, E.; Jackson, C.L. A COPI coat subunit interacts directly with an early-Golgi localized Arf exchange factor. EMBO Rep. 2009, 10, 58-64. [CrossRef]

279. Belov, G.A.; Habbersett, C.; Franco, D.; Ehrenfeld, E. Activation of Cellular Arf GTPases by Poliovirus Protein 3CD Correlates with Virus Replication. J. Virol. 2007, 81, 9259-9267. [CrossRef]

280. Van Der Linden, L.; Van Der Schaar, H.M.; Lanke, K.H.W.; Neyts, J.; Van Kuppeveld, F.J.M. Differential Effects of the Putative GBF1 Inhibitors Golgicide A and AG1478 on Enterovirus Replication. J. Virol. 2010, 84, 7535-7542. [CrossRef]

281. Lowery, J.; Szul, T.; Styers, M.L.; Holloway, Z.G.; Oorschot, V.; Klumperman, J.; Sztul, E. The Sec7 Guanine Nucleotide Exchange Factor GBF1 Regulates Membrane Recruitment of BIG1 and BIG2 Guanine Nucleotide Exchange Factors to the Trans-Golgi Network (TGN). J. Biol. Chem. 2013, 288, 11532-11545. [CrossRef]

282. Moghimi, S.; Viktorova, E.; Zimina, A.; Szul, T.; Sztul, E.; Belov, G.A. Enterovirus Infection Induces Massive Recruitment of All Isoforms of Small Cellular Arf GTPases to the Replication Organelles. J. Virol. 2020, 95, 95. [CrossRef] [PubMed]

283. Oh, H.S.; Banerjee, S.; Aponte-Diaz, D.; Sharma, S.D.; Aligo, J.; Lodeiro, M.F.; Ning, G.; Sharma, R.; Arnold, J.J.; Cameron, C.E. Multiple poliovirus-induced organelles suggested by comparison of spatiotemporal dynamics of membranous structures and phosphoinositides. PLoS Pathog. 2018, 14, e1007036. [CrossRef]

284. Cameron, C.E.; Oh, H.S.; Moustafa, I.M. Expanding knowledge of P3 proteins in the poliovirus lifecycle. Futur. Microbiol. 2010, 5, 867-881. [CrossRef]

285. Crotty, S.; Saleh, M.-C.; Gitlin, L.; Beske, O.; Andino, R. The Poliovirus Replication Machinery Can Escape Inhibition by an Antiviral Drug That Targets a Host Cell Protein. J. Virol. 2004, 78, 3378-3386. [CrossRef]

286. Arita, M.; Kojima, H.; Nagano, T.; Okabe, T.; Wakita, T.; Shimizu, H. Phosphatidylinositol 4-Kinase III Beta Is a Target of Enviroxime-Like Compounds for Antipoliovirus Activity. J. Virol. 2010, 85, 2364-2372. [CrossRef] [PubMed]

287. Van Der Schaar, H.M.; Van Der Linden, L.; Lanke, K.H.W.; Strating, J.R.P.M.; Pürstinger, G.; De Vries, E.; Haan, C.A.M.D.; Neyts, J.; Van Kuppeveld, F.J.M. Coxsackievirus mutants that can bypass host factor PI4KIII $\beta$ and the need for high levels of PI4P lipids for replication. Cell Res. 2012, 22, 1576-1592. [CrossRef]

288. Van Der Schaar, H.M.; Leyssen, P.; Thibaut, H.J.; De Palma, A.; Van Der Linden, L.; Lanke, K.H.W.; Lacroix, C.; Verbeken, E.; Conrath, K.; MacLeod, A.M.; et al. A Novel, Broad-Spectrum Inhibitor of Enterovirus Replication That Targets Host Cell Factor Phosphatidylinositol 4-Kinase III 3 . Antimicrob. Agents Chemother. 2013, 57, 4971-4981. [CrossRef] [PubMed]

289. Strating, J.R.; Van Der Linden, L.; Albulescu, L.; Bigay, J.; Arita, M.; Delang, L.; Leyssen, P.; Van Der Schaar, H.M.; Lanke, K.H.; Thibaut, H.J.; et al. Itraconazole Inhibits Enterovirus Replication by Targeting the Oxysterol-Binding Protein. Cell Rep. 2015, 10, 600-615. [CrossRef] [PubMed]

290. Albulescu, L.; Strating, J.R.; Thibaut, H.J.; Van Der Linden, L.; Shair, M.D.; Neyts, J.; Van Kuppeveld, F.J. Broad-range inhibition of enterovirus replication by OSW-1, a natural compound targeting OSBP. Antivir. Res. 2015, 117, 110-114. [CrossRef] [PubMed] 
291. Arita, M. Mechanism of Poliovirus Resistance to Host Phosphatidylinositol-4 Kinase III $\beta$ Inhibitor. ACS Infect. Dis. 2016, 2, 140-148. [CrossRef]

292. Albulescu, L.; Bigay, J.; Biswas, B.; Weber-Boyvat, M.; Dorobantu, C.M.; Delang, L.; Van Der Schaar, H.M.; Jung, Y.-S.; Neyts, J.; Olkkonen, V.M.; et al. Uncovering oxysterol-binding protein (OSBP) as a target of the anti-enteroviral compound TTP-8307. Antivir. Res. 2017, 140, 37-44. [CrossRef]

293. Heinz, B.A.; Vance, L.M. Sequence determinants of 3A-mediated resistance to enviroxime in rhinoviruses and enteroviruses J. Virol. 1996, 70, 4854-4857. [CrossRef]

294. Arita, M.; Wakita, T.; Shimizu, H. Cellular kinase inhibitors that suppress enterovirus replication have a conserved target in viral protein 3A similar to that of enviroxime. J. Gen. Virol. 2009, 90, 1869-1879. [CrossRef]

295. Lyoo, H.; Dorobantu, C.M.; Van Der Schaar, H.M.; Van Kuppeveld, F.J. Modulation of proteolytic polyprotein processing by coxsackievirus mutants resistant to inhibitors targeting phosphatidylinositol-4-kinase III $\beta$ or oxysterol binding protein. Antivir. Res. 2017, 147, 86-90. [CrossRef]

296. Arita, M.; Bigay, J. Poliovirus Evolution toward Independence from the Phosphatidylinositol-4 Kinase III $\beta /$ Oxysterol-Binding Protein Family I Pathway. ACS Infect. Dis. 2019, 5, 962-973. [CrossRef] [PubMed]

297. Dorobantu, C.M.; Albulescu, L.; Lyoo, H.; Van Kampen, M.; De Francesco, R.; Lohmann, V.; Harak, C.; Van Der Schaar, H.M.; Strating, J.R.P.M.; Gorbalenya, A.E.; et al. Mutations in Encephalomyocarditis Virus 3A Protein Uncouple the Dependency of Genome Replication on Host Factors Phosphatidylinositol 4-Kinase III $\alpha$ and Oxysterol-Binding Protein. mSphere 2016, 1. [CrossRef] [PubMed]

298. Burke, J.E.; Inglis, A.J.; Perisic, O.; Masson, G.R.; McLaughlin, S.H.; Rutaganira, F.; Shokat, K.M.; Williams, R.L. Structures of PI4KIII complexes show simultaneous recruitment of Rab11 and its effectors. Science 2014, 344, 1035-1038. [CrossRef]

299. Valente, C.; Turacchio, G.; Mariggiò, S.; Pagliuso, A.; Gaibisso, R.; Di Tullio, G.; Santoro, M.; Formiggini, F.; Spanò, S.; Piccini, D.; et al. A 14-3-3 $\gamma$ dimer-based scaffold bridges CtBP1-S/BARS to PI(4)KIII $\beta$ to regulate post-Golgi carrier formation. Nat. Cell Biol. 2012, 14, 343-354. [CrossRef]

300. Klima, M.; Tóth, D.J.; Hexnerova, R.; Baumlova, A.; Chalupska, D.; Tykvart, J.; Rezabkova, L.; Sengupta, N.; Man, P.; Dubankova, A.; et al. Structural insights and in vitro reconstitution of membrane targeting and activation of human PI4KB by the ACBD3 protein. Sci. Rep. 2016, 6, 23641. [CrossRef]

301. Petrosyan, A. Unlocking Golgi: Why Does Morphology Matter? Biochem. (Moscow) 2019, 84, 1490-1501. [CrossRef]

302. Sohda, M.; Misumi, Y.; Yamamoto, A.; Yano, A.; Nakamura, N.; Ikehara, Y. Identification and Characterization of a Novel Golgi Protein, GCP60, That Interacts with the Integral Membrane Protein Giantin. J. Biol. Chem. 2001, 276, 45298-45306. [CrossRef] [PubMed]

303. Greninger, A.L.; Knudsen, G.M.; Betegon, M.; Burlingame, A.L.; DeRisi, J.L. ACBD3 Interaction with TBC1 Domain 22 Protein Is Differentially Affected by Enteroviral and Kobuviral 3A Protein Binding. mBio 2013, 4, e00098-13. [CrossRef]

304. Téoulé, F.; Brisac, C.; Pelletier, I.; Vidalain, P.-O.; Jégouic, S.; Mirabelli, C.; Bessaud, M.; Combelas, N.; Autret, A.; Tangy, F.; et al The Golgi Protein ACBD3, an Interactor for Poliovirus Protein 3A, Modulates Poliovirus Replication. J. Virol. 2013, 87, 11031-11046. [CrossRef]

305. Kim, H.S.; Lee, K.; Kim, S.-J.; Cho, S.; Shin, H.J.; Kim, C.; Kim, J.-S. Arrayed CRISPR screen with image-based assay reliably uncovers host genes required for coxsackievirus infection. Genome Res. 2018, 28, 859-868. [CrossRef]

306. Lei, X.; Xiao, X.; Zhang, Z.; Ma, Y.; Qi, J.; Wu, C.; Xiao, Y.; Zhou, Z.; He, B.; Wang, J. The Golgi protein ACBD3 facilitates Enterovirus 71 replication by interacting with 3A. Sci. Rep. 2017, 7, 44592. [CrossRef] [PubMed]

307. Lyoo, H.; Van Der Schaar, H.M.; Dorobantu, C.M.; Rabouw, H.H.; Strating, J.R.P.M.; Van Kuppeveld, F.J.M. ACBD3 Is an Essential Pan-enterovirus Host Factor That Mediates the Interaction between Viral 3A Protein and Cellular Protein PI4KB. mBio 2019, 10, e02742-18. [CrossRef] [PubMed]

308. Klima, M.; Chalupska, D.; Różycki, B.; Humpolickova, J.; Rezabkova, L.; Silhan, J.; Baumlova, A.; Dubankova, A.; Boura, E. Kobuviral Non-structural 3A Proteins Act as Molecular Harnesses to Hijack the Host ACBD3 Protein. Structure 2017, 25, 219-230. [CrossRef] [PubMed]

309. Islinger, M.; Costello, J.L.; Kors, S.; Soupene, E.; Levine, T.P.; Kuypers, F.A.; Schrader, M. The diversity of ACBD proteins-From lipid binding to protein modulators and organelle tethers. Biochim. Biophys. Acta BBA Bioenerg. 2020, 1867, 118675. [CrossRef]

310. Yue, X.; Qian, Y.; Gim, B.; Lee, I. Acyl-CoA-Binding Domain-Containing 3 (ACBD3; PAP7; GCP60): A Multi-Functional Membrane Domain Organizer. Int. J. Mol. Sci. 2019, 20, 2028. [CrossRef]

311. McPhail, J.A.; Ottosen, E.H.; Jenkins, M.L.; Burke, J.E. The Molecular Basis of Aichi Virus 3A Protein Activation of Phosphatidylinositol 4 Kinase III $\beta$, PI4KB, through ACBD3. Struct. 2017, 25, 121-131. [CrossRef]

312. Wei, Z.; Zhang, M.; Li, C.; Huang, W.; Fan, Y.; Guo, J.; Khater, M.; Fukuda, M.; Dong, Z.; Hu, G.; et al. Specific TBC DomainContaining Proteins Control the ER-Golgi-Plasma Membrane Trafficking of GPCRs. Cell Rep. 2019, 28, 554-566.e4. [CrossRef] [PubMed]

313. Olzmann, J.A.; Carvalho, P. Dynamics and functions of lipid droplets. Nat. Rev. Mol. Cell Biol. 2019, 20, 137-155. [CrossRef] [PubMed]

314. Thiam, A.R.; Farese, R.V., Jr.; Walther, T.C. The biophysics and cell biology of lipid droplets. Nat. Rev. Mol. Cell Biol. 2013, 14, 775-786. [CrossRef] 
315. Laufman, O.; Perrino, J.; Andino, R. Viral Generated Inter-Organelle Contacts Redirect Lipid Flux for Genome Replication. Cell 2019, 178, 275-289.e16. [CrossRef]

316. Guan, H.; Tian, J.; Zhang, C.; Qin, B.; Cui, S. Crystal structure of a soluble fragment of poliovirus 2CATPase. PLoS Pathog. 2018, 14, e1007304. [CrossRef] [PubMed]

317. Stevanovic, A.; Thiele, C. Monotopic topology is required for lipid droplet targeting of ancient ubiquitous protein 1. J. Lipid Res. 2013, 54, 503-513. [CrossRef] [PubMed]

318. Ellong, E.N.; Soni, K.G.; Bui, Q.-T.; Sougrat, R.; Golinelli-Cohen, M.-P.; Jackson, C.L. Interaction between the Triglyceride Lipase ATGL and the Arf1 Activator GBF1. PLoS ONE 2011, 6, e21889. [CrossRef]

319. Soni, K.G.; Mardones, G.A.; Sougrat, R.; Smirnova, E.; Jackson, C.L.; Bonifacino, J.S. Coatomer-dependent protein delivery to lipid droplets. J. Cell Sci. 2009, 122, 1834-1841. [CrossRef] [PubMed]

320. Zhao, X.; Claude, A.; Chun, J.; Shields, D.J.; Presley, J.F.; Melançon, P. GBF1, a cis-Golgi and VTCs-localized ARF-GEF, is implicated in ER-to-Golgi protein traffic. J. Cell Sci. 2006, 119, 3743-3753. [CrossRef]

321. Belov, G.A.; Van Kuppeveld, F.J. Lipid Droplets Grease Enterovirus Replication. Cell Host Microbe 2019, 26, 149-151. [CrossRef]

322. Medina, G.N.; Segundo, F.D.-S.; Stenfeldt, C.; Arzt, J.; Santos, T.D.L. The Different Tactics of Foot-and-Mouth Disease Virus to Evade Innate Immunity. Front. Microbiol. 2018, 9, 2644. [CrossRef]

323. Lloyd, R.E. Enterovirus Control of Translation and RNA Granule Stress Responses. Viruses 2016, 8, 93. [CrossRef] [PubMed] 